Florida International University

FIU Digital Commons

$7-1-2014$

\title{
Analysis of Global Compliance and Implementation of the Goals of International Environmental Treaties: A Case study of the Convention on Biodiversity (CBD)
}

George Atisa

Florida International University, george.atisa@fiu.edu

DOI: $10.25148 /$ etd.FI14071170

Follow this and additional works at: https://digitalcommons.fiu.edu/etd

\section{Recommended Citation}

Atisa, George, "Analysis of Global Compliance and Implementation of the Goals of International Environmental Treaties: A Case study of the Convention on Biodiversity (CBD)" (2014). FIU Electronic Theses and Dissertations. 1562.

https://digitalcommons.fiu.edu/etd/1562 


\title{
FLORIDA INTERNATIONAL UNIVERSITY \\ Miami, Florida
}

\begin{abstract}
ANALYSIS OF GLOBAL COMPLIANCE AND IMPLEMENTATION OF THE GOALS OF INTERNATIONAL ENVIRONMENTAL TREATIES: A CASE STUDY OF THE CONVENTION ON BIODIVERSITY (CBD)
\end{abstract}

A dissertation submitted in partial fulfillment of the requirements for the degree of DOCTOR OF PHILOSOPHY in PUBLIC AFFAIRS by

George Atisa 2014 
To: Interim Dean Michael R. Heithaus

College of Arts and Sciences

This dissertation, written by George Atisa, and entitled Analysis of Global Compliance and Implementation of the Goals of International Environmental Treaties: A Case Study of the Convention on Biodiversity (CBD), having been approved in respect to style and intellectual content, is referred to you for judgment.

We have read this dissertation and recommend that it be approved.

$\begin{array}{r}\hline \text { Milena Neshkova } \\ \hline \text { Shaoming Cheng }\end{array}$

$\overline{\text { Allan Rosenbaum }}$

Mahadev Bhat, Co-Major Professor

$\overline{\text { Jean-Claude Garcia-Zamor, Co-Major Professor }}$

Date of Defense: July 1, 2014

The dissertation of George Atisa is approved.

Interim Dean Michael R. Heithaus

College of Arts and Sciences

Dean Lakshmi N. Reddi

University Graduate School

Florida International University, 2014 
(C) Copyright 2014 by George Atisa

All rights reserved. 


\section{ACKNOWLEDGMENTS}

This dissertation has come to fruition because of support I received from so many people, The Institute for Public Management and Community Service and FIU graduate school. I am most grateful to my two major professors, Dr. Jean-Claude Garcia-Zamor and Dr. Mahadev Bhat who constantly conveyed positive attitude, scholarship and close supervision to both my writing and research. My sincerely gratitude is extended to Dr. Allan Rosenbaum for his mentorship and helping me to put together the initial ideas of this dissertation. I am deeply indebted to my other committee members Dr. Shaoming Cheng and Dr. Milena Neshkova for their valuable inputs during writing process.

A special note of appreciation is extended to the FIU University Graduate School for the Doctoral Evidence Acquisition Fellowship. My deepest also appreciation to Dr. Meredith Newman, Vice Dean, College of Arts and Sciences, Dr. Howard Frank, Chair of the Department of Public Administration and Dr. Sukumar Ganapati for their untiring support while I have been in the $\mathrm{PhD}$ program. The administrative personnel within the Department of Public Administration provided helpful support in furnishing logistical and directional guidance, particularly Liga Replogle and Stephanie Miller. I cannot forget to say thank you to the Global Footprint Network and ASAHI Glass Foundation for allowing me to use their data.

I am grateful to my family, wife Eucabeth, sons Andrew and Mathew, and daughter Linda, and my parents, Meshack and Salome for their excellent upbringing. My family has been my source of inspiration to always want to go an extra mile. Thank you to my friends and colleagues for the discussions and support while in the program. 


\begin{abstract}
OF THE DISSERTATION
ANALYSIS OF GLOBAL COMPLIANCE AND IMPLEMENTATION OF THE

GOALS OF INTERNATIONAL ENVIRONMENTAL TREATIES: A CASE STUDY

OF THE CONVENTION ON BIODIVERSITY (CBD)
\end{abstract}

\author{
by
}

George Atisa

Florida International University, 2014

Miami, Florida

\title{
Professor Mahadev Bhat, Co-Major Professor \\ Professor Jean-Claude Garcia-Zamor, Co-Major Professor
}

The Convention on Biodiversity (CBD) was created in 1992 to coordinate global governments to protect biological resources. The CBD has three goals: protection of biodiversity, achievement of sustainable use of biodiversity and facilitation of equitable sharing of the benefits of biological resources. The goal of protecting biological resources has remained both controversial and difficult to implement. This study focused more on the goal of biodiversity protection. The research was designed to examine how globally constructed environmental policies get adapted by national governments and then passed down to local levels where actual implementation takes place. Effectiveness of such policies depends on the extent of actual implementation at local levels. Therefore, compliance was divided and examined at three levels: global, national and local. The study then developed various criteria to measure compliance at these levels. Both qualitative and quantitative methods were used to analyze compliance and implementation. The study was guided by three questions broadly examining critical 
factors that most influence the implementation of biodiversity protection policies at the global, national and local levels. Findings show that despite an overall biodiversity deficit of 0.9 hectares per person, global compliance with the CBD goals is currently at $35 \%$. Compliance is lowest at local levels at $14 \%$, it is slightly better at national level at $50 \%$, and much better at the international level $64 \%$. Compliance appears higher at both national and international levels because compliance here is paper work based and policy formulation. If implementation at local levels continues to produce this low compliance, overall conservation outcomes can only get worse than what it is at present. There are numerous weaknesses and capacity challenges countries are yet to address in their plans. In order to increase local level compliance, the study recommends a set of robust policies that build local capacity, incentivize local resource owners, and implement biodiversity protection programs that are akin to local needs and aspirations. 


\section{TABLE OF CONTENTS}

CHAPTER

PAGE

I. INTRODUCTION TO THE STUDY

1.0 Introduction ......................................................

1.1 Why the Convention on Biodiversity .............................. 4

1.1.1 The definition of biodiversity .................................... 6

1.2 Statement of the problem............................................ 6

1.3 Background of the study ....................................... 10

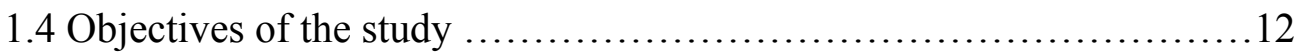

1.5 Significance of the study ......................................... 14

1.6 Interface between policy and implementation ....................... 18

1.7 Understanding compliance as a system ............................. 19

1.8 Defining compliance elements ................................. 22

1.8.1 Role of international treaties .................................. 23

1.9 Implementation of CBD goals ....................................... 25

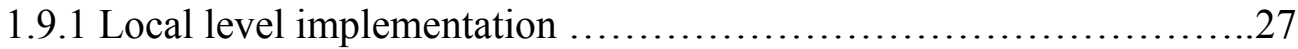

1.9.2 Adaption of local and national policies to international treaties ....... 27

1.10 Global-National-Local conservation model ........................28

\section{LITERATURE REVIEW}

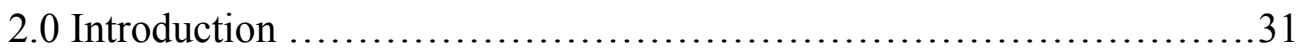

2.1 Management of biological resources ................................ 31

2.2 Theoretical framework ............................................... 33

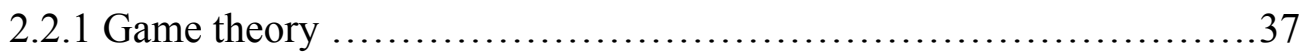

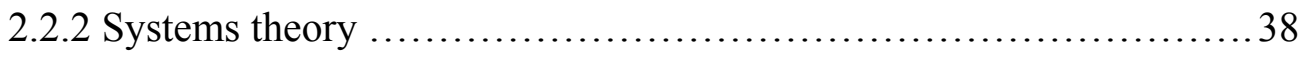

2.3 Institutional development ....................................... 40

2.4 What are the scientists telling us? .......................................... 41

2.4.1 Biodiversity protection is not a quick-fix problem .................. 42

2.5 Public Administration and biodiversity conservation ..................43

2.6 Compliance with international treaties .............................. 45

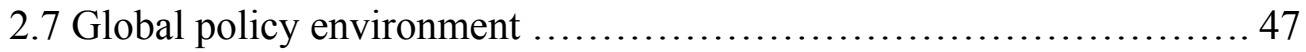

2.7.1 Global strategic plan for biodiversity ............................. 49

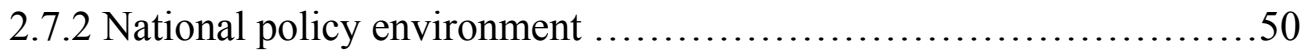

2.7.3 Global-Local policy interface .................................... 51

2.8 Policy making and policy implementation .......................... 53

2.8.1 National Biodiversity Strategy Action Plans (NBSAPs) ............... 55

2.8.2 Local policy environment ..................................... 56

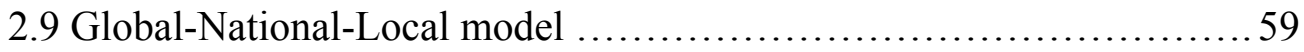


2.10 Sustainable use and equitable sharing of biodiversity benefits ........ 60

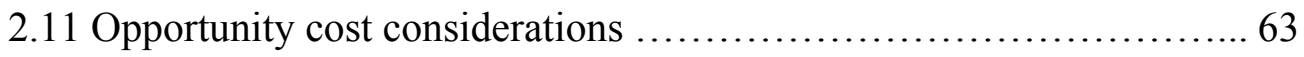

2.11.1 Global opportunity costs ...................................... 64

2.11.2 National opportunity costs ..................................... 65

2.11.3 Local level opportunity costs .................................. 66

2.12 Information technology and information sharing tools ...............6 67

2.13 Institutional leadership ......................................... 70

\section{METHODS AND DATA}

3.0 Data sources and methods ......................................... 73

3.1 Introduction ....................................................... 74

3.2 Sample selection ............................................... 75

3.2.1 Data sources .................................................... 76

3.2.2 Biodiversity hotspot regions.................................... 78

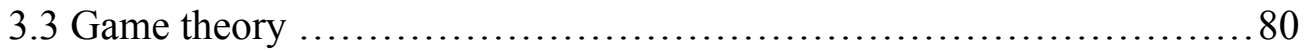

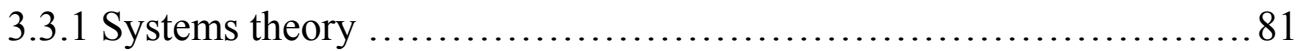

3.4 Research questions and hypotheses............................... 81

3.4.1 Factors that most influence compliance and implementation ......... 82

3.4.2 Cooperative and non-cooperative approaches to conservation ........83

3.4.3 Reconciling global, national and local conservation interests.......... 85

3.4.4 Opportunity costs of biodiversity protection ...................... 87

3.5 Basic compliance requirements ........................................ 89

3.5.1 Development of compliance criteria ............................. 90

3.6 Qualitative methods ............................................. 93

3.6.1 Quantitative methods .......................................... 94

3.7 Compliance measurements ....................................... 96

3.7.1 Compliance measurement as a process ........................... 96

3.7.2 Compliance measurement as an outcome ........................ 98

3.7.3 Compliance stages .................................................... 99

3.7.4 Compliance model .............................................. 102

3.7.5 National compliance ......................................... 103

3.7.6 Local compliance ............................................ 104

3.7.7 Estimation of overall compliance .............................. 106

3.8 Stakeholder cooperation toward compliance .......................... 107

3.8.1 Determinants of institutional cooperation .......................... 109

3.8.2 Application of game theory to biodiversity protection ................ 111

3.8.3 Application of systems theory to biodiversity protection ............. 112

3.8.4 Cooperative and non-cooperative approaches to conservation ......... 117

3.9 Institutional relationships ..................................... 120 
3.9.1 Biodiversity protection coordination problems ..................... 121

3.9.2 Stakeholder shared meaning in biodiversity management ..............124

3.9.3 Stakeholder participation in biodiversity management ............... 125

3.10 Information sharing and communication tools ..................... 126

3.10.1 Local and national information sharing capacity ....................129

3.10.2 Local input to national policy development .........................131

3.11 Opportunity costs of biodiversity protection …................... 132

3.11.1 Opportunity cost estimation .................................... 134

3.11.2 Opportunity cost compensation mechanism ....................... 134

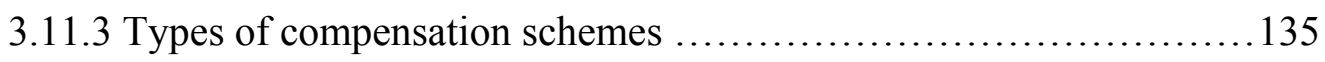

3.11.4 Biodiversity offset schemes ..................................... 136

3.12 Decision making in biodiversity protection ......................... 137

\section{DATA ANALYSIS AND RESULTS}

4.0 Data analysis and determination of compliance ..................... 140

4.1 Introduction ..................................................... 140

4.2 Theoretical findings ........................................... 142

4.3 Qualitative Analysis of NBSAPs, National Reports and NCHMs ...... 143

4.3.1 NBSAPs and the $4^{\text {th }}$ National Report for North and Latin America ... 146

4.3.2 NBSAPs and the $4^{\text {th }}$ National Report Europe ....................... 147

4.3.3 NBSAPs and the $4^{\text {th }}$ National Report for Africa ...................... 148

4.3.4 NBSAPs and the $4^{\text {th }}$ National Report for Asia ..................... 149

4.4 Factors that most influence global compliance ......................... 150

4.4.1 Factors that most influence local level implementation ............... 152

4.4.2 Analysis of compliance levels..................................... 152

4.4.3 Compliance outcomes ........................................ 155

4.5 International relations theory analysis ........................... 163

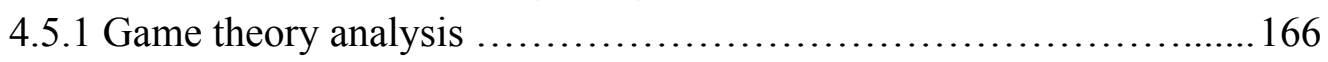

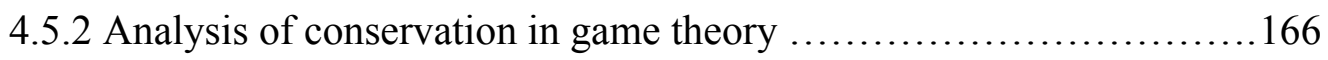

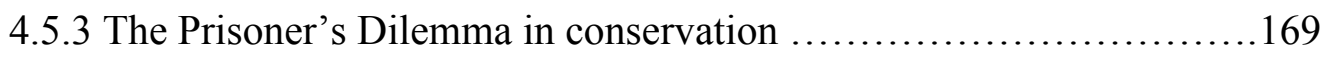

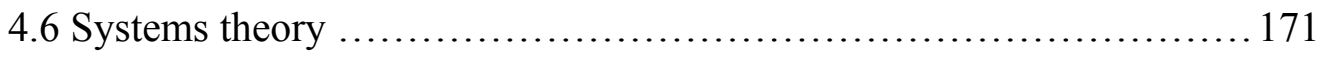

4.6.1 Governments and NGOs collaboration outcomes ................... 172

4.6.2 Application of systems theory ................................ 177

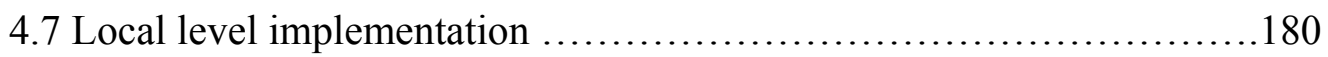

4.7.1 Local level compliance ......................................... 180

4.7.2 Reconciling conservational initiatives from local to global levels ..... 182

4.8 Opportunity costs of biodiversity protection ........................ 185

4.8.1 Estimation of opportunity cost compensation ........................187

4.8.2 Most appropriate compensation mechanisms ........................ 190 


\section{RESULTS AND DISCUSSION}

5.0 Discussion of results ............................................ 192

5.1 Introduction .................................................... 192

5.2 Compliance and implementation capacity challenges .................. 193

5.2.1 North and South America ....................................... 194

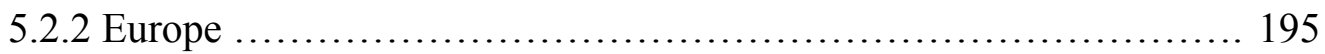

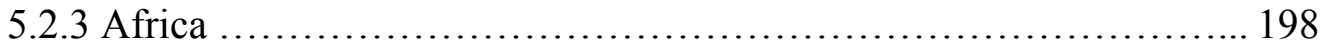

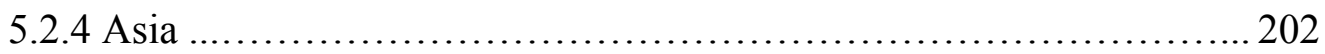

5.3 Compliance within federally administered countries ................ 203

5.3.1 Countries with strong presence of conservation organizations ..... 204

5.3.2 High capacity countries and compliance levels ................... 205

5.3.3 Systems theory and information technology in conservation. ........ 204

5.4 Reconciling conservation initiatives for higher compliance ............. 206

5.5 Theory in biodiversity conservation ............................. 215

5.6 Systems theory in biodiversity protection ........................ 216

5.7 Application of game theory strategies ............................... 219

5.7.1 Cooperation and consensus compared ........................... 219

5.8 Opportunity costs of biodiversity protection ..................... 220

\section{CONCLUSIONS}

6.0 Discussion and conclusions ........................................ 221

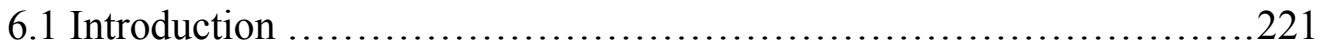

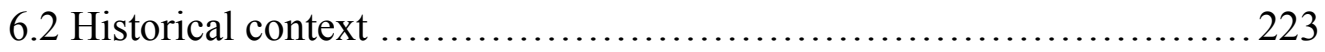

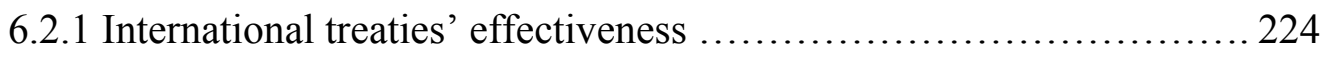

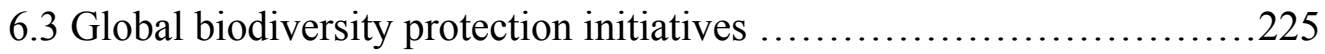

6.3.1 Sustainable use of biodiversity ................................ 226

6.3.2 Implications of global biodiversity deficits ...................... 227

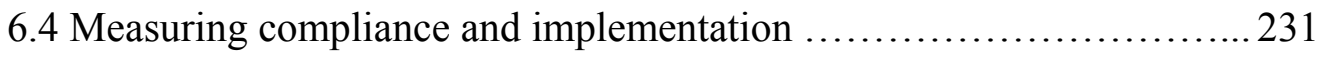

6.4.1 Paper compliance ................................................ 232

6.4.2 National compliance ........................................ 232

6.4.3 Local compliance ................................................. 233

6. 5 Policy implications .............................................. 234

6.6 Limitations of the study ............................................ 234

6.7 Conclusions .................................................... 235

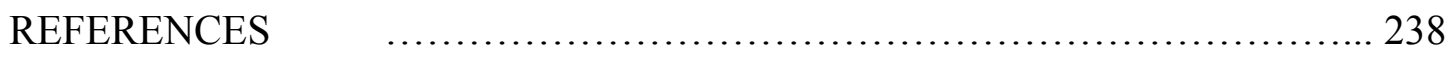


VITA 


\section{LIST OF TABLES}

TABLE

PAGE

1. Status of biological resources globally as of 2008 . 9

2. Sample of countries selected. .76

3. Biodiversity hotspot regions. 79

4. National level compliance criterion .90

5. Criterion used to define compliance of the NCHMs. 92

6. Paper compliance estimation scores. 103

7. National compliance estimation 104

8. Local compliance estimation. 105

9 Determinants of institutional collaboration 110

10. Game theory and conservation strategies

11. Functional systems levels

12. The extent to which biodiversity is given priority in society

13. Influence of national decisions on global conservation 128

14. Frequency of the use of the word capacity by key documents 144

15a. Context in which the word capacity is used - Americas 146 
15b. Context in which the word capacity is used - Europe

15c. Context in which the word capacity is used - Africa.

15d. Context in which the word capacity is used - Asia

16. Factors that most influence compliance and implementation. 150

17. Significance of factors that most influence implementation.

18. National and local compliance levels 156

19. Confirmation of hypothesis one 158

20. Overall global compliance by all countries 159

21. Estimated compliance levels on 15 out of the 20 criteria. 162

22a. Government and NGOs collaboration in the DRC 174

22b. Government and NGOs collaboration in Indonesia. 175

22c. Government and NGOs collaboration in Brazil. 176

23. Analysis of local level implementation 181

24. Perceptions on compliance and implementation at local levels 183

25. Perceptions on compliance at national and international levels 184

26. Status of biological resources measured as of 2008 186

27. Opportunity cost and compensation estimates. 187 
28. National decisions give low priority to biodiversity protection 209

29. Limitations to individual decision making at local levels.

30. Communication and global understanding of biodiversity conservation... 213

31. Reconciling societal levels and different sectors.. 214 


\section{LIST OF FIGURES}

FIGURE

PAGE

1. Compliance framework

101

2. Stakeholders' cooperation

108

3. Compliance network model

4. Stakeholder strategies

120

5. United Kingdom and Brazil cooperative relationship. 164

6. Two conservation players with prisoner's dilemma

7. Status of each country's biological capacity 190

8. Priorities of most sectors in society 207

9. National decisions give low priority to biodiversity protection 209

10. Support given to biodiversity protection is low. .211

11. Poor communication in support of biodiversity Conservation

12. Difficulties in managing biodiversity deficits. 


\section{CHAPTER I}

\section{INTRODUCTION TO THE STUDY}

\subsection{Introduction}

The Convention on Biodiversity (CBD) provides a global governance structure for coordination of countries to try implementing the global goals of biodiversity conservation. The three goals of the CBD include: Protection of biodiversity, achievement of sustainable use of biodiversity and facilitation of equitable sharing of the benefits of biological resources. The CBD only binds national governments. Implementation of these goals requires the binding of national and local institutions, individuals, and conservation organizations through legislation, negotiation, planning and contracting. It is through actual local level implementation of globally and nationally designed policies that meaningful compliance by member states can be attained.

Although good progress in these goals has been made in a number of areas such as national planning structures and information sharing tools, implementation has continued to present very difficult challenges arising from low capacities, lack of political will, and less than optimal decision making (South Africa National Report, 2009). Key aspects of compliance should be comprised of enforcement ability, human and financial resources, action oriented planning, strong national policies, supportive national legislation and institutional capacity building (Kline \& Raustiala, 2000). International conservation organizations also need to find better ways to improve national capacities as well as build structures that support local implementation using local institutions.

The way compliance with the goals of the Convention on Biodiversity (CBD) is defined and measured determines how countries formulate their compliance policies. 
Countries select conservation strategies and determine how compliance is defined. Currently, compliance requirements range from just signing and ratifying an international treaty, sending country representatives to conferences organized by treaty secretariats, and submitting reports. Compliance is not an event but a process that should generate new actions at different levels that continue to set standards, enable participation, and offer knowledge to address implementation challenges.

Effective protection of biodiversity should require that a clear distinction be made between policy formulation and policy implementation. Compliance under the CBD needs more than the fear of reputational implications and sanctions to include financial, human, and institutional capacities within a country to implement the three goals of the CBD. According to Pressman \& Wildavsky (1984), policy formulation is comprised of actions taken by governments to secure objectives whose attainment is difficult. Policy implementation involves the interaction between the setting of goals and actions taken to achieve them, a situation where each element is dependent on the other (Pressman \& Wildavsky, 1984). By "other", here, I mean all stakeholders from local to international levels.

Most compliance theories make assertions that do not explain in-country compliance variables such as different levels of influence from state, non-state actors, and international treaties. Guzman (2002) argues that without a good understanding of the connections between international treaties and how these influence country actions, it would be difficult to articulate policy advice with respect to compliance with international systems. This is one of the reasons there is poor coordination, insufficient 
collaboration and cooperation across levels between organizations involved in biodiversity protection.

It was necessary at this stage to look to theories that explain adoption and implementation of international treaties to understand how both governments and conservation organizations deal with resource management problems. The managerial theory was the first to be examined. It emphasizes global coordination and the idea that managers should be allowed to freely manage. Consent theory makes an assumption that once countries consent to a treaty, they automatically comply. The other theory that was used in this initial analysis was the legitimacy theory. It asserts that countries comply simply because treaties come into being following legitimate processes. Finally, international relations theorists believe that international organizations through collaboration can bring all collaborating countries into compliance (Guzman, 2002). These theories are each explained in greater details under the literature section in chapter two. These theories however fail to explain how globally designed conservation policies are adapted and how they get implemented by national governments.

The purpose of my study was to analyze the extent of influence of the Convention on Biodiversity (CBD) on countries and implementation of specific biodiversity protection initiatives. In addition, my study also identified approaches that countries use for local level implementation. The study took a national and local scale approach to compare and contrast policy development with actual national and local level implementation. Global, national and local implementation analysis using scientific, social, political and economic criterion was made to highlight gaps in policy between global, national, and local implementation. 


\subsection{Why the Convention on Biodiversity?}

Using the CBD as a case study was ideal because it is one of the global treaties with the highest number of countries that have signed membership now standing at 195 and with public-private partnerships of more than 250 (CBD, 2010). The present research set out to uncover underlying capacity challenges and now presents a novel political, socio-economic, policy, structural, institutional, and technological perspectives that would improve compliance. This compliance is by individual countries and the nature of support provided by conservation organizations.

Using a mixed methods approach, the current study analyzed and explained key theoretical and practical elements that constrain or facilitate both implementation and compliance with CBD goals at global, national, and local levels. There are interacting external and internal factors that affect the capacity of various countries during implementation and the level of compliance with treaties (Weiss \& Jacobson, 1998). These capacities were identified. The theoretical meaning of compliance is explained as well as its practical implications on conservation outcomes. Cross sectors as well as vertical political, institutional and organizational relationships were analyzed. An analysis of the CBD's influence and challenges faced by governments on the adoption and internalization of global biodiversity initiatives into national and local policies aimed at achieving the three goals of the CBD is here presented.

Compliance at global level is a total of conservation activities from local to national levels that take into account specific policy and programmatic collaborative actions in areas of implementation. Some of these policy issues include: capacity 
building, data and information sharing, participation, and development of institutions within countries (CBD, 2010, Weiss \& Jacobson, 1998). The study of biodiversity protection is a broad and complex process requiring analysis from the policy perspective, management side, science side, social capital side, and economic side of society. Social capital is seen through active and effective participation of stakeholders, not only at different levels of government, but also from all sectors that potentially impact upon the existence of biological resources. Sufficiently developed conservation social capital augments policy, management, science, institutional and economic systems.

From an economic perspective, there are two categories of local levels. These are the communities in rural settings whose livelihood directly depends on agriculture and land-based resources for their survival. The other category is a more privileged category comprised of businesses that indirectly depend on land-based resources to produce and look to the environment to deposit their waste. The business category has more claims placed on biological resources than rural communities while, rural communities are heavily implicated in their destruction. Looking at the management side, rural communities have not been involved much while the business group is not only heavily involved, but also wields a lot of influence on decisions that directly affect the management of biological resources.

Biodiversity protection therefore is a part of a large and more complex science and socio-political challenge of the whole society; At the international setting, that aspect of the whole society is demonstrated by the number of CBD party membership of 195 countries, participation by so many international conservation organizations and private- 
private partnerships. Similar broad participation as seen at global settings should be replicated nationally and at local levels, especially in rural communities that have direct contacts with biological resources.

\subsubsection{The definition of biodiversity}

Biodiversity, also known simply as biological resources, is the number and variability of all living organisms (plants, animals, fungi and bacteria). Biodiversity conservation in the context of the CBD extends beyond just species extinction to include conservation of natural habitats, ecosystems, and genetic materials (OECD, 1994). Biodiversity can therefore be defined as "the variability among living organisms from all sources including, inter alia, terrestrial, marine and other aquatic ecosystems and the ecological complexes of which they are part; this includes diversity within species, between species and of ecosystems" (CBD, 2002). Biodiversity supports life on earth and is essential in the provision of environmental services like freshwater, fuel, carbon storage and marine life.

\subsection{Statement of the problem}

When the 2010 biodiversity protection target of beginning to reduce biodiversity degradation at global, regional and national settings was not met by countries, the United Nations Environmental Programme (UNEP) put out a statement. This statement said that current conservation efforts and system are not adequate to meet biodiversity protection challenges and also meet economic development needs of the society (Koetz et al. 2011). Key hindrances identified in the UNEP statement were lack of adequate financing, 
incoherence amongst management institutions, weak linkages between science and policy, low capacity at national level to implement policies, and a significant disconnect between various management and consumption sectors (Koetz et al. 2011). At local levels in most countries, there exists chronic shortage of trained conservation professionals; there is no sufficient political support to biodiversity protection policies and low capacity agencies and conservation institutions.

Although the international community, global conservation organizations, and national governments have continued to developed programs and national laws that govern biodiversity protection, the diversity and quality of biological resources has been declining (CBD, 2010). As of 2006, global biological resources consumption was estimated to exceed the earth's capacity by 40\% (Global Footprint Network, 2010). Partly the problem is that current planning methodologies do not incorporate costs beyond administrative restrictions and enforcement of conservation regulations (Naidoo et al. 2006). All levels of biodiversity protection and planning come with different types of costs ranging from specific interventions to protect areas or species to foregone economic opportunities. These goals must be planned for and compensated, but most national plans do not contain this level of detailed initiatives. Some studies rightfully argue that the costs of biodiversity conservation are paid by local communities who in most cases benefit the least from biological resources (Adams et al. 2004).

It is therefore clear that the problem is partly related to the lack of effective engagement of local communities and private sector institutions where actual implementation takes place. Inability to engage with local settings makes it difficult to 
bring about change to local perceptions so as to create an understanding of the value of protecting biodiversity (Myeong \& Choi, 2010). Involvement of local institutions and communities in the design and program implementation is only possible if people at local levels know what the government and conservation experts are doing and when their input is sought after.

According to the Global Outlook Biodiversity Outlook (2010), biological diversity in the world is being lost at an unprecedented rate. The loss is largely a result of habitat destruction from land use changes that include overconsumption of natural resources, pollution of the environment, climate change, invasive alien species and development (CBD, 2010). Continued degradation of biodiversity reveals non-compliance with the CBD goals. Various theories that explain compliance fall short of ideas how countries comply with international treaties (Guzman, 2002).

Reducing consumption, changing lifestyles and the current business operate to bring about sustainable use and reduce overexploitation of biodiversity comes with opportunity costs. Communities and businesses will not undertake protection of biodiversity if this comes with high opportunity costs. Effects of biodiversity degradation are viewed as distant issues in nature whereby a local loss in forest resources due to agricultural expansion or overexploitation to provide timber do not manifest themselves to communities. The manifestations of such effects are likely to be felt and paid for by future generations. There are two types of opportunity costs, opportunity costs of current biodiversity consumption against the externality effects on future generations, and opportunity costs of sustainable use. 
over-consumption of biological resources going into a deficit by an equivalent of 0.92 hectares per person. High income countries were home to about one billion people with biodiversity consumption of negative 2.54 per hectare per person. Middle income countries had about 4.4 billion people with a deficit in biodiversity of negative 0.20 hectares per person. As for low income countries, total population at 2008 was 1.3 billion and had even levels of use and supply of biological resources at 1.14 hectares per person..

Continued overexploitation of biological resources beyond the level where the Earth is able to regenerate brings about an ecological deficit. Biodiversity deficits leads to higher accumulation of greenhouse gases in the atmosphere, more wastes beyond the level the Earth can absorb and could finally lead to the collapse of the ecosystems (Global Footprint Network, 2013). Biological resources deficits should be part of the equation in measuring compliance.

\subsection{Background of the study}

First of all, there is need for greater understanding that biodiversity conservation by countries is not an inconvenient truth to be resisted. Biodiversity is a foundation of economic development, a life support resource, provides for political and social stability and therefore all countries must take a bold collective action to protect it (Global Footprint Network, 2010). The Global Footprint Network (2009) report responding to the Stiglitz Commission argues that we are living in a time when the limiting factor is no longer our factories' capacity to produce, but the biosphere's capacity to provide the ecological services needed for economic development. Therefore, rather than get entangled in ideological debates and ignore the real problems that come with 
overexploitation of biodiversity, countries need empirical facts to facilitate in building political consensus to support policies that guide economies to operate within the Earth's ecological limits (Global Footprint Network, 2010). This study was designed to provide discussions to these empirical facts.

Tracking of distinct policies implementation as well as in combination helps in the understanding of biodiversity degradation drivers and where these effects would most be felt. One example is the push toward the use of biofuels such as eternal as an alternative to fossil fuels for purposes of reducing carbon emissions to the atmosphere. The final outcome according to the Global Footprint Network calculations represents a shift and a net increase of environmental pressure. The reduction on carbon emissions comes with an increase in demand on forest or croplands that in the final analysis reduce the quantity and quality of biological resources.

Founded in 1992, the Convention on Biodiversity (CBD) has made it easy for countries, other partner organizations, and local institutions to learn from one another. There is a clear enabling environment and so many organizations are playing critical roles in collaboration with both government and with each other in biodiversity protection. One challenge currently facing most governments is that rather than having local institutions at local level implementing, many international organizations are doing virtually all conservation work at local levels. International organizations represent both the government and local institutions in training local people, sharing knowledge, and doing actual biodiversity protection programs.

Although these organizations are making very important contributions, there are many local problems they cannot solve and local institutions are supposed to step in. 
Efforts at building effective and innovative local institutions would be sustained and continued if local expertise, knowledge, and buy-in is secured. Efforts to strengthen local institutions should include initiatives to empower all citizens at local settings. One point of departure is the private sector businesses who wield a lot of influence on individual countries policy development usually, toward their profit motives (Coglianese \& Nash, 2004).

National Biodiversity Strategy Action Plans (NBSAPs) provide a roadmap for implementation of the CBD goals. Guided by NBSAPs, individual governments have over the years developed various national and local initiatives that help in the implementation and compliance with CBD goals. The international community in 2002 met and encouraged all parties to the Convention on Biodiversity to start drawing national protection plans. It was expected that as soon as governments ratified the convention on biodiversity and began to draw national plans, implementation of the CBD goals and progress towards beginning to reverse biodiversity degradation globally will be realized (CBD, 2010). National governments continue to face implementation challenges and movement toward compliance has been a very slow process.

\subsection{Objectives of the study}

National biodiversity conservation initiatives need to secure institutional as well as society's confidence in the justification of conservation efforts. Biodiversity conservation is undertaken to ensure continued existence and adequate flow of biological benefits. A framework for collaboration by parties to the CBD and various partnerships is needed for better outcomes; information and data sharing, and capacity building to 
facilitate implementation of CBD goals (Stephens et al., 2002). The broad objective of this study was to analyze and explain how globally designed biodiversity conservation policies get adapted by national governments and are finally passed to local levels for actual implementation.

Specifically, the study has tried to:

i. Uncover critical policy, administrative, economic and political factors affecting the implementation and compliance of international treaties

ii. Describe how national and local environmental policies and priorities evolve and adapt under international environmental treaties.

iii. Estimate opportunity costs of biodiversity protection in local rural settings as well as in the private sector and industry settings

iv. Examine specific combinations of theory, policy interventions, and nationallocal regulatory mechanisms that can move countries towards greater compliance.

Biodiversity protection is the responsibility of governments first. It is at this level where programs are created by law with clearly identified purpose, means and conditions under which they will be implemented (Rose, 1991). But, the reality is that governments have not taken the leadership. Critical structures at the national level needed for coordination are still missing. Very few governments have built an equivalent of Clearing House Mechanisms (CHMs). Most governments are also not publishing their own data. It is from this lack of data at both national and local levels that questions for this research began to emerge. Therefore, there a need to examine different decision points and how information is shared between sectors, agencies and governments. When information and 
data gaps persist, effective policy implementation suffers, and costs of building consensus goes up (Esty \& Ivanova, 2004).

This study addresses the following key questions:

1. What are the critical policy, administrative, economic and political factors that influence the implementation and compliance of international treaties at both national and local levels?

2. How do national and local environmental policies and priorities evolve and adapt under international environmental treaties?

What are the opportunity costs of compliance with all goals of the CBD?

\subsection{Significance of the study}

This study was about extending compliance requirements from the global setting beyond the national level to local levels where actual policy implementation is done. This study was not about whether countries comply or not with international treaties, but rather, when they comply, how they meet treaty requirements and implement specified goals, and the extent that compliance outcomes meet the biological thresholds of the resource in question.

This present study is significant in many different ways:

- There is no literature that has documented the adoption stages that international treaties go through from international conferences where agreements are made to villages and private enterprises that implement these global agreements. This research was designed to fill this gap. 
- For effective analysis and compliance outcomes, this study divided compliance into three distinct stages: compliance on paper at global level, compliance as a policy process at the national level, and compliance as an act of actual implementation at local levels. The study analyzed compliance based on these three stages to see exactly what needs to happen and how each stage is developed to drive compliance to higher levels.

- Compliance should take into account the range of capacities of national governments, institutions, communities and the status of biological resources (Ringquist \& Kostadinova, 2005; Weiss \& Jacobson, 1998). I therefore assert that in addition to other measures of compliance such the signing of a treaty by a country, submitting reports and creating institutions, the degree of understanding and knowing the extent to which every country is able to meet the demand for biological resources, without out-stripping its supply, is a tangible platform to measure compliance. This can about through effective mobilization of all stakeholders at both national and local levels.

- At both national and local levels, there has to be an understanding of the compliance threshold and which components of implementation each sector at different levels in society should put into place so as to comply. The earth's regenerative capacity provides for the ecological threshold which if exceeded, the quality of life on earth begins to get compromised (Borucke et al. 2013). Compliance with CBD goals should take into account the fact that the planet has ecological boundaries within which consumption of natural resources and development has to be secured (Borucke et al. 2013; Rockström et al. 2009). 
Purposely, I have tried to connect compliance at different levels of policy environments and local implementation. I also examined institutional, political, structural and economic aspects of the CBD beyond national levels to include its causal effects on local institutions. How conservation organizations work with both government and communities and the challenges that come with such relationships was analyzed. Uncovering various national and local capacities, strengths and weaknesses that affect most of the compliance theories is critical for effective decision making.

Linking local decision making and implementation challenges to global policy commitments requires a comprehensive examination of capacities; political, and socioeconomic priorities within countries. Although there are many studies that have examined global compliance challenges with international treaties (Jacobson \& Weiss, 2010; Ringquist \& Kostadinova, 2005; Guzman, 2002; Chayes \& Chayes, 1993, 1995; Chayes et al., 1998), my study examines compliance at three levels: Global compliance, national compliance and local compliance. Central to overall compliance is what countries are doing to comply with global treaties, what local communities and institutions are doing at local levels to facilitate compliance, and how global conservation initiatives are taken to local settings where actual policy implementation takes place. My study has generated valuable grass-roots perspectives on compliance, implementation, institutional capacities and relationships at the national and local levels.

Non-compliance with the goals of the Convention on Biodiversity can best be explained by the level of support given and sanctions placed on individuals, communities 
and institutions at local levels within countries. Furthermore, compliance with CBD goals also depends on the nature and strength of cooperation between various stakeholders.

Theories that try to explain why countries comply with international treaties make mere assertions that either lack specific structures or stop short of explaining why and how compliance is attained (Guzman, 2002). It is not through internalization of international treaty norms that national institutions move toward more compliance as asserted by Koh (1996), but through improvement of capacities of both human and national bureaucracies (Guzman 2002; Wilshusen et al. 2002)). I demonstrate that low capacities, weak policies and institutions in society can be strengthened and improved through capacity building, cooperation with more established organizations, through information sharing and human resources training.

Using systems theory, the present study examined the strength of working relations, the extent that problems are shared between government and conservation organizations and the nature of support that exist between governments and conservation organizations. The use of Information Technology (IT) facilitates not just information sharing, but also experiences, and resources. The CBD is using information technology to share reports, data training and conservation information with parties and partner organizations. Countries are encouraged to develop national information sharing tools. Analysis of factors that facilitate governments to create better and more effective tools for information sharing across all institutions so that local level institutions are constructively involved in the implementation, data collection and sharing of biodiversity information nationally was done. 


\subsection{Interface between policy and implementation}

Although governments play a significant role, science has been the guiding policy framework for biodiversity protection and continues to play a significant role in decision making. With the ever rising conservation constraints, there is an increasing need to move toward incorporating the scientific framework with governance and political policy considerations. Finding ways in which various stakeholders cooperate will help to pool more resources to adequately address biodiversity conservation challenges that have persisted through the last four decades. The present study has established institutional linkages based on both science and governance approaches to explain global biodiversity protection and national public policies. Explaining public policies to the public is necessary for the awareness raising of the social and political constraints with regard to conservation at local levels. Public policy is based upon government action in providing guidelines to carry out various government functions that provide for public goods to society (Martin, 2003). My study has put together factors that facilitate understanding of how governments adopt global policies and facilitate their implementation at local levels.

At the national level, critical decisions are made, plans are drawn and programs get created by law with clearly identified purpose, means and conditions under which they will be implemented (Rose, 1991). Notably, under agenda 21, more detailed guidelines and policy recommendation are established, such as development of national strategies, plans and process for effective implementation. The at implementation levels is establishing clear linkages between all sectors and institutional levels. 
Linking local decision making and implementation challenges to global policy will facilitate greater understanding between government, international organizations and local level institutions. This understanding will help in the setting of realistic and achievable goals that take into account local needs and global priorities (Gordon et al. 2005). When governments are involved, political institutions play a central role in either aiding or constraining implementation of any law or plan. According to Gordon et al. (2005), global conservation strategies concern themselves with "where" to protect rather than "how" to protect biodiversity. In doing so, the scientific criteria are used in decision making and not the broader social, economic and political considerations that are sensitive to local needs. The study has tried to find ways to make biodiversity protection more politically appealing.

\subsection{Understanding compliance as a system}

Understanding of compliance in totality requires a systems theory approach. A systems theory is a broad framework that allows different agencies and organizations to work as a collective whole for an overall mission. A system is a combination of many different parts that are meant to work together in order to achieve a specific goal. There are interacting external and internal factors that affect the capacity of various countries during policy formulation and implementation to determine the level of compliance with treaties (Jacbson \& Weiss, 2010). An analysis of the CBD's influence and challenges faced by governments on the adoption and internalization of global initiatives helps to see how the three goals of the $\mathrm{CBD}$ are being met. 
Compliance at the global level is a collection of locally and nationally generated systems of policy. Also, compliance entails programmatic collaborative actions cutting across implementation, capacity building, information sharing, participation, and development of institutions within countries (CBD, 2010, Weiss \& Jacobson, 2010). Compliance is a broad and complex process requiring analysis of actions from the various policy perspective, management, scientific understanding, social capital development and economic considerations of society.

Social capital is seen through the active and effective participation of stakeholders not only at different levels of government, but also from all sectors that potentially impact upon the existence of biological resources (Pretty \& Smith, 2003). Sufficiently developed conservation social capital augments policy, management, science, institutional and economic systems (Ostrom, 2010). From an economic perspective, there are two categories of compliance. These are the communities in rural settings whose livelihood directly depends on agriculture and land-based resources for their survival. The other category is a more privileged category comprised of businesses that indirectly depend on land-based resources to produce and look to the environment to deposit their waste. The business category has more claims placed on biological resources than rural communities while rural communities are heavily implicated in their destruction (Pretty and Smith, 2003). Looking at compliance from the management lens, rural communities have not been involved much while business groups are not only heavily involved but also wield a great deal of influence on decisions that directly affect the management of biological resources. 
Globally, compliance means the extent to which states participate and sign onto the CBD goals (Weiss \& Jaconson, 2010). Domestically, compliance depends on a wide range of institutional, political and socio-economic mechanisms cutting across many sectors and governance levels within countries (Chayes \& Chayes, 1993). Compliance means more than just signing a treaty by government if the goals of the CBD are to be met. Various theories used to explain compliance do not agree on what it would take for governments to comply (Guzman, 2002; Weiss \& Jacobson, 2010). Most studies do not connect compliance with implementation. Other studies examine how reputation and use of various incentives facilitate compliance but these too do not analyze or take into consideration local levels.

Most institutions and individuals involved with biodiversity management within countries seek compliance only if it aligns with their own interests (Rees, 2003). Moreover, they also lack technical capacities and policy conceptualization skills in biological resources management (Kline \& Raustiala, 2000). Prior research has found that strong parliamentary and local legislation enables the development of sound organizational ethics where terms of the treaty are given priority (Oliver, 1991). Political stability as a sign of strength of parliamentary systems and legislative developments is questionable in a lot of countries.

Compliance therefore needs to be seen as a large and more complex system of science and socio-political challenges for the whole society. In the international setting, all governments should be willing not just to participate but also to implement the agreement at the national level. The global broad participation must be seen to be 
replicated within countries by having all sectors and institutions participating in biodiversity protection.

\subsection{Defining compliance elements}

ON the basis of the current global status of biodiversity, investments and efforts all countries have put into conservation, the time to re-evaluate what to consider when defining compliance is now. Compliance can be viewed as performance-based measurement of implementation, a concept often used in areas of energy or other systems of engineering (Eisenhower, 2014). Existing efforts and investment are either not taking all countries fast and far enough or there are important compliance elements missing from the equation. According to the Global Footprint Network (2010), the current rate of natural resources consumption have moved the world much closer to an era of peak energy, climate change, food shortages, biodiversity loss and freshwater stress. An "overshoot" situation where people are using more resources than the earth can support is now being experienced and getting worse. For instance, most land conversion in tropical regions (where most of biodiversity lives) is under pressure from consumers living outside the tropics. Lands allocated to forests are diminishing while the quality of soils is being degraded much faster to feed the ever rising global population. A biodiversity tragedy is not far from happening, because regardless of how successful the current conservation programs get, outcomes will never replicate the original land quality.

It is, therefore, critical that more tangible measurement variables be included as requirements in measuring how countries comply with all the goals of the CBD. Countries need to be informed of their national footprint, their biological capacity and 
level of consumption in relation to available national resources. Countries as well as conservation organizations need to know how much needs to do, and where to concentrate more conservation efforts.

Inclusion of more measures in the definition of what is required for countries to comply at this time when the trend is the rising demand and dwindling supply of biological resources is critical. For countries that know that they are in an ecological deficit, one goal toward compliance is to develop tangible initiatives to get out of the ecological deficit. So as not to ignore overexploitation locally, countries should be required to compare the demand on biodiversity with supply and report the same to the CBD secretariat.

\subsubsection{Role of international treaties}

Environmental treaties provide structures for governments to build commitments and negotiate for consensus on public interest management. Treaties, however, do not go into specific actions that sanction what and how countries comply. When governments enter into a treaty, they are simply expected to comply with the commitments they have made to meet the terms of the treaty (Chayes \& Chayes, 1993; Kline \& Raustailia, 2000). Treaties are negotiated through diplomatic processes to build political consensus that often imposes no concrete obligation, participation is voluntary, and levels of commitments by governments are self-monitored. There is no penalty for noncompliance. 
Individual government compliance is supported through a variety of ways that include international conferences, information sharing tools using the internet and working in partnerships with international non-governmental conservation organizations.

Globally, compliance means the extent to which states participate and sign onto the CBD (Weiss \& Jacobson, 2010). Domestically, compliance depends on a wide range of institutional, political and socio-economic mechanisms cutting across many sectors and governance levels within countries (Chayes \& Chayes, 1993). Compliance means more than just signing a treaty by government if the goals of the CBD are to be met. Various theories used to explain compliance do not agree on what it would take governments to comply (Guzman, 2002; Weiss \& Jacobson, 2010). Most studies do not connect compliance with implementation. Other studies examine how reputation and use of various incentives facilitate states compliance but these too do not go down to local levels where actual implementation takes place.

Biodiversity conservation can be very abstract in the sense that it is difficult to situate in real life situations and within institutional policies. The abstract characteristic coupled with lack of understanding and inability to conceptualize policy process requires creates a disconnection between policy and implementation. Effective information sharing, therefore, human and institutional capacity building, and development of governance structures across national and local settings is needed. Some studies argue that even when the benefits and sustainable use of biological resources may be positive, most sectors are reluctant to justify spending time and effort unless they are either sanctioned by law and or by the society to get involved (Coglianese \& Nash, 2002). 
Most institutions, for profit organizations and individuals within countries comply with biodiversity protection goals only when it aligns with their own interests (Rees, 2003). Moreover, most also lack technical capacities and policy conceptualization skills in biological resources management (Kline \& Raustiala, 2000). Although strong parliamentary and legislative systems may facilitate the development of sound organizational ethics where terms of the treaty are given priority (Oliver, 1979), weak local and national have remained barriers to effective implementation. In addition, political instability and parliamentary systems in most countries account much of the conservation problems.

\subsection{Implementation of CBD goals}

Science has been the guiding policy framework for biodiversity protection and continues to play significant role in decision making. There is an increasing tendency now to move toward incorporating the scientific framework with governance so as to adequately address the conservation challenges that have persisted throughout the last four decades. Governments, private institutions and international conservations organizations have begun to play critical roles in biodiversity conservation.

Guided by the global strategic plan, individual governments began in 2002 to draw their own National Biodiversity Strategy Action Plans (NBSAPs) upon which local initiatives and implementation of conservation policies and actions were supposed to be clearly outlined. However, NBSAPs in most countries remain simply a mere bundle of declaration of intentions rather than commitments to specific actions (Harrop \& Ptichard, 2011). All member countries to the Convention on Biodiversity (CBD) now have 
NBSAPs but most do not have the capacity nor clear commitments and strategies on how to implement specific actions on a sufficient scale to meet all the CBD goals.

Some of the challenges start with the global approach because the CBD urges countries rather than requiring parties to fulfill specific implementation obligations (CBD, 2010). Effective implementation of CBD goals depends on how governments sanction NBSAPs to lower level structures and communities. As governments try to confront biodiversity protection challenges, they need good analysis of both the macro and micro complex relevant factors that influence the choices that people make at different levels in society and within government. This kind of capacity is lacking within many government institutions.

National plans developed by individual countries fail to match the goals outlined by the CBD with the interests of all groups in government and the communities (Tang et al., 2009). National plans are supposed to provide feasible bottom-up means to establish concrete strategic goals, identify biodiversity degradation drivers and establish mechanisms for coordination, monitoring, measuring trends, and reporting performance (Tang et al., 2010) but stakeholder participation remains very narrow and highly skewed to those with different interests (Sajor, 2009). This study tries to reconcile NBSAPs on paper with the on the ground realities both nationally and at the local level.

How governments take NBSAPs to lower level structures and communities where implementation takes place is extremely challenging. Most people involved within countries and local settings not only look after their own economic interests but also lack technical skills, policy conceptualization, training and understanding on how to 
implement the goals of international treaties (Kline \& Raustiala, 2000). The mainstreaming of biodiversity protection initiatives into national and local day-to-day issues so that they are seen as beneficial concrete actions and not costly abstract ideas does not seem to be well articulated to lower level institutions and structures within countries.

\subsubsection{Local level implementation}

Local policy implementation is not just about biodiversity conservation in itself. There needs to be a clear understanding of how biodiversity conservation policies impact upon community needs, business interests, poverty and local economic development priorities. According to Pressman \& Wildavsky (1984) out of one goal - to protect biodiversity, multiple goals start to emerge requiring multiple decision paths. This multiplicity of decision paths requires multiple decision makers who may have different priorities and may not care about outcomes from other decision paths (Pressman \& Wildavsky, 1984).

\subsubsection{Adaption of local and national policies to international treaties}

The challenge to biodiversity protection is the inability to find ways which policies can be widely adopted and effectively implemented at all levels in society. Habitats that host biological resources have continued to lose out to the rising human population and the needs of economic development (Wilshusen et al. 2002; Rands et al. 2010). Biodiversity continues to be depleted at an increasing rate (CBD, 2006). Towards the end of the 1990s, habitat reserved for biodiversity stood at 5 percent and for humans 
at 95 percent (Terborg, 1999). Terborg (1999) calls for radical changes in conservation governance policies in all countries to avert total destruction of biological resources. Consumption of biological resources has persistently superseded conservation efforts (Global Footprint Network, 2010). The ongoing development of biodiversity protection policies and efforts put into various international and national institutions will be futile if in the long-run these are not widely adopted, are not be effective and functioning.

Advancement in democratic international institutional instruments and use of information technology (IT) has created awareness and global cooperation in biodiversity management. Governments that are parties have taken up the big role of implementing the goals of these treaties to protect biodiversity within their borders. The convention on biological diversity (CBD) also known as the Biodiversity Convention is an international legally binding treaty such that countries that join it are required to implement its provisions.

\subsection{Global - National - Local conservation model}

At the global setting, just ratifying a treaty is seen as one aspect of complying. Globally, many treaties are in a sense drafted to generate policy rather than as a source of obligations (Harrop \& Pritchard, 2011). Actual implementation of treaty goals locally calls for governments to provide capacity, direction to all stakeholders and develop a fair framework for conservation and equitable distribution of benefits of biological resources in more practical ways. Because of perceived immediate costs of biodiversity protection many governments are not willing to build environmentally sound protection structures for distant biological resources (Harrop \& Pritchard, 2011). 
Any plan, therefore, that promotes biodiversity protection at local levels should be developed with the main objective of changing people's perceptions. This includes improving local knowledge, developing clear sanctions and penalties, and also creating specific institutions to manage biological resources (Alexander, 2005). This calls for biodiversity protection to be pursued simultaneously at three levels; global, national/country and local levels. It is the local level implementation strategies that add to national level success/failure and finally the global status and outlook of biological resources. It is in the local setting that government regulations/laws that govern the society are most felt. Also it is in these settings where frameworks for political relationships are developed and where specific policies and practices are implemented.

Effective biodiversity protection initiative and planning must be based on constant interplay between theory and practice and thus subject to constant modification as new information is acquired. Issues that arise out of putting together theory and practice should be solved collaborative between government institutions across all levels and various organizations as well as communities and private sector institutions.

Examination and analysis of country plans, progress reports, analysis of national and local institutional developments, capacity building in the form of information technology, human resources training to build epistemic communities, and specific connections from the $\mathrm{CBD}$ to governments to local levels.

Measurement of implementation and compliance was tried by Jacobson \& Weiss (2010) but was not very clear. My study has taken the issue of measurement seriously and wants to examine the relationship between national governments and local institutions. 
The next chapter examines theoretical constructs that speak to institutional collaboration and international relations. A review of various literature on compliance with international treaties and implementation in general was done. Some other literature on the goals of the $\mathrm{CBD}$ and implementation of various actions to protect biodiversity (Jacobson \& Weiss, 1998), show strong indications that this is something that countries would want to do. There are however implementation and compliance problems of varying magnitudes in different countries (Wilshusen et al., 2002). Successful implementation of all goals of the CBD and achievement of greater compliance rests on collective action by all parties to the CBD, its partnerships and many other sectors. 


\section{CHAPTER II}

\section{LITERATURE REVIEW}

\subsection{Introduction}

Chapter 2 is a literature review on compliance and implementation of the Convention on Biodiversity. This review of literature was done in the context of human needs, the laws that govern human society and the forces inherent in human nature (Thompson \& Morgenthau, 1948). Specifically, the chapter examined the literature on international and national politics, policy formulation, local leadership, institutional cooperation, and economics of biological resources, the scientific explanations and social capital. The study examined international relations literature from the perspective of global, national and local policy environments and institutional evolution. The literature reviewed thus far provided a good foundation for the methods chapter.

\subsection{Management of biological resources}

Biodiversity management falls under multiple governing authorities and jurisdictions, therefore, are most likely to be under-produced if mechanisms meant to promote and reinforce cooperation are missing (Grunberg \& Stern, 1999; Esty \& Ivanova, 2002). At regional levels, government-to-government cooperation is required for successful implementation of biodiversity protection policies. At national levels, devolved authority and decision making to local levels so as to encourage popular participation and capacity building for communities is required to strengthen the implementation of the goals, therefore, leading to higher compliance (Basurto, 2008). 
The underlying conceptual framework of biodiversity overexploitation is their public good nature. Public goods are available for enjoyment for free by the society and are difficult to confine to a single individual or group and are non-rivalry in consumption (Esty \& Ivanova, 2002). Management of environmental public resources requires strong public policy solutions that have to be tailored to meet social equity, ecological effectiveness, political feasibility, and economic efficiency (TEEB, 2009). Policy making and program implementation for public goods such as the management of biological resources should not be based on narrow self-interests but collective action by all stakeholders cooperatively (Esty \& Ivanova, 2002; Ostrom, 1990).

The influence of the Convention on Biodiversity on government policy as well as at local level implementation and what types of institutions get created deserves a deeper analysis. This because over the last two decades, the goals of biodiversity protection have not been met, implementation has not been sufficient and compliance levels have remained below expectations. Borrowing from the theory of cross-scale linkages, this study examined the nature of relationships that has evolved at local, national and international levels. Specific variables looked into in these linkages were financial support linkages, capacity building linkages, technological and management linkages (Igoe \& Kelsall, 2005). These linkages take various forms such as formal or informal rules of interaction between international organizations and local level institutions to define the nature and type of support, information sharing and transfer of intellectual expertise (Basurto, 2008). 
Local implementation takes two distinct approaches; there is the political process and the administrative process (Pressman \& Wildavsky, 1984). The political process takes the form of authority and power that is given to agencies created to implement policies. Administrative process speaks to the capacity of these conservation agencies and community institutions in management, financial and human resources (Pressman \& Wildavsky, 1984). A key constraint to implementation is that conservation of biological resources continues to be seen as a cost to society. Since biodiversity protection is a multi-layered and multi-sector resource of interest, explaining implementation, therefore, requires theories that can bring order and meaning to those that are tasked with implementation as well as to those that would be impacted most.

\subsection{Theoretical framework}

Although there are more than 50,000 international treaties globally today covering most issues across the society, the general lack of central enforcement ability and the voluntary nature of their requirements make them rather ineffective in shaping states behavior (Hathaway, 2005). Hathaway (2005) places the power of international treaties at the crossroads of when treaties actually influence states behavior and when they do not. Understanding the politics that influences governments' decision to commit and to comply helps to see the extent that treaties influence countries (Hathaway, 2005).

Examining most existing theories from the lens of biodiversity protection, they do not sufficiently explain compliance with the convention on biodiversity (CBD) goals. At the global setting, just ratifying a treaty is seen as one aspect of complying. Locally, compliance has to mean much more than just ratification of a treaty and should go 
beyond policy making. Although the Convention on Biodiversity merely urges member states rather than requiring them to fulfill its goals, national initiatives should commit countries to more stringent obligations for higher compliance if biodiversity protection targets have to be met in the future.

Wilshusen et al. (2002) argues that biodiversity protection should stop being placed secondary to other priorities by governments and instead focus on strict enforcement of conservation laws. Compliance with the CBD should call for much more than just state reputations and sanctions. Compliance with the CBD requires much than political commitments. Countries must have financial capacity, human resources, strong institutions and willingness of the citizenry to change their lifestyles and consumption.

Conservation of biodiversity presents a very long and broad chain of causality across sectors at different levels globally (Jasanoff, 1998; Guzman, 2014). Causality comes with numerous decision points as different levels present their aspirations and interests to each other (Wang, 2011). Individuals and institutions tasked with the responsibility of biodiversity protection find themselves having to answer to multiple principals such government, communities, private sector institutions and their own employers creating multiple decision points. Conservationists are in effect, required to be able to balance conflicting interests and expectations of their many principals. This makes coordination difficult and weakens enforcement of regulations.

Going forward, the key questions to ask are: (1) How much compliance and what type of compliance is expected at every decision point? (2) To what extent are the means matched with the ends? This kind of compliance is better explained using the managerial 
theory rather than enforcement, sanctions and reputational costs. Managerial theory is based on a cooperative problem-solving model (Chayes \& Chayes, 1993) and therefore can serve the CBD goals better. The managerial theory allows more freedom for managers to manage and has given rise to the popular saying "managing for results" (Boston et al. 1996). A cooperative problem-solving approach to decision making allows parties to identify all their strategies both strong and weak. The weak strategies get supported without compromising their strong strategies.

Other leading theories that have contributed to explanations on compliance are: international relations theories, legitimacy theory, consent-based theory and institutional theory. International relations theories concern themselves more with inter-state relations and less on what actually takes place within states (Guzman, 2002). Protection and management of biodiversity takes place inside states so this does not really help much going forward in this research. Consent-based theories hold that states are not subject to any external obligations which they have not consented to (Guzman, 2014). However, for conservation of biodiversity, consent to comply is not enough. Commitment to the goals of the CBD requires both commitment and capacity to carry through to completion specific implementation obligations.

According to Guzman (2002), the legitimacy and consent-based theories make assertions that countries obey international treaties either because they have consented to those treaties or because treaties come into being through legitimate processes. Where there is determinacy, symbolic validation, coherence and adherence, it is assumed that there is a strong tendency toward high compliance. Determinacy means clarity of rules, 
symbolic validation is the presence of procedural practices, coherence is the connection between rational principles and the rules, and adherence is the connection between the rule and those secondary rules used to interpret and apply primary rules (Guzman, 2014). Institutional theory views countries as primary international actors and uses cooperation to explain how institutions within countries can move countries toward greater compliance by reducing costs of verification in international treaty commitments (Koh, 1997). Institutional theory goes deeper to explain how individuals, interest-groups and how private actors impact upon national decisions.

The problem with these theories is that they cannot explain the acceptable level of compliance and what it would take to attain that level. According to Guzman (2014), consent by a country is in itself an incentive to comply. At the same time, legitimacy of a treaty does not give capacity to countries to comply. The legitimacy theory fails to explain why nations should actually obey a legitimate treaty.

Conservation of biological resources cannot be left to governments alone. According to Koh (1997), there exist non-state actors that share this responsibility as explained by the transactions theory. This theory explains how public and private sector organizations interact to internalize international treaties, interpret rules and enforce them. This theory goes beyond treating governments as unitary actors to also bring in all other stakeholders into the decision making ring. These are classified as transactional actors whose role is to facilitate interactions and help to develop patterns of behavior, and norms that can go into supporting compliance. Actual decisions at national level to comply or not are heavily influenced from domestic institutions (Guzman, 2014). 
However, compliance with environmental treaties requires more than participation of local institutions and stakeholders. It requires changes in perception, lifestyles, conservation skills, training and information sharing tools.

Going forward, this study has used game theory and living systems theory to model compliance and implementation of biodiversity protection goals.

\subsubsection{Game theory}

Conservation of biodiversity has always been implemented through negotiations by interested parties within the confinements of normative social goals such as access to use of resources to support basic needs, poverty alleviation, economic wellbeing among many other priorities (Frank \& Sarkar, 2010). Different groups with competing interests such as communities, conservation agencies, governments, and private sector businesses get modeled as decisions of a single agent trying to maximize objectives of each interest.

There is potential for conflicts as each party wants to strategically get maximum benefits out of the negotiations. When such conflicts occur, decision support tools such as the use of multi-criteria analysis have often been used to settle the conflict (Frank \& Sarkar, 2010). However, in situations where there exist multiple interested parties, game theory provides the best way to model strategic positions taken by all parties. Frank and Sarkar (2010) argue that game theory helps to identify conservation conflicts with Paretoinefficient Nash Equilibrium, thus, enabling actions that achieve closer to optimal conservation outcomes. This is based on policy solutions that use mechanisms designed to provide optimal individual incentives structures. 
Across many sectors and geographic regions, there is evidence that conservation negotiations lead to trade-offs between different interests (McShae et al. 2011). The full range of trade-offs are often under-estimated and rarely lead to win-win situations. When Nash equilibria are Pareto-inefficient, stakeholders should cooperate otherwise seek the intervention of higher authority. This works only if the higher authority is not perceived as a stakeholder, otherwise it gets very problematic (Colyvan et al. 2011). Game theory is a normative approach with a precise analytical framework that recognizes sub-optimal conservation outcomes while facilitating players (countries or conservation organizations in this case) to see possible best solutions.

There exist two equilibriums: when conservations and owners of biodiversity resources fully cooperate and also when they fail to fully cooperate. A full cooperation leads to an efficient equilibrium outcome because conservation strategies get implemented. A failed cooperation results in an inefficient equilibrium outcome because conservation strategies do not get implemented (Hoven, 2004).

\subsubsection{Systems theory}

Borrowing from the living systems theory (Wang, 2004), the study examined organizational, community, society and supranational systems that have to be designed for purposes of information sharing and organizational learning at the international level. Systems theory provides answers to the question how globally designed biodiversity protection programs fit into the needs of local situations as well as effective relationship between global and local institutions (Deming, 1986). The purpose of an institution according to the living systems theory is to reach a desired steady state where institutions 
are effective and their existence to continue to meet specified goals is guaranteed (Wang, 2004).

In the context of information management, this study asserts that the CBD can be viewed as a decider subsystem. Wang (2004) argues that the decider is an information process sub-system that receives, in this case, reports, plans and data from all other subsystems and transmits information outputs for guidance, coordination and management of the whole global structure. The relationship between the CBD, its member countries and local institutions can be viewed as a living system. Information Technology facilitates communication across these systems otherwise known as countries, and facilitates global, national and local coordination. Governments with information, policy and data rich websites will enhance local level biodiversity protection through better communication, sharing ideas and feedback (Witzel, 2012). The systems concept is a presentation of how the different units/structures in different hierarchies within an organization interact and manipulate when it is convenient or adapt the organization to the external environmental demands (Almaney, 1974).

Organizations are best managed when they are viewed as a form of information network with the flow of information providing decision makers at varying management levels with information needed to make decisions of all types (Mockler, 1968). Decisions are made in a dynamic and interactive environment. Organizational control, decision making and planning for specified objectives is best done by combining different authorities with a diverse set of specializations in different organizational units using 
systems theory. The systems approach facilitates for more comprehensive information, faster, at the point and in the form it is needed to make better decisions (Mockler, 1968).

\subsection{Institutional development}

Numerous international, national and local institutions working across boundaries at various jurisdictions to find solutions for biodiversity degradation across geographical and political boundaries have been created (Reischl, 2012). Reischl (2012) introduces the idea of "planetary boundaries" so as to show the shortcoming of international institutions when working at national or local levels as these are likely to affect and be affected by decisions taken at different levels and by different institutions. There is not enough understanding of various global governance systems in light of interacting planetary boundaries (Reisch, 2012). There is great concern that the capacity of international institutions alone cannot be able to project multilevel interacting earth process (Reischl, 2012). This therefore renders support to the importance of local organizations and cooperation with local institutions. What then has to be done is to establish linkages between institutions with a clear consensus on how to manage the relationship (Devall, 2006; Smith, et al. 2009; Resischl, 2012).

Governments often voluntarily create institutions as they see needs. There are also times when institutions emerge spontaneously not because they are designed but as a response to human actions (Brousseau, 2011). The current structure by most governments gives conservation responsibility to government institutions and not the people at local levels to make decisions on the fate of natural habitats (Wilshusen et al. 2002). While some literature compellingly supports the top-down approach to biodiversity protection 
(Rabinowitz, 1999), there is a general trend by more scholars to write in support of bottom-up approach.

There is an increased tendency now to dialogue with management avenues found in public sector institutions, communities, private sector and other international organizations to find creative approaches and initiatives that go beyond the scientific management in conservation (Wilshusen et al., 2002). There are more other factors such as social, economic, political, institutional and technological that determines the success of biodiversity conservation policies regardless of how sound a policy could be scientifically (Carlson, 2013).

The management side takes two avenues. The top-down restrictions that stop communities from the use of biological resources are often viewed as imposing economic hardships. Other scholars argue that although biological resources are local, non-local interests also have a stake in local resources. Wilshusen et al., (2002) argues that local interests should not supersede national and global interests. Conflicts then start to emerge and estimation of opportunity costs to determine winners and losers when conservation goals are implemented.

\subsection{What are scientists telling us?}

Before going deep into the literature, it is important to find out what scientists are saying to all other stakeholders in biodiversity management. The full story itself is very long with too many details, but this study has instead chosen to highlight a very long journey in very few words. Human beings have been causing extinctions of other species for over 50,000 years (Zedan, 2004; Devall, 2006). In the past 500 years alone, the rate of 
human caused extinctions has increased exponentially (Devall, 2006). From the end of the $20^{\text {th }}$ century to date, many more types of accelerated activities are creating huge cumulative effects that scientists call the "crisis of extinction" (Zedan, 2004; Devall, 2006).

Many scientists are now making projections that between 30 to 50 percent of the biodiversity could be extinct by the year 2050 (Ibid, 2004). According to the World Conservation Union (WCU), as of 2003, there were 12,259 plants and animals threatened with extinction due to human activities. The rate of species extinction is 1,000 to 10,000 times higher than it would be under natural conditions (Devall, 2006; WCU, 2003). According to Kremen et al. (2000), more than 13 million hectares of forests are destroyed annually. Deforestation of tropical forests alone leads to loss of most species extinction.

\subsubsection{Biodiversity protection is not a quick-fix problem}

Some studies (Guzman, 2002; Esty \& Ivanova, 2002) have examined the influence of environmental treaties in countries at a national level. At a national level, what really happens there is policy development, which in most cases does not reflect implementation at local levels. There can be a policy on paper that does not exist at implementation levels. At a national level, governments have been known to play what is known as symbolic politics (Davidson \& Frickel, Edelman, 1964) where rhetorical policies are advanced to imply commitment and reinforce public's convictions that real implementation of policy to protect biodiversity is being competently addressed, when in actuality this is not true. 
At the global setting, just ratifying a treaty is seen as one aspect of complying. Locally, compliance must mean much more than just ratification of a treaty and should go beyond policy making. Although the Convention on Biodiversity merely urges member states rather than requiring them to fulfill its goals, national initiatives should commit countries to more stringent obligations for higher compliance if biodiversity protection targets have to be met in the future. Wilshusen et al. (2002) argues that biodiversity protection should stop trying to be everything to all people and focus on strict enforcement of conservation laws.

One key objective of this research was to examine how national policies and institutions evolve and adapt under international environmental treaties. Policy and institutional evolution process is still under theorized and under analyzed (Brousseau, 2011). Biodiversity protection is not a quick fix problem to be done with so that other forms of development can proceed (Chan et al., 2006). The arguments made by private sector institutions that environmentalism hurts economies and will cost economic growth works against government intervention and weakens regulation meant to protect the environment. The sticking point between full implementation of international environmental treaties by all countries has been about the tradeoffs between more development and environmental conservation.

\subsection{Public Administration and biodiversity conservation}

Biodiversity protection is sometimes regarded as a political motive skillfully constructed with the aim of crystallizing problems in order to influence public policy (Devall, 2006). It is the conflicting interests between development and conservation that 
infuse the scientific discourse into politics in government (Devall, 2006; Crist, 2003). Concerns over biodiversity protection need to go further beyond scientific boundaries, to include policy, sociological, economic and cultural issues in society. International treaties are not adequately structured to deal with national policies.

Treaties not only lack enforcement ability, their language is mostly rhetorical in nature and full of discretionary statements such as "where feasible" or if the "State decides" (Devall, 2006). Biodiversity protection requires strong and enforceable regulations that can only come from a national government. Provisions of international treaties, therefore, have to be translated into national and local legislation for treaty objectives to be realized. While policy making is the responsibility of elected officials, policy implementation in conservation needs to go beyond public administrators and bureaucracies to include communities and local organizations.

There is limited policy literature that explicitly explains the political role in conservation policy. This limitation arises out of the distance between natural sciencetrained conservationists on one side one side and the other side, the politicsadministration dichotomy within government bureaucracies, and private sector influence (Adams \& Hutton, 2007; Fesler \& Kettl, 1996). This difference is more pronounced in the context of capacity for natural resources conservationists to engage with the politics of conservation at both government and private sector institutional levels (Adams \& Hutton, 2007).

The status of conservation outcomes depends more on political processes, while implementation of various conservation policies are inherently political (Adams \& 
Hutton, 2007). Biodiversity protection problems have continued to persist globally because of lack of strong public administration. By placing the political processes of biodiversity conservation in the context of a strong public administration arm of government, policy implementation and national compliance with biodiversity protection goals will be transformed. According to the Organization for Economic Cooperation and Development (OECD, 1994), government intervention failure was described as an underlying source depletion pressures of biological diversity and the sustainable use of its components. Intervention failures result from weak institutions that implement and enforce conservation policies.

\subsection{Compliance with international treaties}

Biodiversity protection and natural resources management in general do not have developed systems of measurement, monitoring and reporting (TEEB, 2009). For effective implementation and compliance, an understanding of quantitative measurement of biodiversity and ecosystem values is needed to alert policy makers to possible tipping points (TEEB, 2009). Countries are required to report their compliance but it is not possible to develop specific guidelines for every country as to the scope and methodology of the reports ( Esty \& Ivanova, 2002). Most countries do not have the capacity in human resources, information technology, and institutional structures to meet their reporting obligations. Furthermore, the Convention on Biodiversity does not contain strong enforcement provisions. Therefore, the only incentive for compliance is if there is pressure from the public, moral requirements or local legislations. There are again difficulties in an environment where there is insufficient performance data such that 
"name and shame" strategy fails when wanting to point out serious policy violators (Esty \&Ivanova, 2002).

Jacobson and Weiss (1998) argue that very little is known about national compliance with and implementation of international treaties. Compliance means observance of regulations and adherence to commitments contained in the treaty. Weak or unenforced legislations produce weak compliance, meaning that the mere existence of legislation does not mean that there is compliance. At the same time, there can be compliance even when there is weak and ineffective implementation. At the global level, the mere submission of reports by governments is a measure of compliance. Slow movement toward meeting all the goals of the CBD provides reasons to believe that compliance with and implementation of international environmental treaties is both imperfect and inadequate.

Studies conducted on compliance so far (Mitchell, 1994) examines factors that affect compliance, (Jacobson \&Weiss, 1998), looks at factors that lead to improved implementation of and compliance with environmental treaties such as political, economic and cultural variables, (Rinquist \& Kastodinova, 2005) have analyzed effectiveness of environmental treaties and outlined the challenges of measuring effectiveness. Biodiversity management problems have been persistent over the years, they span jurisdictions and generations. The inter-jurisdictional and intergenerational span of these problems calls for governance mechanisms that can alter incentives in favor of environmentally sound choices. These choices can provide for adequate information and establish concrete mechanisms for policy implementation (Esty \& Ivanova, 2002). 


\subsection{Global policy environment}

The global policy formulation and implementation should be guided by first establishing the optimal level of global consumption that can be defined as contributing to sustainable use of biological resources. Short of this, there is no reference point. What is being done at the moment is the historical conservation discourse, which I believ if well understood is a good basis for conservation policies development.

According to Mangel et al., (1996), the first batches of global policies for the protection of biodiversity were developed in 1978. These did not include explicit set of mechanisms for implementation and were therefore not widely adopted. In the year1994, reviews to examine why the 1978 policies failed were initiated and designed to incorporate effective guiding principles and mechanisms for implementation. Policy adoption and implementation still remained the key challenge. In 1992, an institution in the name of the Convention on Biodiversity (CBD) was created to coordinate global governments to start to reverse biodiversity degradation through implementation of specific initiatives to meet specific global goals.

Since then, there has been an increasing number of global, regional and national policy initiatives aimed at biodiversity protection and management (Rands et al. 2010). All parties to the CBD met in 2002 and agreed to develop a framework to facilitate implementation of the CBD goals, so as to start reversing biodiversity degradation by the year 2010. The approach agreed to was to develop national plans. About $90 \%$ of the countries that have signed membership with the CBD now have fully developed National Biodiversity Strategy Action Plans (NBSAPs). The question to ask now is whether these 
plans can actually propel national governments towards better implementation and higher compliance.

The NBSAPs have elicited support to biodiversity protection activities from local, national and regional civil society organizations that add to the work of international organizations (Rands et al. 2010). Despite this growing support, biodiversity has continued to decline (CBD, 2010). This has prompted the international community to shift conservation approaches toward a more targeted framework of national parks and protected area networks (CBD 2006) and Public-Private Partnerships. Over the last 20 years, protected area networks have grown steadily at an average of $2.5 \%$ and was found to be covering 24 million $\mathrm{Km}^{2}$ with 133,000 designated sites as of 2006 (Rands et al. 2010).

The CBD initiatives were widely adopted by governments but were not effective as all countries missed the target of starting to reverse biodiversity degradation by the year 2010. The CBD does not have enforcement mechanisms to sanction countries and therefore implementation has been problematic (Adenle, 2010). The capacity of most countries does not come near the threshold of global implementation requirements. For instance, many countries lack scientific infrastructure in the form of high quality universities, research labs, technical institutions and network infrastructure. There exist weak information technology linkages between governments, international organizations and private partnerships. Biodiversity protection targets were re-set again in 2011 to the year 2020 (CBD, 2010). 
However, the challenge to biodiversity protection is still to find ways that policies can be widely adopted and effectively implemented at all levels in society. Habitats that host biological resources have continued to lose out to the rising human population and the needs of economic development (Wilshusen et al. 2002; Rands et al. 2010). Biodiversity continues to be depleted at an increasing rate (CBD, 2006). Toward the end of the 1990s, habitat reserved for biodiversity stood at 5 percent and for humans at 95 percent (Terborg, 1999). Terborg (1999) calls for radical changes in conservation governance policies in all countries to avert total destruction of biological resources. Consumption of biological resources has persistently superseded supply (Global Footprint Network, 2010).

Advancement in democratic international institutional instruments and use of information technology (IT) has created awareness and global cooperation in biodiversity management. Governments that are parties to the CBD have taken up the big role of implementing the goals of these treaties to protect biodiversity within their borders. The convention on biological diversity (CBD) also known as the Biodiversity Convention is an international, legally binding treaty, such that countries that join it are required to implement its provisions.

\subsubsection{Global strategic plan for biodiversity}

According to the new Strategic Plan (SP) $2011-2020$, the 2010 biodiversity targets were both a learning process as well as an inspiration at many levels, but it appears the resulting actions have not risen to the scale sufficient enough to reduce the rate of biodiversity degradation. Even with many lessons learned and more awareness 
among all parties to the $\mathrm{CBD}$, there is no adequate integration of biodiversity protection initiatives, policies and programs across all sectors and levels of the economy (SP, 2011). Key impediments to implementation at the country level include lack of financial resources, low human capacity, lack of technological capital, and insufficient data and information necessary for policy formulation and decision making (SP, 2011). To adequately address the underlying causes of biodiversity loss and direct pressures that lead to its depletion, there is need for actions across all levels from global to local levels and across all sectors (SP, 2011). Engagement with local level consumption and production sectors is critical, so as to identify trade-offs between basic societal needs and conservation, and build appropriate incentives and institutions (SP, 2011).

Although the 2011-2020 strategic plan is clear on what needs to be done to avoid the mistakes made when trying to meet the 2010 biodiversity protection targets, countries would have to come up with more specific and concrete initiatives at national levels. There is a desire by the international community to support national governments with capacity building and financial resources for local policies. However, countries would have to build mechanisms on how to respond to lack of financial resources, how to enhance human capacities and how to build sufficient data and information for decisionmaking that is scientifically sound, socially feasible and politically acceptable.

\subsubsection{National policy environment}

Governments play significant roles in the development of both national and local institutions. Institutions in this context refer to the rules or laws that govern relationships between individuals, groups, organizational norms and practices in society. Biodiversity 
protection as is constructed is a political, economic, social and organizational process. Biodiversity protection is embedded in all these processes. All groups, organizations and institutions involved in biodiversity protection engage with each process differently, thus making it difficult for collective action (Brechin et al., 2002). Only the government can sanction all these processes to produce political justification and social justification, so that organizational process can set in motion the collective protection efforts.

\subsubsection{Global-Local policy interface}

Although the international community has done a great deal of work identifying important conservation areas and fashioning the research agenda, more successful outcomes and larger big impact can only come from local institutions (Smith et al. 2009). Successful conservation strategies are those that are developed with clear relationships between local communities, national government, international organizations and the scientific community (Devall, 2006).

The challenge is that many local institutions are greatly underfunded and government institutions in most biodiversity rich locations are ineffective (Smith et al. 2009). Most international organizations answer to their members and donors and therefore their priorities do not usually match those of local agencies (Smith et al. 2009). When local institutions are weak, various problems begin to manifest: (1) projects that do not gain local long-term support, (2) conservation approaches that are developed do not match local needs and (3) research on local issues are overlooked. Local institutions, agencies and other local groups should set the agenda for research, data collection and 
decide on implementation while international organizations are only left with supportive roles (Smith, et al. 2009).

Conservation plans are more legitimate and politically acceptable when local institutions and groups participate in making them. These plans can be better coordinated locally with other sectors such as land-use planning, agriculture, water and climate change (Smith et al. 2009). In many countries, especially developing countries, national plans are made by international experts and national bureaucrats with very little input from communities.

Local agencies in many developing countries lack the means and influence to implement change (Smith et al. 2009). Many conservation programs in biodiversity-rich developing countries are driven by international organizations, an approach that causes local resentment and makes conservation seem a marginal issue (Smith et al. 2009). This can be overcome through the development of social-learning institutions which bring together local and international conservationists and researchers. Government staff are poorly trained, funded and motivated. Working with staff from international organizations gives them access to new skills and contacts, enabling them to develop their own conservation agendas (Smith et al. 2009).

To assist local organizations with skills and capacity to meet conservation challenges and make the right decisions, foreign donors have to ensure good collaboration directly with them especially in understanding their specific requirements. Donors should also fund local groups directly to enable them to finance the establishment of social-learning institutions and their research priorities as well as train agency staff and 
local experts. Weak institutions will not develop because currently, donor money tends to flow through international NGOs, in so many countries (Smith et al. 2009).

\subsection{Policy making and policy implementation}

Just like many other public policies, biodiversity protection policies by governments can best be created and implemented when there are separate institutions that make policy while others implement the policy. National governments pass legislation but implementation is done at local levels and enforced by local bureaucracies (Vogel \& Kessler, 2002; Gussman, 2004). It is movement through these different levels of policy making and policy implementation that gaps in standards established by the legislation and required implementation arise thus creating opportunities for noncompliance (Gjertsen \& Barrett, 2003). Public policies have to be designed to make implementation effective by facilitating adequate institutional structures, regulations and incentives (TEEB, 2009).

There are several sources of mismatch between national legislation, implementation and compliance. The mismatch in most countries between legislation and implementation result from the low level of government's administrative capacities. Countries join and ratify treaties before they build sufficient capacities to take on added responsibilities which lead to administrative overload (Vogel \& Kesler, 2002; Perkins \& Neumayer, 2007). In other cases, this comes about because those tasked with implementation at local levels do not contribute in any way to making legislation (Perkins \& Neumayer, 2007). Structures enabling participation by all stakeholders is key to successful implementation. Although voluntary, treaties impose directives on 
governments that call for further directives by the same governments on local level institutions and communities. These different levels do not share the same level of resource capacities, administrative capacities, institutional capacities, technical knowledge and values (Porter \& Brown, 1990).

Environmental institutions in most countries are relatively new at the national government level. In most local levels, these institutions are just being introduced and most countries are working at replacing traditional practices with the best management practices (Jacobson \& Weiss, 1998). These processes take time to be understood (Jacobson \& Weiss, 1998). Administrative capacities are critical to successful implementation and national compliance with environmental treaties. Although not true all the time, national capacities, implementation and compliance are also associated with the level of national income of a country (Porter \& Brown, 1991; Vogel \& Kesler, 2002; Jacobson \& Weiss, 1998). High levels of compliance should be accompanied with advanced national environmental regulations.

Policy making and implementation within countries is influenced by various types of groups. In some countries such as India and the Democratic Republic of Congo, guerrilla insurgents keep their bases in tropical forests and wildlife parks and keep good relationships with poachers. Some of these countries are not able to comply because of unstable political environments (Vogel \& Kesler, 2002; DR Congo Progress report, 2004). In other countries, policy making is influenced by elites in government, corporate executives and industry leaders ( Feinerman \& Fujikura, 2008). This locks out those tasked with implementation from participating, thus making enforcement problematic. 
International environmental treaties do not contain criminal enforcement provisions (Vogel \& Kesler, 2002). The only reason that implementation is done is because: (1) of the moral standpoint, (2) it benefits local communities or the industry being regulated and (3) when there exists strong legislative and enforcement authorities.

\subsubsection{National Biodiversity Strategy Action Plans (NBSAPs)}

Although the goals of the CBD are very specific, different countries' national strategic planned goals and objectives vary because of different circumstances in those countries. What should not vary are the consistence and details, timelines and funding sources, including the measure and how well a plan is being implemented. In addition, most plan preparation activities should not overly orient to the production of a plan as a product that becomes a formalized series of words on paper (Tang et al., 2009). According to Chapin and Kaiser (1979), there are three definitions of a good national plan.

National plans should contain specific goals linked to local conditions rather than vague umbrella goals such as protection of biodiversity, economic development or greater governmental responsiveness that are non-substantive. These goals must represent the general aspirations, problem alleviations, and needs that are premised on shared national values of each country.

A plan should have fact-based specifics on the existing local conditions with identified needs related to the community's physical development. High quality plans are produced by fact finding, frequent community-wide exchanges of information and proposal for action. Such plans are more effective in facilitating government 
responsiveness because guidelines are predicated on a fact basis tailored to local conditions and expected patterns of public behavior. Policies or actions within a plan serve as a general guide to decisions about the location, density, type and timing of public and private development to ensure that plan goals are achieved. Good plans contain policies that are specific and stated in action-oriented language, using words like will or must, rather than might or should. Good plans contain data and analysis that is essential for building the foundation for meeting objectives and developing policies.

A plan is a product from a planning process that forms a foundation for future actions and therefore must continuously undergo revisions and updates. This is necessary because plans have to be made to constantly adapt over time to needs of the society and the changing physical environment (Brody, 2003).

\subsubsection{Local policy environment}

Local policy environment at both community and business levels features significant shortcomings as a result of either the perceived costs associated biodiversity protection, low institutional capacities or lack of sufficient knowledge (TEEB, 2009; Brechin et al. 2002). Current local policy approaches to biodiversity protection emphasize three frameworks of protecting biological resources: sustainable use, protected area networks and mainstreaming $(\mathrm{CBD}, 2010)$. There is a shift from strict protection toward broader participation. This, however, cannot succeed without building structures that can connect people, institutions and organizations across different levels and sectors. Such participation is important for developing epistemic communities necessary for 
mobilization of political constituencies from various civil and private sector organizations to build resilient conservation institutions (Rands et al., 2010).

At local levels, one can experience the argument often discussed in the literature is that infinite growth does not exist in a finite environment. Demand for natural resources that far exceeds the capacity of natural environment will eventually overwhelm the natural resources base (Mangel at al., 1996). Compliance with all goals of the CBD cannot be realized unless resource use is guided by policies that would maintain levels that provide for future generations that policies also should minimize changes in the structure and dynamics of ecosystems to the extent that any damage can be reversed within one human generation (Mangel et al., 1996). These are very complex statements especially when there is a lot of literature that highlights the difficulties communities at local levels experience in the context of pollution, deforestation, poverty, landlessness, insecure land tenure and political oppression (Myer 1998; Myers et al. 2000).

Opportunity costs of biodiversity protection at local levels have direct impacts on communities. The levels of opportunity costs of foregoing consumption at present for the sake of future generations as well as opportunity costs of sustainable use, determines how compliance will be attained. Policies that link biodiversity protection to economic benefits, such as REDD+, have great potential to provide revenue benefits to communities to protect forest resources (Rands et al. 2010). Biodiversity degradation is not the intended consequence of human actions but rather it is an unintended consequence of actions taken for other reasons. Biodiversity protection can therefore be 
seen as an economic externality of outcomes of doing what is perceived as normal business by the society (Rands et al. 2010; Dasgupta, 1979).

Communities and businesses have no incentives to change their consumption, lifestyle, and way of doing business if opportunity costs of change are too high (Atisa et al. 2012). This calls for biodiversity protection to be managed as a public good provided collectively through conscious choices (Rands et al. 2010). Valuation techniques that quantify economic values of biodiversity are not well developed to provide close to exact measures of biological resources (TEEB, 2009). Economic value of biodiversity has to be built into the social, economic, legal and political decision making institutions across sectors and at all levels in a country to facilitate acceptable policy changes (Rands et al 2010).

Local institutions and community based organizations at local levels provide a platform for building partnerships with international organizations, government institutions and private sector businesses to promote effective policies for biodiversity protection (Colyvan, 2010). Rands et al. (2010) argues that policy responses to biodiversity degradation fail because they do not establish appropriate institutions, governance and behaviors. Partnerships provide a learning environment where experiences and resources are shared to build a sound knowledge base where policies generated are more acceptable to all. The challenge to local level biodiversity protection is that key and the much needed institutions are either non-existent, lack sufficient capacity or are just being created and are at learning stages (Atisa et al. 2012). 


\subsection{Global-National-Local model}

The global-national-local model is a framework that has been developed by this study to examine conservation policies meant to resolve conflicting use of biodiversity at national and local levels. These conflicts emerge when policies created to further global interests are in conflict with national interests. National conflicts also emerge when policies created by national governments through the influence of global policies conflict with local interests. It is important to resolve conflicting interests that arise at different levels so that there is no perceived inherent policy superiority in the way resources are either used or conserved. There is a need for a clear separation of basic interests and nonbasic interest. The process of global policy making should be designed in ways that allow national and local interests the same worth for basic and non-basic interests (Sagoff \& Taylor, 1988). The challenge is how to ensure that interests at all levels are taken into account as much as it is clear that not all stakeholders from local levels can participate in policy making at global and national levels.

The use of biodiversity falls into either basic need or non-basic category. Conservation policies should not be seen as denying communities an opportunity to either develop or meet their basic needs. Basic human resource interests are those which are morally legitimate to be fulfilled, such as land to grow food (Sagoff \& Taylor, 1988). Violating people's moral and legitimate rights to basic needs deprives them of their ability to live at the best minimum living standards. When conflicts of this nature occur, there must be appropriate compensation mechanisms for the forgone resources. It remains challenging to conservationists to separate basic needs and non-basic needs so as to 
develop appropriate compensation mechanisms. There are resources that are non-basic to the industry but basic to rural communities. Some are basic to plants and wildlife but non-basic to human beings, while their use is not based on whether they are basic to specific categories.

Ability to identify and develop policies that separate basic and non-basic biodiversity needs by different categories of consumers and users is difficult. It is full of uncertainties, pervaded by information asymmetry problems, imbalance of power, and legitimacy conflicts among irreconcilable representations and incompatible interests (Boisvert \& Vivien, 2005). Most studies examining conflicts in the consumption and use of biodiversity have unanimously advocated for compromises and sustainable use. This study brings into the equation two factors, appropriate compensation mechanisms and capacity building. It is not so much about efficiency and equity but how much communities can afford to forego for the sake of conservation. How much can businesses afford to cut and still remain profitable?

\subsection{Sustainable use and equitable sharing of biodiversity benefits}

Sustainable use and equitable sharing are the other two goals of the CBD. The "Sustainable development" model was born out of the Brudtland Commission created by the United Nations in 1983 to address concerns that the rate of resources depletion and environmental degradation by current generation was disabling the ability of future generations to meet their needs. This commission defined sustainable development as the use of resources now without compromising the ability of future generations to meet their 
own (UN, 1987). The big challenge to global economies is how to balance economic development and natural resources consumption (Carlson, 2013).

Carlson (2013) argues that sustainable development is a risk minimization and risk management initiative that supports economic development within environmental resources constraints and scientific uncertainty. As the global society has continued to adapt to sustainable development, progressive degeneration of biological resources and loss of species has continued at an accelerated rate (Wilshusen et al. 2002; Carlson, 2013). Many of the current approaches to biodiversity protection do not provide adequate measures that can protect biological resources up to the rate of current consumption (Brechin et al. 2002). Social stability in many countries depends on high rates of biodiversity consumption that supports economic growth (Carlson, 2013). Policies that curtail the free use of biodiversity have raised concerns among businesses who argue that such policies hobbles economic development.

The greatest threats to biodiversity come from the desire by humans to pursue economic development and to provide for basic needs. Although sustainable development approaches to sustainable living and natural resource use has been successful at changing the way various sectors use natural resources, it does not provide concrete and verifiable targets on many fronts. Sustainable development fails to show a concrete relationship between total available resources and total consumption so as to see whether the two are converging or diverging. Going the sustainable development route in biodiversity conservation will miss big opportunities as this does not advocate for a cap on the pursuit of economic growth (Carlson, 2013). Sustainable use of biological resources does not 
provide any targets that have to be attained for a specific level of biological resources in relation to demand or level of consumption (Carlson, 2013).

Studies of various sustainable development literature in relation to biodiversity protection does not show how implementation of sustainability approaches affect national and local biodiversity protection policies (Rosales, 2005). The basic definition of sustainable use is to continue to use biological resources so that there are some left for future generations. This statement does not provide both the economic demand and biological resources threshold that can meet both today's and future generation's needs. There is tremendous literature on the adoption of various sustainable development mechanisms (Porter and Brown, 1991; Rosales, 2005), such as green technology in various sectors, but not much is known about the final outcomes on actual positive impacts on biodiversity. Rosales (2005) argues that initiatives that have been developed to address the root cause of environmental decline cannot be successful unless there is a cap on economic growth based on ecological thresholds.

The way to ensure sustainable use of biodiversity is to restrict economic activities at a level that is ecologically sustainable (Rosales, 2005). The problem is that there is no identified threshold level of economic development that provides for sustainable use. It is this cap that will provide guidelines to local, national and global policies (Rosales, 2005). The biggest challenge of capping growth at local levels is that biological resources consumption by some of the rural communities can be classified as basic needs. Opportunity costs of foregone use of biological resources might mean life or death for some people. This kind of situation requires a mixed bag of policies that protects 
communities from an unfair deprivation of resource use while at the same time protection biodiversity from overexploitation.

Rapidly rising population growth leading to higher per capita consumption causes overexploitation of biological resources. No matter how sustainably resources are used, depletion will continue ( Rosales, 2005; Wilshusen et al. 2002). However, successful conservation depends upon rewarding communities at local settings for the opportunity costs of conservation (Atisa et al. 2013; Rosales, 2005), otherwise future generations will pay.

\subsection{Opportunity cost considerations}

Implementation and compliance with international environmental treaties concerns more than just global consensus building toward agreed conservation objectives. Opportunity costs of economic development, geopolitics of global consumption of biological resources and wealth distribution are central to any success with implementation of conservation goals and the level of compliance realized (Drumbl, 2002). Interdependence of economic development and environmental regulations pits the more developed North against the less developed Southern countries that requires compromises to be made, both in terms sharing financial resources to go towards reducing opportunity costs of conservation by the South and technological transfer to ameliorate conservation challenges from the North (Drumbl, 2002).

Jacobson and Weiss (1998) use costs and benefits calculation to argue that the smaller the costs and the greater the benefits, the greater the probability of implementation and compliance. The nature of these costs needs to be clearly identified; 
they do not do that. They make another assumption that countries with large gross national product and higher per capita Gross National Product (GNP), have greater probability of implementation and compliance. In some cases, this is usually the opposite.

Drumbl (2002) asserts that more developed nations of the North show more demonstration toward proposing international treaties than the developing nations. The reason for this observation is that developing countries priorities are more to carter for basic needs such as safe provision for safe drinking water, healthcare, education and food (Drumbl, 2002). In addition, implementation and observation of international treaties come with associated costs. Some of these costs go toward supporting legislation, institutions and enforcement of laws required to give force to an international treaty including investments in technology and manpower development (Strategic plan, 2011; Drumbl, 2002).

The desire by both developed and developing countries to continue to grow their economies as a priority creates fears of economic decline if nations were to strictly implement the requirements of international environmental treaties. Economic deceleration is a big opportunity cost (Drumbl, 2002).

\subsubsection{Global opportunity costs}

Global consumption of natural resources and waste generation has reached a tipping-point (Drumbl. 2002). It has become abundantly clear that the planet can longer be able to supply resources that meet the demand placed on it as well as absorb the amount of waste generated (Global Footprint Work, 2006). There are conflicting global views on who should do more to ameliorate the impeding biodiversity crisis. Global 
opportunity costs of biodiversity protection is what it costs the world now to reverse the degradation of biological resources and what it would cost the future generations to acquire the same resources to meet their own needs. The main point is that the future generations should not be made to pay for unnecessary overexploitation of natural resources by this generation.

Under the North-South global relations, developing countries have entered into a negotiation strategy where the more developed Northern nations are to pay for implementation and compliance costs incurred by the developing nations (Drumbl, 2002). Financial commitments to developing nations have evolved into solid obligations upon which developing countries who are combating global environmental threads is predicated (Drumbl, 2002).

\subsubsection{National opportunity costs}

International treaties lack enforcement authority over nations and therefore nations have to design and implement conservation objectives which entail various costs (Adams et al. 2010). Some of these costs may come in the form of welfare loss. Nations need to develop mechanisms for assessing benefits and costs of biodiversity protection (Sinden, 2004). Treaties, therefore, have to be seen to provide more benefits to all participating nations for successful adoption and implementation of treaty goals. In addition, credible, transparent and simple punishment options need to be institutionalized within the treaty to ensure compliance and avoid "loophole-effects". The costs associated with filling in the gaps in welfare loss or gain is the national opportunity cost. 
National plans for biodiversity protection should adequately take into full account the economic costs of conservation that arise in the form of acquisition, management, damage, transaction and benefits (Adams et al. 2010; Naidoo et al. 2006). One example to show this is the establishment of a protected area networks. The government has to acquire land, and this land comes with long-term management costs (Adams et al. 2010). National opportunity costs come in two ways, organizational and social costs. National plans should be drawn so that they can ensure that conservation goals move to implementation on the ground but first they need to consider both organizational and social costs (Adams et al. 2010; Knight et al. 2006; Pierce at al. 2005).

\subsubsection{Local level opportunity costs}

At local levels, opportunity costs arise because sacrifices have to be made in terms of not using some resources. Communities may forego the use of land for farming and have it reserved for forestry purposes, or businesses may not use certain resources if these are considered threatened by overexploitation. National governments for example have enacted legislation to protect habitats, forests, water resources and wildlife. These legislations protect biodiversity by preventing communities from clearing forests on their land. Consequently, this reduces farm incomes.

"The opportunity cost of protecting biodiversity on farmland is the income foregone in the alternative agricultural use of land, and is the major cost of protection" (Sinden, 2004). 
Biodiversity protection legislation removes the community's right to develop their own lands as they wish. This does impose a cost on the community. Opportunity costs of land use changes and natural resources conservation in many places has not been given attention to match their economic importance in decision making (Panyotou, 1994). The use of economic incentives for conservation has therefore continued to be compromised as opportunity costs are not fully considered in the valuation of biological resources (Griffiths \& Southey, 1995). Opportunity costs are a major influence on the net benefits that local communities obtain from natural resources (Atisa et al. 2013). Increasing dependence on land due to limited employment opportunities and high rate of population growth exacerbates opportunity costs. Although global negotiations provide for more developed nations to finance conservation of biodiversity by less developed countries, there are no clear compensation mechanisms for local level opportunity costs.

\subsection{Information technology and information sharing tools}

Jacobson and Weiss (2010) argue that more information about conservation problems leads to more understanding, and more effective implementation and compliance. Biodiversity protection is the responsibility of governments first. It is at this level where programs are created by law with clearly identified purpose, means and conditions under which they will be implemented (Rose, 1991). The CBD encourages national governments to establish and strengthen National Clearing House Mechanisms (NCHM) websites which is hoped will contribute to cooperation and development of regional, sub-regional information and knowledge sharing. Very few governments have 
built an equivalent of GBIF at national level. How governments are making effective use of National Biodiversity Information Facility (NBIF) or a similar agency has been analyzed in this study.

Information Technology is being used as a tool for coordination of activities within and between organizations, governments and a host of other institutions (Dedrick et al., 2008). Use of IT at global level allows information and data sharing, coordination, discussions and transfer of ideas between regions/countries with high capacities and those with low capacities. The most developed and widely available information found in the internet is that provided by international organizations and more developed government's institutions with high capacities. Most of these data is only at the country level which makes it less usable by resource managers and planners who require more human and ecological relationships at specific local regions (Guralnick et al., 2007). This study introduces and explores aspects of human-institutional-biological resource relationships in the context of information sharing. It does place local communities at the center of biodiversity protection and planning.

The Internet and the World Wide Web (www) are the most significant, cheap and fastest communication tools so far developed and being used to share information and data. Within the United Nations system, the CBD has a well-developed CHMs which provides global information services to facilitate implementation of biodiversity protection plans. The CBD website (www.cbd.int) acts as the central node. The CHM is a place for national governments and partners to openly exchange biodiversity information, promote and facilitate technical scientific cooperation. Also, it is for use by 
governments with limited IT infrastructure to find data and information needed for sound decision making.

Use of IT improves communication across sectors and between countries, and facilitates global, national and local coordination. Governments with information, policy and data rich websites will enhance local level biodiversity protection through better communication, sharing ideas and feedback (Witzel, 2012). Regions facing common conservation challenges can learn from each other how to deal with problems when policies and conservation programs are posted online. Effectiveness of programs developed for a specific region or place can be measured by comparison with others being implemented elsewhere (Rose, 1991) when these are easily accessible in the web. It is also possible to obtain and adopt information from online sources to help facilitate national policy development and local planning.

The use of IT in management is viewed as one way that efficiently meets the demands of public institutions, lowers administrative costs and improves service delivery (Myeong \& Choi, 2010). Public institutions use IT to reduce uncertainty and ambiguity about goals and cause-effect relationships during the time of implementation. Successful application and employment of IT in public settings requires investments in infrastructure, computers and relevant software which must be accompanied with training and capacity building.

Management of biological resources is a complex process of balancing immediate benefits with long-term conservation goals and political priorities. Generating of relevant information and data sharing is crucial to reaching an optimal balance of various 
stakeholder interests (Simon, 1977). Emphasis on long-term conservation goals can be viewed negatively when communities have no alternative to their immediate needs. IT facilitates in the scanning of the conservation environment for information and data needed to understand local and national priorities and to build a consensus on immediate benefits and long-term conservation goals (Esty, 2004).

Environmental policy and decision-making critically depends on available information, data and analysis. Information technology tools such as wireless communications, remote sensing, and internet communication, have vastly increased the capacity to collect, share and utilize data (Esty, 2004). Information technology provides access to opportunities that make biodiversity protection more data driven, empirically verifiable and analytically rigorous.

Biodiversity protection falls into the ranks of open projects (Witzel, 2012) that know no boundaries. This is the reason why it is a global effort by 195 countries and numerous non-governmental organizations working across borders, sharing resources, information and having a common purpose. A globally unified effort for biodiversity like this one requires systems that provide a high degree of transparence, information sharing, and distributed accountability among all participants at all levels (Witzel, 2012). It is for these reasons that Information Technology is of critical importance to the success of biodiversity management and protection.

\subsection{Institutional leadership}

Pallemaerts (2003) argues that social responsibility activities undertaken by different sectors or organizations are geared toward enabling them to choose 
arrangements that serve their own self-interests. The same applies to communities and individuals. Biodiversity protection does not fall into the class of interests that private sector and communities would have as their priority interest. Governments, therefore, face problems trying to find ways to design and implement policies that will generate organizational leadership that is able to solve problems in different spheres of the society (Alkadry \& Nyhan, 2005). At the same time, organizational leadership has limits in its discretionary space. Such requirements can only be met under a leadership that has a great deal of discretion and style that adopts power-with management approach that leads to a win-win situation by consensus and policy expansion (Graham, 1996; Golden, 1998).

Using the structural equation model, Alkadry \& Nyhan (2005) explain bureaucratic experience and its impact on the behavior of public organizational leadership. The best way to understand organizational behavior is to study it as a system (Scott, 1961, Kast \& Rozenweig, 2001). The systems approach has great potential in facilitating in understanding of the complexities as open systems, closed systems, feedback and hierarchy (Kast \& Rozenweig, 2001). Vancouver (1996) examines how living systems are used to model human, organization and communication to signify the importance of the nature of relationships in organizations.

The international community has continued to build institutions and partnerships that remain central at influencing the behavior of individual governments. These institutions include the United Nations Agencies and the International Treaties. They provide structures upon which governments come together to take actions that form important tools for pooling resources to confront global environmental problems (Hanf, 
2000). The difficulties that exist in the implementation of international treaties are mainly because there is no coercive body at the international level equivalent to law enforcement agents within a country (Stretton, 2010). Institutions that are necessary for the effective implementation of an international treaty exist at the national level where it is possible to coerce different actors into adopting relevant environmental policies using either sanctions or incentives.

According to the new public management (NPM), agencies create expertise to increase effectiveness and efficiency of government intervention on issues that are considered most important (Stampfer et al., 2010). Looking at efficiency from the principle-agent model, principles and agents move through processes of policy formulation, institutional development, data collection, information sharing, capacity building and partnerships with all stakeholders.

Domestically, national decisions on biodiversity protection are shaped by national politics of party states guided by domestic economic considerations, administrative capacities and availability of funds (Chan et al., 2006). Implementation of the CBD goals has continued to face great challenges because of incompatibility of basic interests, mandates and interest between the different agencies in government and other sectors (Wilshusen et, al 2002). Fragmented processes and structures of government agencies impede the achievement of goals, such as when there are no formal institutional mechanisms and institutional linkages between land and agricultural planners (Calder, 2005). 


\section{CHAPTER III}

\section{METHODS AND DATA}

\subsection{Data sources and methods}

This chapter is divided into four sections. It starts with a general introduction to compliance and various measures that exist in current studies, sample selection and data sources, and the specific hypotheses guiding the study. This is followed by an explanation of analytical methods, both qualitative and quantitative. The next section is where the conceptual model and factors that most influence compliance with CBD goals are explained. The study then developed an analytical approach to explain ways of reconciling global, national and local interest, and a shared meaning of biodiversity protection among stakeholders. The chapter concludes with a detailed methodology that examines opportunity costs of biodiversity conservation.

Estimation of opportunity costs of biodiversity conservation is important. Consequently, I want to show the status of biological resources and costs of protecting these resources in the context of compliance. Many compliance studies simply give a qualitative measure of compliance with no figures attached. In addition, there are no agreed measures of compliance. It is for this reason that even when some countries are running huge deficits in the status of biological resources, they can get classified as compliant because there is standard criterion for measuring compliance. Estimation of opportunity costs helps to highlight what it would take countries to actually comply. 


\subsection{Introduction}

A number of studies have analyzed compliance with international treaties, but substantive implementation and compliance within countries is not known (Jacobson \& Weiss, 2010). There are numerous measurement variables targeting different compliance measures with international treaties at various levels. Guzman (2014) has analyzed compliance with customary international law. He uses a reputational model of compliance to explain that countries comply with treaties simply because other countries have committed to honor the treaty. Hathaway (2005), along with Jacobson and Weiss (2010), have examined compliance from the perspective of costs and benefits that may arise for a country when it complies with an international treaty. Their research argues that transnational actors and rule of law within a country are important factors that reinforce implementation and compliance.

Perkins and Neumayer (2007) have divided compliance into four models: domestic adjustment, reputational, constructivist, and managerial to analyze why countries comply but they do not really explain how and what it takes countries to comply with international treaties. There are no studies done so far to validate these compliance levels or even try to attach numbers that could give a certain threshold of compliance.

Even when the rules are very clear, there are always significant gaps between the set of rules that are in force and actual implementation (Vogel \& Kessler, 2002). There is clearly a research gap on compliance at the global setting, national and local levels that explain how countries comply and what should go into compliance at these three levels. 
It was with these gaps in mind that I designed this research to analyze compliance by countries with CBD goals and implementation of specific policies, knowing that there are very different global requirements, different national capacities and different local needs. Factors that go into compliance, and how compliance can be developed, can be very complex. While there are clearly defined requirements at the global level, the requirements at both national and local levels are not defined. Countries are merely urged to implement global policies. How countries take these global policies to local levels and ensure that they get implemented is even more difficult to determine. I developed specific criteria in this study to try to construct what countries should do at both national and local levels to comply.

Conservation responsibility starts at the signing and ratification of international environmental treaties, global conferences where negotiations are held, and critical conservation information shared. Once all negotiations are finalized and agreements drawn, individual governments are then encouraged to implement those agreements as they deem possible.

\subsection{Sample selection}

A sample of 16 countries was selected for this study. Various selection criteria were used, namely, geographic distribution, size of administration, biodiversity richness, and strong presence of conservation organizations In order to have a broad geographic representation, I selected four countries from each continent (Table 3). The sample included a sub-set of three countries, namely Canada, India, and Australia, because they were the largest and federally administered countries. The idea was to see how central 
governments work with regional/provincial governments. Another group of three countries was chosen because they have been identified as the richest biodiversity countries in the world. These were Brazil, Democratic Republic of Congo and Indonesia. The study made an assumption that because these are biodiversity rich countries, it might be easy to measure conservation efforts and compliance easily. Another criterion was either the presence of strong conservation organizations or countries that greatly support conservation programs globally. The countries chosen under these criteria were Kenya, Great Britain, Switzerland and the Netherlands.

Kenya is the host country to the United Nations Environmental Programme (UNEP); Switzerland is host to both WWF and IUCN head offices; both the UK and the Netherlands are some of the largest conservation donors globally. A final group of six countries were chosen randomly to represent all other countries who are members of the CBD. These were South Africa, Ghana, Mexico, Jamaica, Jordan and Poland.

Table 2: Sample of countries selected

\begin{tabular}{|l|l|l|l|}
\hline Europe & Africa & N \& S America & Asia \\
\hline Great Britain & Kenya & Canada & Australia \\
\hline Switzerland & Ghana & Jamaica & India \\
\hline Netherlands & DR Congo & Mexico & Indonesia \\
\hline Poland & South Africa & Brazil & Jordan \\
\hline
\end{tabular}

\subsubsection{Data sources}

The study used mainly secondary data obtained from a variety of sources.

- $\quad$ CBD Website - Country Plans, reports and CBD documents

- Clearing House Mechanisms of the CBD and also of individual countries 
- National government, international and local NGO websites

- Google.com - International and local organizations websites

- ASAHI Glass Foundation

- FAOSTAT

- Global Footprint Network

- Existing biodiversity conservation literature

Key data obtained from NBSAPs were about the quality of the plans themselves.

Plans must be developed in ways that are able to effectively support biodiversity protection. They must have a proper language, funding, timelines, specific goals and objectives. Data obtained from national reports included implementation challenges, funding status, capacity building, monitoring and evaluation, and building of national and local institutions. The CHMs provided data regarding availability of national and local data, local reports, and national, regional and local profiles.

Other pieces information came from the websites of conservation organizations working in each country. Information on organizations working in these countries was obtained from the Internet using the search engine via . The following criteria were used in choosing the organizations during the search process. (1) There is a clearly identified collaboration with government and local organizations (2) They have been in the country for at least five years. Local organizations were selected based on the following criteria: (1) They have been operational for at least five years (2) They work in collaboration with international organizations. 


\subsubsection{Biodiversity hotspot regions}

Two to three internationally recognized biodiversity hotspot regions in each country were identified. Biodiversity hotspot regions are defined as bio-geographic regions with a significant reservoir of biodiversity that are under pressure of overexploitation and degradation by humans (WWF, 2006). Biodiversity hotspot regions are areas of great concentration of endemic species. It is around biodiversity hotspot regions where there is the most rapid deforestation, habitat destruction and transformation of landforms. In terms of management, these regions provide a more precise location where conservation outcomes provide the greatest payoff (Myers et al., 2000). The purpose for this was to help focus attention to the most important conservation areas, and mainly to gauge how wisely conservation resources are being invested in each country.

Negative or degradation of the environment has greater impacts on biodiversity hotspots than other areas. These are areas of the greatest focus by conservation organizations and governments. Outcomes from conserving hotspot regions would be more visible than many other places. How countries and conservation organizations respond to conserve hotspot areas would provide a better understanding in terms of whether a country is ready, its capacity, and the strength of the policies developed. It is around biodiversity hotspot regions where it is easy to see the extent of policy formulation and implementation.

There were no hotspots regions identified for the Netherlands and Jordan from their respective government websites, plans or by conservation organizations working in these countries. Poland and Switzerland each have only one biodiversity hotspot. 
Use of biological resources beyond the levels they are able to replenish themselves otherwise known biodiversity degradation, can be more pronounced at biodiversity hotspots more than other areas. These are areas of greatest focus by conservation organizations and governments. Therefore, outcomes from conserving hotspots regions would be more visible than many other places.

Table 3: Biodiversity hotspot regions

\begin{tabular}{|c|c|c|c|}
\hline & \multicolumn{3}{|c|}{ Biodiversity Hotspot regions } \\
\hline Country & 1 & 2 & 3 \\
\hline South Africa & $\begin{array}{l}\text { Cape Floristic Region - } \\
\text { Kogelberg Biosphere Reserve }\end{array}$ & $\begin{array}{l}\text { Maputoland - } \\
\text { Pondoland-Albany }\end{array}$ & Karoo region \\
\hline Kenya & $\begin{array}{l}\text { Arid Horn of Africa region - } \\
\text { NE Kenya }\end{array}$ & $\begin{array}{l}\text { Arabuko-Sokoke Forest } \\
\text { Reserve }\end{array}$ & $\begin{array}{l}\text { Eastern } \\
\text { Afromontane - Mau } \\
\text { Forest }\end{array}$ \\
\hline Ghana & Atewa Range Forest Reserve & Coastal Guinea Forests & ---- \\
\hline DR Congo & Virunga National Park & Kahuzi-Biega N. Park & Garamba N.Park \\
\hline Switzerland & Pfynwald & ---- & ----- \\
\hline Poland & Carpathians & $\begin{array}{ll}----- \\
\end{array}$ & ------- \\
\hline Netherlands & ------- & $\begin{array}{ll}------ \\
--1\end{array}$ & $\begin{array}{ll}------ \\
--1\end{array}$ \\
\hline Canada & Broadback River Watershed & $\begin{array}{l}\text { Saskatchewan River } \\
\text { Delta }\end{array}$ & $\begin{array}{l}\text { Peel River } \\
\text { Watershed }\end{array}$ \\
\hline Jamaica & $\begin{array}{l}\text { Cockpit County-North Coast } \\
\text { Forest }\end{array}$ & $\begin{array}{l}\text { Portland Bight Protected } \\
\text { Area }\end{array}$ & $\begin{array}{l}\text { Surrey County } \\
\text { Corridor }\end{array}$ \\
\hline Brazil & Atlantic Forest region & Chapada dos Veadeiros & Emas N. Park \\
\hline Mexico & $\begin{array}{l}\text { Madrean Pine-Oak } \\
\text { Woodlands (Sierra Madre } \\
\text { Occidental) }\end{array}$ & $\begin{array}{l}\text { the Sierra Madre } \\
\text { Oriental }\end{array}$ & $\begin{array}{l}\text { the Trans-Mexican } \\
\text { Volcanic Belt }\end{array}$ \\
\hline Australia & $\begin{array}{l}\text { Einasleigh and Desert uplands } \\
\text { - Queensland }\end{array}$ & $\begin{array}{l}\text { Mamersley-Pilbara } \\
\text { (Western Australia) }\end{array}$ & $\begin{array}{l}\text { Central and Eastern } \\
\text { Avon Wheatbelt } \\
\text { (Western Australia) }\end{array}$ \\
\hline India & Western Ghats & Eastern Himalayas & $\begin{array}{l}\text { North Eastern India } \\
\text { (Indo-Burma) }\end{array}$ \\
\hline Indonesia & Sundaland & Wallacea & \\
\hline Jordan & ------- & -------- & ------- \\
\hline Great Britain & South Uist & Lundy & Menai Strait \\
\hline
\end{tabular}

Source: government websites, conservation organizations websites and national plans 


\subsection{Game Theory}

Stakeholder strategies that would improve biodiversity protection are those that would make one stakeholder better off without making any other stakeholder worse off. This condition is known as Pareto improving. Compliance outcomes that satisfy this condition exist when each stakeholder has full information concerning all other stakeholder strategies. Stakeholders in biodiversity have been known to be self-interested more and would care about others only when they can benefit.

A situation where all stakeholders' benefits are improved can be achieved either through consensus or cooperation. Consensus often involves the use of a third party to force a decision that often may or may not be the maximum payoff (Colyvan et al. 2011). Cooperation allows stakeholders to deal with each other directly with clearly identified set of available strategies without relying on third parties or other authorities. Managing conservation conflicts without relying on consensus is an important element to attaining maximum outcomes and effective decision-making (Colyvan et al. 2011). Stakeholders/players cooperating with each other want mutually beneficial outcomes, and know each other's strategies that would produce maximum payoffs.

According to Villasant and Sumaila (2010), non-cooperative games are also known as competitive games. In competitive games, stakeholders are entirely motivated by self-interests. Also, in competitive games, there are no established lines of communication. This nature of games, therefore, fall into what in game theory is known as "prisoner's dilemma". This is often the case with biodiversity protection. Although 
information regarding biodiversity conservation is freely accessible online, the selfinterest behavior has greater influence on stakeholders.

\subsubsection{Systems theory}

The systems theory provided a basis upon which to examine individual and collective institutional works and relationships within and across countries. The planning strategies and problems identified by government documents were compared with the works and problems identified by conservation organizations using systems approach. It was possible to place specific works of individual institutions in a wider context of biodiversity conservation. This was necessary to be able to see both the shared understanding and differences in approach to biodiversity conservation at the same time. Analytical outcomes of the works of governments were assessed against the works of international organizations.

\subsection{Research questions and hypotheses}

Advancing public policies through various stages from formulation to implementation in society is always determined by how relevant a problem is perceived by stakeholders (Pressman \& Wildavsky, 1984). While implementation is at specific local settings, biodiversity protection defies fragmentation and demands the collaboration of governments and institutions at all levels and across boundaries. Responding to biodiversity protection problems calls for action from the political, legal and administrative arms governmental, community, scientists and international efforts. 
In trying to address the challenges facing biodiversity protection, the research questions were formulated to address structural, policy and multi-level and multi-sector conservation relationships at the international level, and national governments and local level implementation. These questions were intended to find answers for strategies needed to identify most supportive initiatives and compliance variables to be implemented in various countries. What happens at global and national levels is not in direct conflict with local level consumptive priorities but rather supports local priorities alongside implementation of conservation measures.

The key questions designed to guide this study were the following:

1. What critical factors most influence the implementation of biodiversity protection policies at the global, national and local levels?

2. How can conservation initiatives at different levels and in different countries be reconciled in order to support global compliance with CBD goals?

3. How do opportunity costs of biodiversity protection affect implementation of CBD goals at the local levels?

\subsubsection{Factors that most influence compliance and implementation}

The level of attention and supportive efforts given to biodiversity conservation at the global level, national level and local levels differ in many different ways. Factors that most influence global, national and local level conservation efforts are also very different. I argue that globally designed conservation policies that are sensitive to local level needs have a greater chance of implementation. 
Globally designed conservation programs must be sensitive to both national priorities as well as local needs such, as poverty alleviation, sustainable use of natural resources, and the shielding of communities from incurring higher expenses in the process of adopting biodiversity protection programs. The first guiding hypothesis for this study is:

Hypothesis 1: International and national conservation initiatives fall short of conservation outcomes, and because of inadequate support to local institutions where actual implementation takes place, global compliance with CBD goals is low

To test this hypothesis, qualitative content analysis of NBSAPs and conservation progress reports was done to determine what variables either constrain or aid in the implementation of conservation programs at international and national levels. Data obtained from the ASAHI Glass Foundation (AGF) was analyzed and used to test compliance at local levels. The critical variables that were used to test the above hypothesis included the 20 criteria used for evaluating compliance in table 1 . The other variables came from the AGF data, where the survey identified global conservation barriers to biodiversity protection.

\subsubsection{Cooperative and non-cooperative approaches to conservation}

Many methods that analyze global compliance with international treaties have done so in very general terms. In analyzing compliance, I argue that these treaties must be open to what various actors bring to the negotiation table in terms of strengths, 
weaknesses and interests. Porter \& Brown (1991) argue that countries do influence other countries' actions on the global environmental arena through roles as a lead state, supporting state or swing state.

Hypothesis 2: Cooperation by stakeholders in the use and management of biodiversity protection reconciles different self-interests better and, therefore, leads to higher compliance with CBD goals.

This hypothesis was tested using game theory strategies. The central assumption taken in game theory was that all players/stakeholders are interested in each other and will play to bring out best outcomes in the game. The higher the outcomes for each player the more satisfied both will be.

The advantage of game theory is that each player/stakeholder is often allowed to consider the interests of others. Looking to reconcile multi-stakeholder interests in biodiversity, surveys of several games were conducted, and their possible outcomes and stakeholder conflicts were explained. Under the game-theoretic approach, it is possible to see the different stakeholder objectives and the strategies that they will adopt when consensus, compromise, or cooperation are feasible as well as the best types of cooperation that reflect various interests and meet various objectives (Colyvan et al., 2011).

Stakeholders in the use and management of biodiversity take their positions on the negotiation or implementation table to critically examine and play using strategies they think gives them the highest payoff. Responses from each stakeholder are anticipated even before the negotiations begin, and therefore, the best counter-strategies meant to 
generate optimal decisions can be developed. The way governments are expected to deal with each other is very different from the way other stakeholders such as the communities, businesses, industries and conservation organizations play games with each other. For example, in the case of two countries coming together to protect a specific resource, they may be motivated differently about the details of and why it is in both their interest to protect that specific resource. The following hypothesis was also formulated to test question two at local levels

\subsubsection{Reconciling global, national and local conservation interests}

The trade-offs that exist between human basic needs and biodiversity protection goals, and between biodiversity protection and various economic, political, and social considerations across sectors, are extremely difficult to reconcile (McSahene et al., 2011). Efforts and initiatives aimed at producing outcomes that demonstrate how biological resources can be managed to support the needs of local people while sustaining local, national and global conservation goals have not been developed in the literature. Therefore, the way forward would be to establish negotiations with all other salient social and economic interests for purposes of diffusing potential conflicts (Frank \& Sarkar, 2010). However, the sticking point surrounding over-exploitation of biodiversity is often the failure of the management of biological resources to ensure equitable distribution of the benefits of biological resources with disproportionately more benefits going to more powerful interests. The positions held by various interest groups in the use and consumption of biodiversity can therefore be classified as irresolvable (Colyvan et al., 
2011). In order to address the second question, the following hypothesis was formulated to help test how to reconcile various stakeholder interests.

Hypothesis 3: National and local environmental policies that evolve on the basis of shared meaning at all levels and across sectors and institutions have a higher rate of acceptance, and would therefore lead to high levels of compliance with CBD goals.

Using both qualitative and quantitative methods, the study analyzed how policies evolve and adapt to different levels and sectors by examining whether there is collaboration between various institutions working on biodiversity protection in each country. Specifically, the study examined how different institutions at different levels of government render support to conservation activities, how well local offices work with national government offices, who reports to whom, and the nature of collaboration between governments and international conservation organizations. The study also investigated the coordination between the central government and communities in the implementation of national plans.

Environmental problems have local, regional, national and global consequences and need to be addressed at all these levels to achieve meaningful global compliance (Ringquist \& Kostadinova, 2005; Vig \& Axelrod, 1999). Commitment to all requirements and terms of international environmental treaties calls for a national governing structure that enables institutional capacity to be able to develop policies and to facilitate expression of political demands for biodiversity conservation toward local regions and other countries (Ringquist \& Kostadinova, 2005). 
There is a tendency for most countries to rely on the experts and international organizations to draw plans and public policies, especially in environmental conservation. Borrowing from Jones (2001), there is no solid distinction between policy making and policy administration. Jones discusses the makers of policy who are the politicians, and doers/implementers who are the administrators. In the same way, as governments make policy, input from local level settings where implementation takes place is hypothesized would lead to greater compliance. The implementers at local levels are communities. Their input towards national conservation policies is therefore very important. Input from local level citizens and individuals was measured by looking at whether there are structures that facilitate participation, key information sharing structures, capacity building programs and data availability.

\subsubsection{Opportunity costs of biodiversity protection}

Opportunity cost estimation is one way of accounting for the status of available biological resources. This way of accounting for biodiversity helps to strengthen support for policies developed to protect biological resources, evaluation and ensure that the value of biodiversity is realistically reflected alongside other national priorities within countries (NBSAP Australia, 2011). Using market based incentives through compensation for opportunity costs help to effectively engage resources managers to protect and conserve the resources under their management.

The opportunity cost of biodiversity protection is a significant determinant of implementation decisions and compliance with the goals of the CBD. There are payoffs in terms of costs and benefits when people or organizations undertake conservation 
programs. Costs act as deterrents of positive actions, while benefits act as incentives to adopt an action, negative or positive. Costs can come in the form of direct monetary loss, fines or fees imposed for failure to act. Benefits also come in the form of higher incomes, tax rebates or recognition. In order to address the third question, the following hypothesis was formulated.

Hypothesis 4: The use of appropriate compensation mechanisms to offset opportunity costs that would be incurred by those that supply biodiversity services will increase the probability of effective implementation, and thus lead to higher compliance with CBD goals.

There are various ways to measure the opportunity costs of biodiversity protection. The first approach to measuring opportunity costs was based upon the estimated costs of conservation as opposed to the available funding. When costs of conservation are higher than available funding, both local and external, it is assumed that communities or businesses will be asked to pay for the unfunded portion of conservation. If the costs of conservation are lower than available funding, it is assumed that conservation will easily be implemented. However, this is not always the case.

Another approach to measuring opportunity costs is by the number of taxes initiated, fees charged for violations, and the difference between available biological resources in each country as opposed to the level of use/consumption of the same resource. Another source is the information on the presence or the absence of economic incentives meant to encourage or discourage certain activities. This information may not be easily available in the plans and reports written by various countries. 


\subsection{Basic compliance requirements}

At the international level, the CBD has a specific set of compliance requirements. These requirements include submitting national plans and reports on a regular basis, and participation at international conferences. The monitoring to ensure that what is written in the plans and reported is actually implemented is the responsibility of the countries themselves.

At national level, there is no country that has set any sort of compliance criteria for monitoring and implementing of CBD goals. What emerged from the literature was that even when there are well developed environmental laws, these are not sufficiently implemented and enforced. Non-compliance therefore comes to light only when there are specific measurable violations such as industries releasing a chemical into a body of water or oil leaking into an open natural resource. There are so many other sectors whose activities are constantly degrading biological resources such the poor agricultural practices and deforestation, which are often not seen as violations and therefore cannot be penalized.

At local levels, it is even more difficult because there is very scanty information to begin to tell just how much of the influence the CBD goals have reached local levels in various settings. These settings could be the farms in rural areas, the industries that depend on biological resources for their business and even urban constructions that tend to destroy natural areas. The extent that biodiversity considerations are given weight in major investment decisions is not clear. 


\subsubsection{Development of compliance criteria}

The Table 4 below shows the 20 criteria developed to determine policy compliance.

Table 4: National level compliance criterion

\begin{tabular}{|c|c|c|c|}
\hline & $\begin{array}{l}\text { Criteria for NBSAPs } \\
\text { and National Reports }\end{array}$ & Description & Sources \\
\hline 1 & Language & Specific, strong, clear, not vague & Tang et al. 2010 \\
\hline 2 & Goals & $\begin{array}{l}\text { Specific, covering all aspects of a specific } \\
\text { resource, time-bound }\end{array}$ & $\begin{array}{l}\text { Tanget al. 2010; } \\
\text { NBSAPs various }\end{array}$ \\
\hline 3 & Objectives & Clear, covering all aspects, detailed & NBSAPs various \\
\hline 4 & Depth \& Scope & Covering all aspects, detailed, & NBSAPs various \\
\hline 5 & National Capacity & $\begin{array}{l}\text { Ability of the country to implement the plan, } \\
\text { human, financial and technological }\end{array}$ & NBSAPs various \\
\hline 6 & Funding & Amount and sources of funding, & NBSAPs various \\
\hline 7 & Surveys \& Research & Surveys, research for information and data & NBSAPs various \\
\hline 8 & Coordination & $\begin{array}{l}\text { Coordinating agencies, institutions and fining } \\
\text { common goals }\end{array}$ & NBSAPs various \\
\hline 9 & National Institutions & $\begin{array}{l}\text { The number, nature and strength of national } \\
\text { institutions }\end{array}$ & NBSAPs various \\
\hline 10 & $\begin{array}{l}\text { Support to local } \\
\text { regions }\end{array}$ & $\begin{array}{l}\text { National support in terms funding, human } \\
\text { resources and technological support }\end{array}$ & NBSAPs various \\
\hline 11 & Legislation/Acts & The number, types and supportive & NBSAPs various \\
\hline 12 & Timing/Milestones & Clear timelines to meet specific targets & $\begin{array}{l}\text { NBSAPs various; } \\
\text { Tang et al. } 2010\end{array}$ \\
\hline 13 & Capacity Building & institutional, people, technological & NBSAPs various \\
\hline 14 & National Network & $\begin{array}{l}\text { Easily identifiable relationships between } \\
\text { different sectors, institutions, organizations and } \\
\text { public agencies }\end{array}$ & $\begin{array}{l}\text { NBSAPs various; } \\
\text { Tang et al. } 2010\end{array}$ \\
\hline 15 & Key Activities & $\begin{array}{l}\text { Recruitment of qualified personnel, creation of } \\
\text { institutions, creation of protected areas, } \\
\text { negotiations with donors, communities, }\end{array}$ & NBSAPs various \\
\hline 16 & Outcomes & Clearly identified outcomes, & NBSAPs various \\
\hline 17 & $\begin{array}{l}\text { Monitoring } \\
\text { Evaluation }\end{array}$ & Taking all recommendations taken seriously & NBSAPs various \\
\hline 18 & Participants & $\begin{array}{l}\text { Less international and more local participation } \\
\text { of organizations/communities }\end{array}$ & NBSAPs various \\
\hline 19 & $\begin{array}{l}\text { Information } \\
\text { Technology }\end{array}$ & $\begin{array}{l}\text { Use of IT, information sharing tools, } \\
\text { Technology transfer }\end{array}$ & Tang et al. 2010 \\
\hline 20 & Enforcement ability & Ability to enforcement conserv. regulations & NBSAPs various \\
\hline
\end{tabular}


At the international level, compliance was measured between zero and 100 percent depending on the number of plans, reports and whether a country had a national clearing house mechanism (NCHM). Just submitting one plan or one report was rated $20 \%$ complaint. If a country has a NCHM, it was allocated $100 \%$ compliant. If a country does not have a NCHM, it was allocated $0 \%$ compliant.

At the national level, 20 criteria were developed from the literature, plans, and reports with information that spoke to effective implementation and compliance. For instance, plans in general should have a language that is clear, specific, strong and not vague. These criteria are listed in Table 4 below. Each criterion was worth 5 percentage points. Compliance was measured between zero and 100 percent.

The presence of a NCHM was also evaluated against 10 criteria that were established from the literature, national plans and the CBD website. Each criterion was worth 10 percentage points. These criteria are listed in table 5 below.

Within countries, implementation takes place at local levels. Countries can submit all their plans and reports to the $\mathrm{CBD}$ as required, but this does not mean that they are implementing conservation programs as stated on paper. This called for a different approach to analyze compliance at local levels. The study therefore used Likert scale data from AGF to measure local compliance.

As for the NCHMs, there must be working links, reports from local regions, participants and other resources that national stakeholders may need in conservation decisions. Table 5 below shows the list of 10 criteria used to rate compliance with NCHMs. 
Table 5. Criterion used to define compliance of the NCHMs

\begin{tabular}{|l|l|l|}
\hline & Criteria for NCHMs & Description \\
\hline 1 & Working links & $\begin{array}{l}\text { Links that connect and cover all aspects of } \\
\text { biodiversity within a country }\end{array}$ \\
\hline 2 & Availability of local reports/plans & $\begin{array}{l}\text { Reports/plans from different conservation local } \\
\text { areas within the country }\end{array}$ \\
\hline 3 & $\begin{array}{l}\text { Participation }- \text { Individuals and } \\
\text { Organizations }\end{array}$ & $\begin{array}{l}\text { Identified partnerships, epistemic groups, } \\
\text { institutions, experts and local agencies }\end{array}$ \\
\hline 4 & National Contacts & Online contacts to find all relevant information \\
\hline 5 & National Data & Data on all aspects of biodiversity protection \\
\hline 7 & Biological Resources & The extent to which all resources are covered \\
\hline 8 & Funding & Funding levels, sources and \\
\hline 9 & List of regions and focal points & $\begin{array}{l}\text { List of conservation areas and focal points } \\
\text { from those regions }\end{array}$ \\
\hline 10 & Resources for local implementation & $\begin{array}{l}\text { This refers to technology, trained human } \\
\text { resources, }\end{array}$ \\
\hline
\end{tabular}

Although it has been agreed that treaties do influence state behavior (Hathaway, 2005; Ringquist \& Kostadinova, 2005; Weiss \& Jacobson, 2010), understanding biodiversity conservation in the national and local contexts so as to be able to start to draw plans, formulate goals, iron out conflicts and develop implementation strategies is a process that evolves over time (Brachthauser, 2011). This study makes the assumption that this is the reason why there exists a big lag between the time when the treaties are signed and when conservation outcomes start to be seen. In most countries, ministries of the environment did not exist when the Convention on Biodiversity was created. To date, there are not enough local institutions and trained conservation experts in most countries. There is not enough data on biodiversity to facilitate decision making. There is also insufficient information sharing structures within most countries to facilitate effective engagement with local levels. 
Global biodiversity conservation efforts do not equal national policy development and local implementation of conservation programs. This study therefore estimated compliance status and has examined what countries need to do to move toward a level of compliance where they can start to reverse overexploitation of biodiversity. The unit of analysis was the country. Both qualitative and quantitative methodologies were used. Qualitative methodology was used in the review and analysis of country biodiversity strategy conservation plans submitted to the CBD secretariat, country conservation progress reports, and websites of organizations and institutions involved in biodiversity conservation in each country. Quantitative methodology was also useful in trying to determine the significance of various compliance variables, inputs and conservation outcomes at various levels.

\subsection{Qualitative methods}

The key sources of data for this research was the country plans, reports and information found in the websites of major conservation organizations, which was mainly qualitative. The data is in linguistic form. A linguistic representation of data is best analyzed using qualitative methodologies. Both direct and indirect methodology was utilized. Direct methodology is when qualitative data is used directly in qualitative analysis. Indirect methodology is when qualitative data is transformed into a cardinal one and then used for quantitative analysis.

Content analysis of information in the plans, reports and conservation organization websites was done. For each country, a folder for source documents was created. The National Biodiversity Strategy Action Plans (NBSAPs) and the fourth 
national biodiversity implementation progress reports were uploaded to NVivo10 and posted into a government folder. In addition, 15 websites of other organizations working in these countries obtained from the Google.com search engine were uploaded into NVivo10 using NCapture. A separate folder for other organizations obtained from Google.com was created. Coding for each country was done in separate nodes. These nodes were further broken down into national and international in order to code for information for national institutions and international organizations.

Using InVivo coding to keep the data rooted in the original documents (Saldana, 2013), key words that made references to the research questions in this study were identified using the word frequency query. These words were assigned their own nodes in separate folders. For each node, a descriptive message of the word obtained from their textual context from all documents was then coded into same nodes for each country. This makes it easy to see these words in a passage form, see the messages they are conveying, and be able to decipher how various plans, reports and information on websites relate to research questions.

\subsubsection{Quantitative methods}

Quantitative methodology was equally useful because it helps to explain a research phenomenon through analysis of numerical data using mathematical models (Aliaga \& Gunderson, 2000). It was necessary to complement qualitative analysis with quantitative methodology because quantitative data is more explicit, easily generalizable, transferable and defensible (Hargrove, 2005). Quantitative analysis was done in three 
stages: using qualitative data in a transformed form, using data obtained from the Global Footprint Network and also data from AGF.

Using the 20 criteria identified for purposes of analyzing the quality of NBSAPs and national reports, each criterion was scored between $0 \%$ and $100 \%$ for each country on the NBSAPs and national reports. Averages were estimated to give the percentage level of compliance for every country.

A second cycle of coding was done for national institutions and international organizations for each country. This was aimed at exploring themes most emphasized by biodiversity protection reports, plans and other documents. This was to find out how they could be used to answer research questions and test the research hypothesis. The emerging themes became topics for further analysis. Saldana (2013) argues that social life happens at given coordinates or intersections of one or more actors who are engaging in one or more activities. The study therefore examined how the emerging themes relate to those found in the NBSAPs, government reports, government websites and other conservation organizations. Central to understanding the critical factors that most influence compliance with CBD goals and implementation of biodiversity protection policies was the number of references or the frequency with which specific themes are found at each intersection.

Themes obtained from global organizations were linked to node matrices of national policy themes and also to node matrices of local implementation themes. Matrix tables for each country were generated to show various relationships based on the frequency that different national policy themes shared with local program 
implementation. The actual words used in the original documents were retained as themes for easier reference. The data generated through matrix coding for each country were then subjected to regression analysis to determine the significance of various relationships between policy at the national and implementation levels.

\subsection{Compliance measurement}

Borrowing from measurements of diffusion of innovation in the private sector (Bamberger, 1991) compliance can be conceptualized as either a process or an outcome at community level, institutional, organizational, or global levels. Compliance as a process means identifying various stages, the time taken at each stage and the key attributes of all the stages (Daft, 1978; Van de \& Chu, 1988; Bamberger, 1991). Compliance as an outcome means the final tangible outcomes. These may include the creation of specific programs, organizations, institutions, plans and strategies that represent a significant departure of the state of resources from the time the problem is identified going forward. Measuring compliance based on time is outside the scope of this study. Instead, various compliance attributes, outcomes and stages have been analyzed.

\subsubsection{Compliance measurement as a process}

Key attributes of compliance are explained in this section. When compliance with the goals of the CBD is measured based on implementation and conservation outcomes, conflicts emerge out of the technical, social, economic, political and value judgments from different stakeholders (Munda et al. 1994). This means that there have to be more 
ways to measure outcomes at different levels. These conflicts are partly the sources of non-compliance and they take forms of both quantitative and qualitative variables.

The technical conflicts arise from the global and national planning strategies that are multi-layered across many sectors and therefore always in search for compromises in decision making. The social conflicts come about as a result of the losses and benefits accruing to the society when implementing specific goals required for compliance standards. Economic perspectives of conflicting values originate from allocation (efficiency), distribution (equity), and scale (sustainability) (Daly, 1991; Munda et al., 1994). While it is believed that the market provides optimal allocation of resources (Munda et al., 1994), an optimal scale of compliance with CBD goals requires more than the market forces. This study has taken care of this by employing both the living systems theory and game theory, where stakeholders cooperate as well as negotiate towards arriving at a consensus through compromise. Compromised conservation strategies bring along with them some difficulties at the implementation stages.

The political aspect of measuring compliance is in the formulation of policy instruments, where targets to be met, or statements setting minimum threshold for the entire community, are set. Value judgment conflicts take various forms as follows: i) when the compliance requires minimum exploitation of natural resources but provides optimum yield (Munda et al., 1994) while the society wants to overexploit and get maximum yields; ii) maximum production of goods and services at minimum (private and social) costs (Munda et al., 1994) while the society is not really worried about social 
costs; and iii) maximum sustainable use of biological resources (Munda et al., 1994) while the society does not have any sustainable use ability, knowledge or capacity.

Solutions to conflicting conservation interests require an analysis of various conservation alternatives from those that provide superior protection to those considered merely rhetoric. Compliance with CBD goals calls for a collective action by the community, a nation, non-governmental sector and the international community. These different stakeholder levels see different acceptable compliance avenues. Greater compliance, therefore, my study argues, can come from more cooperative strategies, restrictive initiatives but not compromised policies and negotiated agreements. Availability of various alternatives to conservation settings with a clear rank from most restrictive, cooperative arrangements to incentive based policies needs to be determined.

\subsubsection{Compliance measurement as an outcome}

According to Bamberger (1991), when compliance is conceptualized as an outcome requires a listing of criteria to facilitate the measuring of compliance. There are two types of conceptualizations: a "closed list" or an "open list". A "closed list" approach uses a universal criterion where program reports and documents are used to generate a list of items selected on the basis that these are critical to aiding of obstructing compliance. An ordered rank is then placed on each criterion. The "open list" approach is when a study uses survey methodologies to ask informants to provide the criteria and information to help develop the rankings.

Measuring compliance is best done through the use objective or nonjudgmental ratings. Nonjudgmental ratings are ideal when research findings need to be presented 
quantitatively (Bamberger, 1991). Under nonjudgmental ratings, a measure of compliance was generated by identifying specific criteria and then ranking a variety of items under each criterion from zero to $100 \%$.

\subsubsection{Compliance stages}

Most literature defines compliance but does not explain in detail what actually goes into compliance. Based on the information gathered from the existing literature, my study has divided compliance with the CBD into three levels: i) paper compliance ii) policy compliance and iii) implementation compliance. The processes and implementation of programs needed to comply is not a one-time event but is an effort that should be carried throughout the life of the program. It is through the long-term process that institutions are built, knowledge is accumulated, capacities are improved, experience acquired, and various obstacles get eliminated. Some of the key obstacles include untrained staff, lack of funding opportunities, lack of communication technology, and lack of political support (NBSAPs South Africa, 2006; India, 2000; Canada, 1999; Ghana, 2002; Jamaica, 2004).

Paper compliance is attained when countries sign and ratify a treaty, start to draw national policies as per the terms of the treaty and begin regular or irregular submission of required reports and revised plans. Under the Global-National-Local Model, this type of compliance fits at the global level. At the global level, the key to successful policy adoption by governments is first to identify biodiversity conservation needs and match these with government priorities. Communication should be structured so as to facilitate reporting and planning. 
Policy compliance is a country effort when countries begin to create institutions and structures to coordinate programs, hire conservationists, share information and build human capacities. For most countries it is the processes and national level readiness that defines how local level implementation is done to halt degradation of biological resources. Structural support mechanisms and human resources are acquired to ready national institutions.

Policies that bring about partial implementation and thus low compliance are the result of less than ready national government in terms of human resources, inadequate funding and legislation. Policy compliance helps to bring national policies and programs into direct contact with local level communities, institutions and staff directly involved with implementation. It is at this stage when local level needs have to be matched with national biodiversity protection policies. It is at this level where major implementation obstacles are eliminated.

Implementation compliance is the product of local level efforts that lead to the creation of institutions, conservation structures, national governments assessment of community needs, capacities and strengths of specific communities or organizations. By community here it means people in a village who share common resources, a business community, a neighborhood, a city or a group of organizations. Epistemic groups start to emerge. However, unless communities recognize and buy into the new policies, that biodiversity conservation is affordable and is not in conflict with local priorities implementation will be resisted and undermined. Compliance that results from implementation at local levels brings about changes in overall institutional and 
organizational environment that can be seen in the capacities that begin to emerge, cultures and new social practices.

Figure 1. Compliance framework

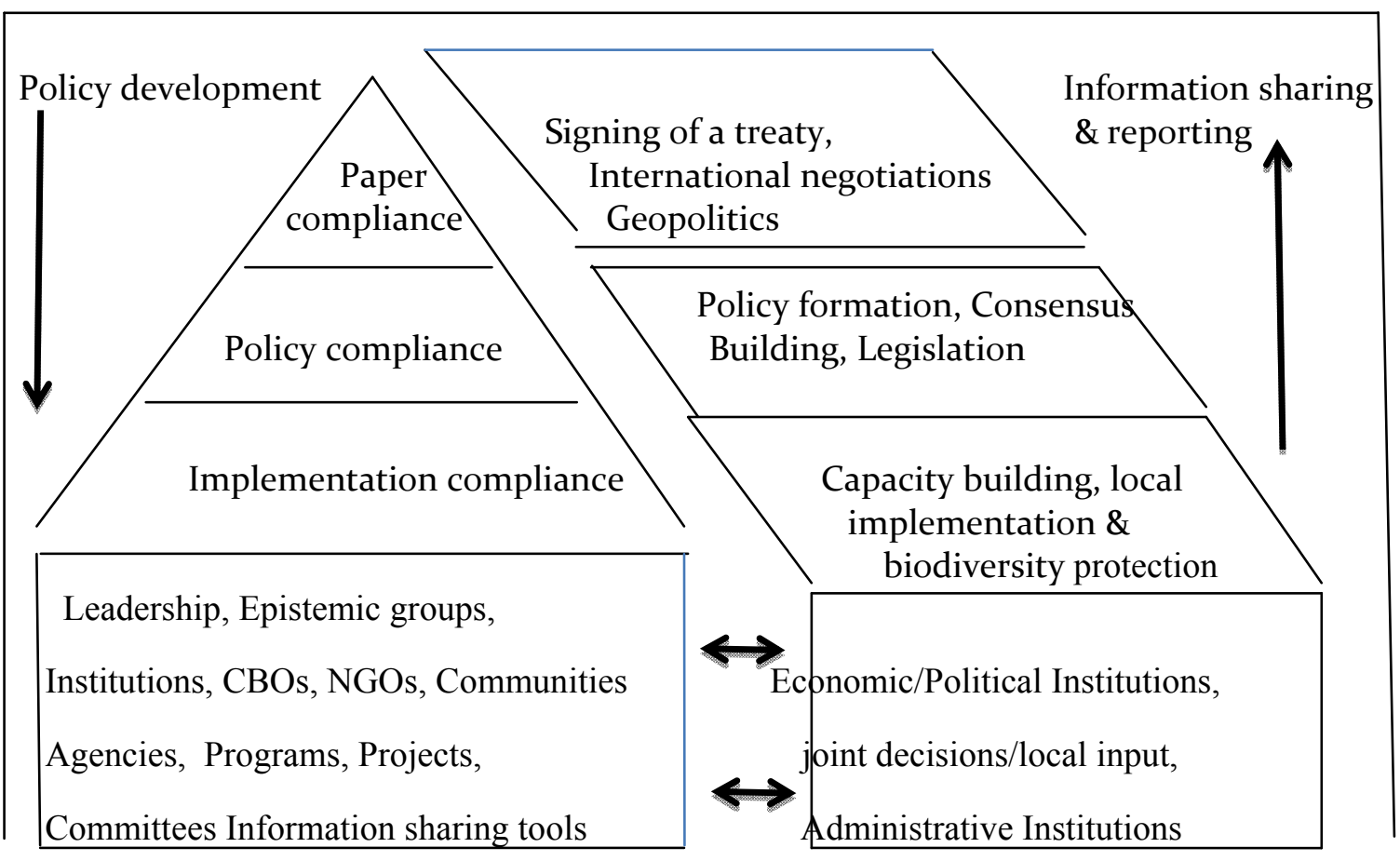

Source: Constructed by my study using information from the literature

Implementation in the context of compliance is defined as the number and types of activities designed to put into practice a program that meets specified objectives and goals. It is through implementation processes that programs can be seen, described, and felt. The following conceptual compliance model has been designed to break down these compliance activities. 


\subsubsection{Compliance Model}

Going by the scientific findings regarding the overexploitation and degradation of biodiversity, each variable in the mathematical model below is in itself a step towards higher compliance. My research indicates that global compliance should be the sum of all the variables from the local level implementation programs to global ratification of a treaty. The various components of compliance take both qualitative as well as quantitative measurements. At the global level, my study has controlled for the fact that countries have signed and ratified the $\mathrm{CBD}$, attendance to conferences, country incomes, country population and size of each country. Global compliance can therefore be defined as in the model below. At both national and local levels, this study controlled for availability of data, consumption of natural resources, restoration activities and costs of conservation.

$$
G_{c}=f\left(P a_{c}+P_{c}+I_{c}+N a_{c}+R_{c}+O P_{C}\right)
$$

Where:

$\mathrm{Gl}_{\mathrm{c}}=$ Global compliance

$\mathrm{Pa}_{\mathrm{c}}=$ Paper compliance

$\operatorname{Pr}_{\mathrm{c}}=$ Policy compliance

$\mathrm{I}_{\mathrm{c}}=$ Implementation compliance

$\mathrm{Na}_{\mathrm{r}}=$ Natural resources consumption level

$R e_{a}=$ Restoration activities

$\mathrm{OP}_{\mathrm{c}}=$ Opportunity costs

$\mathrm{Pa}_{\mathrm{ci}}=\frac{1}{3}\left[\sum_{1}^{5} \mathrm{NBSAPs}+\sum_{1}^{5} \mathrm{NRs}+\mathrm{NCHMs}\right]$

$\mathrm{Pa}_{\mathrm{ci}} \quad=$ Paper compliance by country $\mathrm{i}$ 
NBDSAPs $=$ All countries expected to have submitted up to 5 NBSAPs.

NRs $=$ All countries expected to have submitted up to 5 National reports.

NCHMs $\quad=$ Presence or absence of National Clearing House Mechanisms

Paper compliance was scored based upon countries meeting all/some of the specific requirements set by the $\mathrm{CBD}$. These requirements were; the submission of the first NBSAP; submission of up to four revised NBSAPs; submission of up to five national reports; and establishment of national clearing house mechanisms by each country. The scores were allocated according to table 6 below. These scores were allocated simply based on the number of plans or reports submitted to the CBD. As for the Clearing House Mechanism, it was a question of whether a country has one or not so a country got $0 \%$ or $100 \%$.

Table 6: Paper compliance estimation scores

\begin{tabular}{|l|l|l|l|}
\hline Submissions & NBSAPs & $\begin{array}{l}\text { National } \\
\text { Reports }\end{array}$ & CHMs \\
\hline $1-$ First plan/Report & 20 & 20 & \\
\hline $2-$ First Revised plan/Report & 20 & 20 & \\
\hline $3-2^{\text {nd }}$ Revised plan/Report & 20 & 20 & \\
\hline $4-3^{\text {rd }}$ Revised plan/Report & 20 & 20 & \\
\hline $5-4^{\text {th }}$ Revised plan/Report & 20 & 20 & $0 \%$ or $100 \%$ \\
\hline Total Percent & $100 \%$ & $100 \%$ & \\
\hline
\end{tabular}

\subsubsection{National compliance}

Estimation of national compliance was based on the quality of NBSAPs, information on the progress of national conservation from national reports and the ability of NCHMs to both coordinate and facilitate information sharing within a country. The 
assumption made was that the quality of planning and how countries meet planned activities is a sign of compliance levels.

National compliance $=\mathrm{f}\left(\mathrm{Q}_{\mathrm{NBSAPs}}+\mathrm{Q}_{\mathrm{NRs}}+\mathrm{Q}_{\mathrm{NCHMs}}\right) \quad \ldots \ldots \ldots \ldots \ldots \ldots \ldots \ldots \ldots \ldots$

Where

$\mathrm{Q}_{\mathrm{NBSAPs}} \quad=$ Quality of NBSAPs

$\mathrm{Q}_{\mathrm{NRs}} \quad=$ Quality of National Reports

$\mathrm{Q}_{\mathrm{NCHMs}} \quad=$ Quality of NCHMs

National compliance was scored based on the 20 criteria identified in table 4. Fulfilment of each criterion was scored up to a maximum of five percentage points for the NBSAPs and national reports. The score for NCHMs was based on 10 criteria and therefore each criterion received a maximum of 10 percentage points.

Table 7: National compliance estimation of scores

\begin{tabular}{|l|l|l|l|}
\hline & NBSAPs & National Reports & CHMs \\
\hline $\begin{array}{l}\text { Number of Criterion } \\
\text { for developing scores }\end{array}$ & $\begin{array}{l}(0-5) \% \text { X } 20 \\
=(0 \%-100 \%)\end{array}$ & $\begin{array}{l}(0-5) \% \text { X } 20 \\
=(0 \%-100 \%)\end{array}$ & $\begin{array}{l}(0-10) \% \text { X } 10 \\
=(0 \%-100 \%)\end{array}$ \\
\hline
\end{tabular}

\subsubsection{Local compliance}

Implementation and compliance at the local level was estimated using data from ASAHI Glass Foundation as presented in Table 8 below. Specific data was categorized as measuring local implementation, local capacities and direct national and international support for local implementation. 
The data was in the form of Likert scale responses to given statements with the following scales: 1 (strongly disagree), 2(disagree), 3 (neutral), 4 (agree)and 5 (strongly agree). These statements were structured in a negative way to show that what was actually taking place with regard to local conservation was good enough to produce positive conservation outcomes.

Table 8: Local compliance estimation

\begin{tabular}{|l|l|r|r|}
\hline & Local level implementation variable description (N=1009) & Agree & Disagree \\
\hline 1 & Other national interests often take precedence over conservation & 13 & 79 \\
\hline 2 & Individuals make decisions based on immediate benefits & 12 & 83 \\
\hline 3 & Economic considerations given higher priority over environment & 15 & 80 \\
\hline 4 & Policies that optimize the whole are secondary - economics \& environment & 10 & 80 \\
\hline 5 & Members of the public shoulder conservation costs & 6 & 86 \\
\hline 6 & Conservation policies face high resistance & 9 & 78 \\
\hline 7 & International organizations do not optimize the whole - socio-economics/enviro & 7 & 86 \\
\hline 8 & Unanimous consent voting by the UN is not good for biodiversity conservation & 11 & 75 \\
\hline 9 & Lack of enforcement by UN makes global coordination weak & 12 & 79 \\
\hline 10 & Systematic and organizational reforms are lacking, are much needed now & 10 & 71 \\
\hline 11 & There is no reference point for the natural environment and life forms & 13 & 74 \\
\hline 12 & Society and cultural practices that support common resources are lacking & 10 & 81 \\
\hline 13 & Societal practices that value the environment are few and far in between & 15 & 65 \\
\hline 14 & There is capacity to recognize environmental problems locally but not globally & 25 & 61 \\
\hline 15 & Decisions based on self-interests, not others or future generations & 18 & 64 \\
\hline 16 & Human nature to care for others is often overwhelmed by economic & & \\
& considerations & 12 & 77 \\
\hline 17 & Values that respect environment and economic activities are inconsistent & 11 & 74 \\
\hline 18 & Lifestyles towards high energy consumption cannot be abandoned & 32 & 76 \\
\hline 19 & Easily comprehensible information is not communicated to the public & 12 & 80 \\
\hline 20 & Conservation experts communicate more with political decision makers & 26 & 53 \\
\hline 21 & Political decision makers do not pass on enough information to the public & 10 & 80 \\
\hline 22 & Environmental information is valued only when disaster occurs & 15 & 77 \\
\hline 23 & NGOs communicate more to political decision makers than local citizens & 17 & 50 \\
\hline 24 & Certain level of environmental needed to understand environment is lacking & 8 & 79 \\
\hline 25 & Organizations give higher priority to economics and not environmental issues & 15 & 80 \\
\hline & & 344 & 1868 \\
\hline & & 13.76 & 74.72 \\
\hline
\end{tabular}

Source: Asahi Glass Foundation 
A total of 1009 people responded to these questions. The percentage of people that gave neutral responses was eliminated. Those that responded strongly agree and agree were classified as agree. In general, those that responded strongly disagree and disagree were classified as disagree. Table 8 above shows the percentage of those respondents that agreed and those that disagreed. An average percentage for each was estimated. The percentage of people that agreed was assumed to represent the level of local compliance.

The average numbers of people that agree to the statements reflect the view of the success of local level implementation and compliance. The responses of the people that disagreed reflect the views that conservation of natural resources face numerous difficulties at all levels with the greatest impacts felt at local levels.

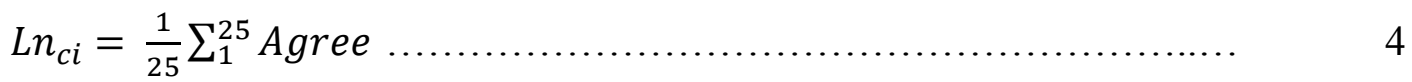

Where $N_{c i}$

$L n_{c i}=$ Local compliance of country i.

$L S=$ Likert scale responses from table 8 above

\subsubsection{Estimation of overall compliance}

The final compliance was estimated by putting together the average of compliance level by each country as follows;

$$
\mathrm{GL}_{\mathrm{ci}}=\mathrm{Pa}_{\mathrm{ci}}+\operatorname{Pr}_{\mathrm{ci}}+\mathrm{Ln}_{\mathrm{ci}}
$$

Where $\mathrm{Pa}_{\mathrm{ci}}+\mathrm{Pr}_{\mathrm{ci}}+\mathrm{Ln}_{\mathrm{ci}}$ is paper compliance by country $\mathrm{i}+$ national compliance by country i local implementation by country $i$.

$\mathrm{Pa}_{\mathrm{ci}}=\sum\left(\mathrm{R}_{1}+\mathrm{R}_{2}+\cdots+\mathrm{R}_{20}\right)+\mathrm{N}_{\mathrm{CHM}}$ 
$\operatorname{Pr}_{\mathrm{ci}}=\sum\left(\mathrm{R}_{1}+\mathrm{R}_{2}+\cdots+\mathrm{R}_{20}\right)$

Where: $\mathrm{R}_{1-20}=$ Various criterias

$N_{C H M}=$ National Clearing House Mechanism

$\mathrm{GL}_{\mathrm{c}}=\frac{1}{3} \sum\left(\mathrm{Pa}_{\mathrm{ci}}+\mathrm{Pr}_{\mathrm{ci}}+\mathrm{Ln}_{\mathrm{ci}}\right)$

\subsection{Stakeholder cooperation toward compliance}

Many biological resources such as forests and fisheries exist in common pool resources and are therefore easily overexploited (Basurto, 2008). Implementation of many conservation programs especially in developing countries is done by international organizations often serving in more than one country. According to Ostrom (2010), most effective systems of governance require small to medium sized departments to provide direct services such as conservation institutions at the local level such as communities. International as well as local organizations lack enforcement ability and thus to act as change agents without sufficient government support and local policy ownership does not always bring about the desired outcomes.

From the perspective of the $\mathrm{CBD}$, biodiversity protection is a universal responsibility. All countries that have joined the membership of the CBD have the prerogative to choose how they wish to carry out conservation. Factors that support or inhibit biodiversity protection are many and vary across countries and regions. Using game theory methodology, I have tried to examine individual country strengths and weaknesses. Specific country strengths can be used to support another country's weakness under international relations theories. The key assumption made here is that when countries cooperate, the kind of support they render each other takes them to a 
higher compliance level. This happens when the strengths and weaknesses of each country are known to each other. Because biodiversity protection is a collective global responsibility, countries with strengths in specific strategies will support weak strategies in other countries.

Figure 2: Stakeholders' cooperation

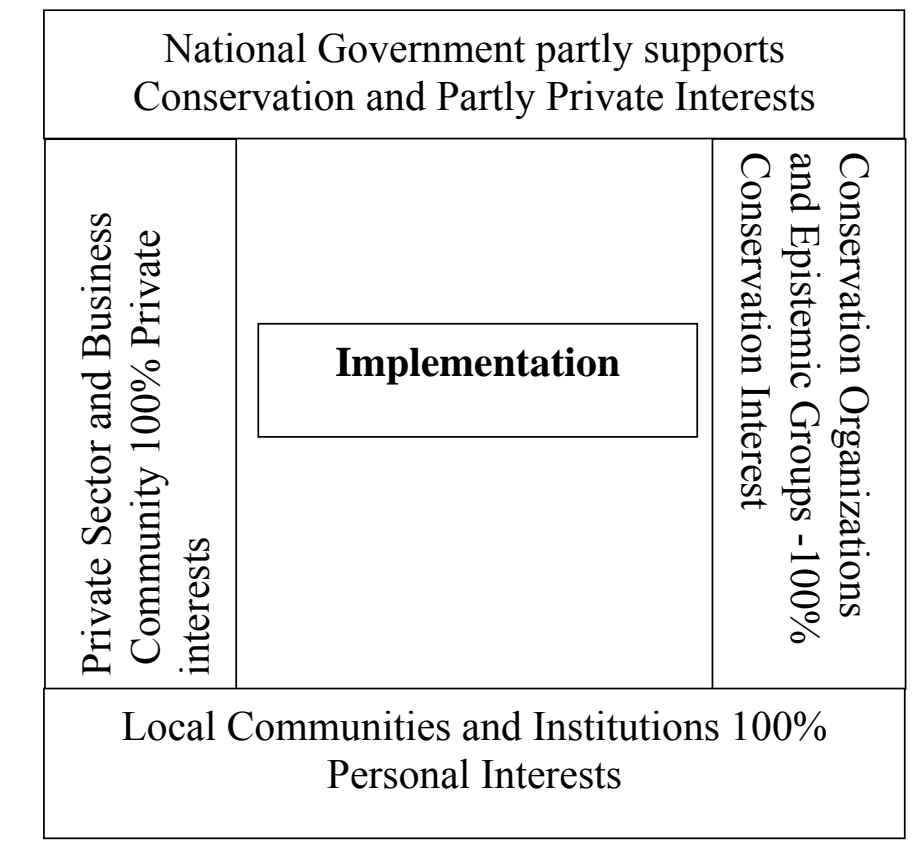

Source: Own conceptualization of game theory

Figure 2 above shows the initial theoretical approach to explain cooperation under both international relations and game theories. At this stage, stakeholders are involved in negotiations to build consensus as well cooperatively looking at the extent to which they can benefit from the use of biological resources. In this figure, stakeholders come to the negotiation table hoping to go away with $100 \%$ of their interests met. As negotiations progress, realization sets in that they all have to give up a portion of their interest. A coalition is formed which then is tasked with implementation. The same process is repeated in all countries. These coalitions within countries then need to cooperate and 
support conservation based on the strengths of their capacity in specific conservation issues. These are referred to as a strategy in game theory.

This study has used theoretical relationship to examine strategic relations between implementers or owners of biodiversity and donors or the international community. Various benefit and loses scenarios were developed in order to see how various stakeholder make conservation decisions. These decisions are both local when looked at from the lens of implementers (owners of biological resources) and global if we were to look at them from to donors perspectives. Local conservation decisions reduce the benefits that communities enjoy from using more biological resources. It is only logical that these communities be compensated for more sustainable long-term conservation goals. The type of compensation mechanisms developed greatly depends on the type governmental and organizational cooperation with local institutions.

\subsubsection{Determinants of institutional cooperation}

The challenge to determining institutional cooperation arose from insufficient literature that explains how institutional arrangements work in various places and how they are able to work with each other across multiple countries. Within a country, there are differences at the operational level (how resources are used), the collective choice level (policy making level), and the constitutional level (making of laws that govern institutions) (Ostrom, 2010). It is for this reason that collaboration between global institutions, international organizations, national and local governments is important for successful local conservation efforts. Borrowing from Ostrom's identified structural 
elements of a game used to predict outcomes (Ostrom, 2010), the table below was constructed to show how institutions could work with each other.

Using the components in column one under the rules of game theory (Ostrom, 2010), the study was able to build an institutional working model in column 2 . The study developed an analytical framework where analysis of different actions at different levels in different organizations was clearly displayed, see Table 9 below. There are numerous structures that arise when organizations work in cooperation that warrants the analysis of rules and other factors which usually affect how organizations work together.

Table 9: Determinants of institutional collaboration

\begin{tabular}{|l|l|l|}
\hline \multicolumn{1}{|c|}{ Elements of Game Theory } & \multicolumn{1}{|c|}{ Institutional arrangement } & \multicolumn{1}{|c|}{ Factors to consider } \\
\hline Number of actors & Number of institutions & $\begin{array}{l}\text { Knowledge and } \\
\text { Resources available }\end{array}$ \\
\hline $\begin{array}{l}\text { Positions players occupy } \\
\text { (Rows or Columns) }\end{array}$ & $\begin{array}{l}\text { Origin of and } \\
\text { organization/institution (local, } \\
\text { national or international }\end{array}$ & Working relationships \\
\hline $\begin{array}{l}\text { Amount of information } \\
\text { available to each } \\
\text { stakeholder/player }\end{array}$ & $\begin{array}{l}\text { Amount of information available to } \\
\text { each organization/institution }\end{array}$ & $\begin{array}{l}\text { Organizational } \\
\text { capacity, Information } \\
\text { sharing tools }\end{array}$ \\
\hline $\begin{array}{l}\text { Set of Actions that players } \\
\text { take at specific nodes in a } \\
\text { decision table }\end{array}$ & $\begin{array}{l}\text { Set of actions different } \\
\text { organizations take at different levels }\end{array}$ & $\begin{array}{l}\text { Legislation, policy } \\
\text { making, } \\
\text { Implementation }\end{array}$ \\
\hline $\begin{array}{l}\text { How much to give up, how } \\
\text { much to gain, joint losses or } \\
\text { joint benefits }\end{array}$ & $\begin{array}{l}\text { How legislation, policy and } \\
\text { implementation connect with } \\
\text { intermediate or final outcomes }\end{array}$ & $\begin{array}{l}\text { What each organization } \\
\text { brings in, Impact }\end{array}$ \\
\hline $\begin{array}{l}\text { Outcomes that players jointly } \\
\text { affect }\end{array}$ & $\begin{array}{l}\text { Outcomes that organizations jointly } \\
\text { affected }\end{array}$ & $\begin{array}{l}\text { How courses of action } \\
\text { are selected, }\end{array}$ \\
\hline $\begin{array}{l}\text { Benefits and costs assigned to } \\
\text { actions and outcomes }\end{array}$ & $\begin{array}{l}\text { Benefits and costs assigned to } \\
\text { actions and outcomes at different } \\
\text { levels and organizations }\end{array}$ & $\begin{array}{l}\text { Available incentives to } \\
\text { act or not to act, } \\
\text { Opportunity costs }\end{array}$ \\
\hline
\end{tabular}

Source: Ostrom, 2010 
Cooperation is the working together of biodiversity stakeholders to accomplish shared goals (Smith, 1995) while collaboration is the working together to achieve common goals (McLnnerney \& Robert, 2004). In a cooperative arrangement, each stakeholder is responsible for that portion of conservation work that affects them directly. Collaboration on the other hand comes with costs in the form of time and resources devoted to establishing and maintaining working relationships, the value attached to such relationships and the reputations for being reliable and building trust between organizations (Williams, 1979; Breton \& Wintrobe, 1982; Ostrom, 2011).

\subsubsection{Application of game theory to biodiversity protection}

In more practical ways, several stakeholders with differing interests are involved in biodiversity management, policy making and implementation. Conservation efforts will yield higher compliance outcomes if all stakeholders cooperate. Several games from simple two-country and two-stakeholder scenario to multiple country cooperation and multiple stakeholder complex games were analyzed.

Table 10: Game theory and conservation strategies

\begin{tabular}{|l|l|l|l|l|}
\hline & Implementer 1 & implementer 2 & implementer 3 & Implementer 4 \\
\hline Conservation Orgn 1 & $\mathrm{X} 1, \mathrm{Y} 1$ & $\mathrm{X} 1, \mathrm{Y} 2$ & $\mathrm{X} 1, \mathrm{Y} 3$ & $\mathrm{X} 1, \mathrm{Y} 4$ \\
\hline Conservation Orgn 2 & $\mathrm{X} 2, \mathrm{Y} 1$ & $\mathrm{X} 2, \mathrm{Y} 2$ & $\mathrm{X} 2, \mathrm{Y} 3$ & $\mathrm{X} 2, \mathrm{Y} 4$ \\
\hline Conservation Orgn 3 & $\mathrm{X} 3, \mathrm{Y} 1$ & $\mathrm{X} 3, \mathrm{Y} 2$ & $\mathrm{X} 3, \mathrm{Y} 3$ & $\mathrm{X} 3, \mathrm{Y} 4$ \\
\hline Conservation Orgn 4 & $\mathrm{X} 4, \mathrm{Y} 1$ & $\mathrm{X} 4, \mathrm{Y} 2$ & $\mathrm{X} 4, \mathrm{Y} 3$ & $\mathrm{X} 4, \mathrm{Y} 4$ \\
\hline Conservation Orgn 5 & $\mathrm{X} 5, \mathrm{Y} 1$ & $\mathrm{X} 5, \mathrm{Y} 2$ & $\mathrm{X} 5, \mathrm{Y} 3$ & $\mathrm{X} 5, \mathrm{Y} 4$ \\
\hline
\end{tabular}


Table 10 shows various game combinations that can build both cooperative and non-cooperative strategies between owners of biological resources and conservationists. The Xs and Ys are the different strategies available to conservation organizations and implementer (owners of biological resources) in a game. Strategies are not the same as outcomes. The rows represent conservation organizations' strategies and columns represent owners of biological resources and these can be countries, communities or even private sector institutions. Each strategy leads to a specific outcome/payoff in conservation. The illustration in table 10 shows just one strategy for an implementer and the conservation organization. It is important to point out that each of these players can have more than one strategy.

\subsubsection{Application of systems theory to biodiversity protection}

Protection of biodiversity ideas originate from conservation organizations. The avenues that these organizations take toward compliance are either direct, through community involvement, government involvement or private sector involvement. Within these avenues, there are several parties (agents) that conservation organizations will work with. Working with any of these agents has been referred to by this study as a strategy. Successful biodiversity protection can be realized when there are strong strategic actions from the conservation community. These actions should favor public involvement in public discourses through government structures in order to shape citizen's perceptions. Once perceptions are changed, opposition diminishes and influence toward conservation starts to grow (Box, 2010). 
Most citizens are not well informed and not so involved in public discourse processes such that decisions are made by self-interested people and by community activists pushing their particular view of the public interest (Box, 2010). For public administrators to intervene in order to protect biological resources, citizens support and cooperation is critical. The Figure 3 below shows various avenues (strategies) available for conservation organizations to drive the global society toward compliance. They can work through governments directly, through communities, through private sector or through all these avenues. When they choose to cooperate with either communities or private sector only, the level of compliance achieved is a narrow one, therefore can be classified as low.

Figure 3: Compliance network model

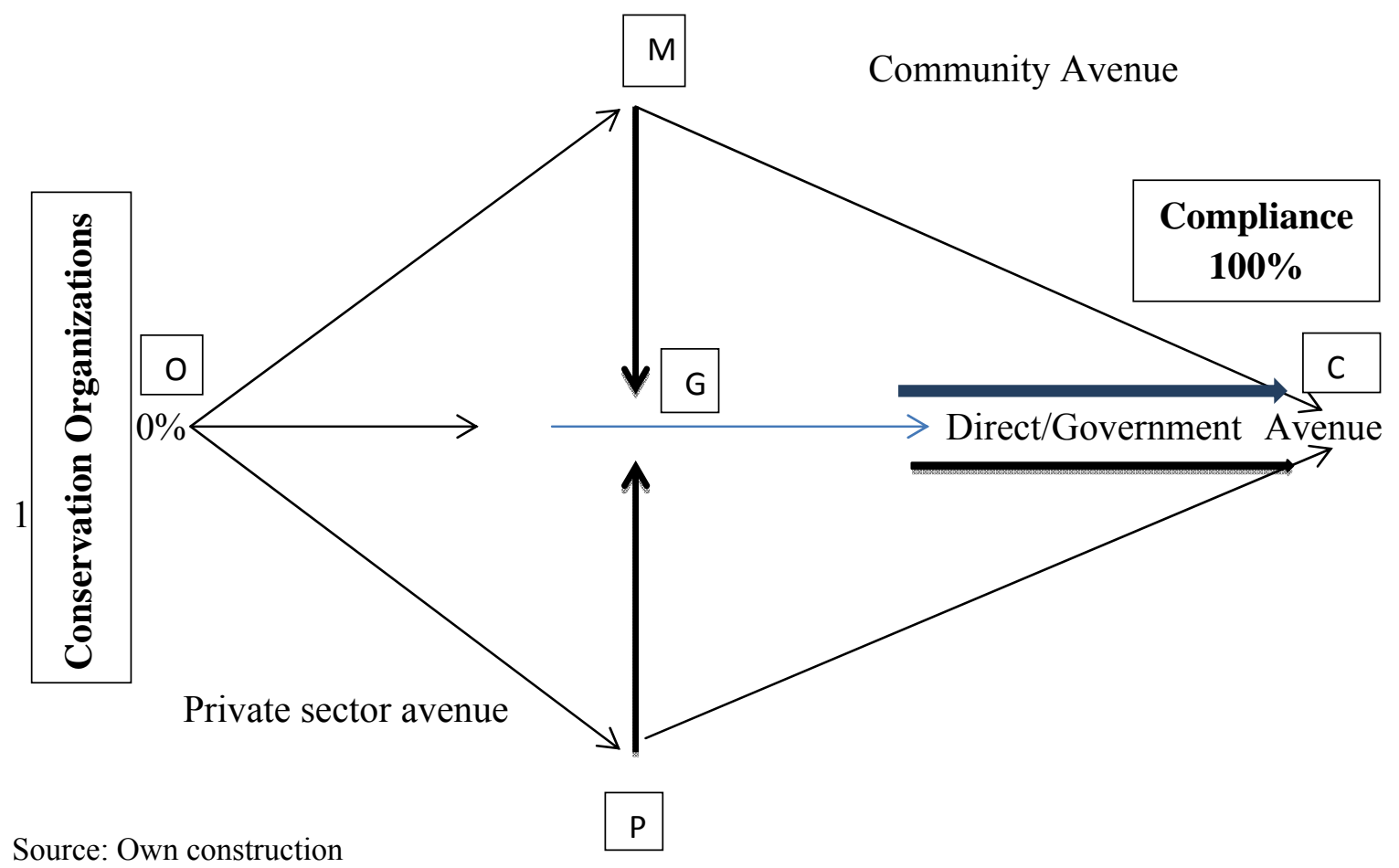


When conservation organizations drive communities, private sector organizations and all other stakeholders to cooperate with governments, the path towards higher compliance is longer but wider and therefore can be classified as higher. Compliance spectrum ranges between $0 \%$ and $100 \%$. The $100 \%$ compliance is a desired state which can only be achieved if all stakeholders are cooperating and if the conservationists are advancing strong strategies that are fully supported by governments. When stakeholders work individually, compliance can only be narrowly defined, for example, when a government submits a report to the $\mathrm{CBD}$ it is seen as complying even though the demand for biological resources far exceeds national biological capacity.

Conservation organizations have to travel the distance from $0 \%$ to $100 \%$ compliance. For explanation sake, working through governments is the shortest distance while the strategies of working through communities or the private sector will take longer to get to $100 \%$ compliance.

However, it is not possible to ignore communities and private sector interests if meaningful compliance is to be achieved. Conservation organizations will therefore have to work with governments to reach community and private sector interests. The distance travelled from $0 \%$ compliance will go through $\mathrm{G}$, to either $\mathrm{M}$ or $\mathrm{P}$ or both depending on the socio-economic structure of a specific country.

Although the compliance network above shows a flow that does not seem to have problems that could arise as organizations or governments work together, disagreements on how to solve environmental problems have often played out publicly. For instance, environmental regulations have always led to high level conflicts between private sector 
organizations, international NGOs and civil society institutions, such as what was witnessed at the Rio Earth Summit in 1992. The demands for strict and compulsory implementation advanced by environmental NGOs were disregarded and a voluntary code of conduct developed by the Business Council for Sustainable Development that consisted mainly of private sector corporations adopted in what should have a democratic process (Hawken, 1995; Banerjee, 2008). Businesses do not want to be told what to do and how to do what is perceived as beneficial for the whole society.

In figure 3 above, suppose the strategies conservation organizations employ are $\left(S_{0}, S_{1}, S_{2}, S_{3} \ldots S_{6}\right)$ if they wish to work alone. In game theory, one player game is known as a decision problem (Turocy \& Stengel, 2002). This, however, can be difficult in biodiversity protection because of many stakeholders who have to use biological resources. Conservation organizations have to build a working relationship with all other stakeholders. In games of this nature, players/stakeholders have a choice to maximize their payoff/benefits.

Strategy $\left(S_{1}\right)$ is when conservation organizations choose to work with the community (OMC), $\left(S_{2}\right)$ is when they work with government (OGC), $\left(S_{3}\right)$ is when they work with private sector (OPC), $\left(S_{4}\right)$ is if they work with government and communities (OGMC), $\left(S_{5}\right)$ is if they choose to work with government and private sector (OGPC), and $\left(S_{6}\right)$ is when they work with all other stakeholders. For any avenue that conservation organizations take, there is an action profile, $\left(A_{0}, A_{1}, A_{2}, \ldots \ldots A_{6}\right)$. Expected compliance, therefore, is multiplied by the probability of every action.

$$
C\left(S_{0}, S_{1}, S_{2}, \ldots \ldots, S_{6}\right)=S_{0}\left(A_{0}\right)+S_{1}\left(A_{1}\right)+S_{2}\left(A_{2}\right) \ldots \ldots+S_{6}\left(A_{6}\right) \ldots \ldots \ldots
$$


To be able to predict various outcomes or payoffs in a conservation game, I introduced the cooperative and non-cooperative strategies between conservationists and owners of biological resources, also classified as implementers of conservation policies. It is theoretically expected that cooperative strategies lead to higher payoffs/benefits while non-cooperative strategies always bring about a lower collective payoff/benefits (Jackson, 2011).

In any cooperative game between stakeholders, various strategies $X_{i}, Y_{i}$ can be seen as either favoring conservation when they lead to better implementation or constraining conservation when they obstruct implementation. For a conservation outcome $O_{i}(S)$ for conservation organization $i$ in a conservation profile $(S), s_{i}$ in a cooperative gave leads to better implementation than $s_{i}^{\prime}$ in a non-cooperative game. Conservation organizations do better with $s_{i}$ than with $s_{i}^{\prime}$.

$O_{i}\left(X_{i}, Y_{i}\right)>O_{i}\left(X_{i}^{\prime} Y_{i}^{\prime}\right)$ 10

In some cases, conservationists and implementers end up with less than optimal outcomes. This arises when both conservationists and implementers fail to axecute their portion of responsibility. This leads to what is known as prisoner's dilemma in game theory.

$O_{i}\left(X_{i} Y_{i}\right)<O_{i}\left(X_{i}^{\prime} Y_{i}^{\prime}\right)$

11

The government, communities and private sector organizations are expected to respond to conservation organizations by either embracing completely the conservation agenda, partly embracing or completely rejecting conservation. Implementers of 
conservation goals can choose to fit or corrupt the environment in which they find themselves. This can be observed from claims made based on the force-field concept that for each driving force, there is a restraining force acting to prevent the transformation (Rago, 1996). In this context, the following strategy profile is proposed:

Borrowing from Turocy \& Stengel (2002), $S=\left(S_{0}, \ldots \ldots S_{n}\right)$ is the conservation organization's strategy profile, then, $S_{-i}=\left(S_{i-1}, \ldots \ldots, S_{0}, S_{1+1}, \ldots \ldots, S_{n}\right)$. Where $S_{-i}$ is the strategy of all other stakeholders except conservation organizations. Therefore, a weak strategy $S_{i}^{\prime}$ is advanced by all other stakeholders, such that;

$$
\left(S_{i}^{\prime}, S_{-i}\right)=\left(S_{1}, \ldots, S_{i-1}, S_{i}^{\prime}, S_{i+1}, \ldots, S_{n}\right)
$$

such that $\left(S_{i}, S_{-i}\right)=S$

Conservation strategy $S_{1}$ is meant to influence stakeholder position $S_{-i}$ and is supposed to lead to better conservation outcomes if $C\left(S_{i}, S_{-i}\right) \geq C\left(S_{i}^{\prime}, S_{-i}\right)$ for every strategy $S_{i}^{\prime}$ available to all stakeholders. $S_{i}$ will lead to more efficient outcomes if $C\left(S_{i}, S_{-i}\right)>$ $C\left(S_{i}^{\prime}, S_{-i}\right)$ for every $S_{i}^{\prime} \neq S_{i}$. Conservation will be implemented when strategies chosen do not reduce the benefits $(B)$ that communities enjoy from the consumption of more biodiversity. When such benefits are reduced, there must be some form of compensation.

\subsubsection{Cooperation and non-cooperation approaches to conservation}

It is not all the time that stakeholders in biodiversity protection have one common agenda. Some and often very strong stakeholders from the private sector want to exploit 
biological resources for maximum benefits without hindrance. It is important to examine how the non-cooperation from some stakeholders affects conservation.

Although there are arguments to the effect that communities cannot genuinely participate in biodiversity protection, Future Generations (2008) asserts that it is the question of capacity more than anything else that prevents communities from effective participation. Sources of community capacity building include establishing linkages with outside groups and introduction of technological innovations (Future Generations, 2008). In many countries, national governments delegate conservation responsibility to local levels where capacities do not match these responsibilities. There is no adequate literature explaining capacities at local levels to enable facilitation, institutionalization and transfer of appropriate technology to community organizations (Nagedre et al. 2005; Salam et al., 2006; Future Generations, 2008).

Organizations are created and rely on people to guide their institutional agenda, control systems and formal hierarchies to meet set goals and objectives. People come into organizations as leaders, managers or as mere workers. How organizations structure themselves and empower the people at different levels in these structures greatly influences how successful and sustainable their programs become. Therefore, for any meaningful cooperation to be realized between different hierarchies and across institutions there is a need to build local level institutions (Bawa et al. 2007; Tucker 2004; Future Generations, 2008). When institutions internal to communities are too weak, any cooperation with external institutions is most likely to fail in realizing conservation goals (Future Generations, 2008). Building community capacities takes time, sometimes as long 10 years (Baral \& Gautam, 2007; Future Generations, 2008). 
There are specific variables that characterize action situations at these levels of service production (Kiser \& Ostrom, 1982). Game theory is a powerful tool used by scholars to develop mathematical models that satisfy various situations and is used to predict expected behavior of rational individuals (Ostrom, 2010). The game theory parts of a game can be conceptualized as universal working parts of an action situation (Ostrom, 2010). The basic components of a game in this context provide a good foundation to build a common method for analyzing different action situations (Ostrom, 2010). In addition, the flow of activities, information sharing organizations and who receives what benefits and who pays what costs (Ostrom, 2011).

Conservation organizations

$\left(C_{o}\right)=\left(B_{1}, B_{2}, \ldots B_{n}\right),\left(C_{1}, C_{2} \ldots C_{n}\right), \ldots,\left(I_{1}, I_{2} \ldots I_{n}\right)$

Where $\mathrm{B}, \mathrm{C}, \ldots . . \mathrm{I}$ are conservation organizations while the $1,2, \ldots \mathrm{n}$ are conservation strategies

$$
\left(A_{s}\right)=\left(D_{1}, D_{2}, \ldots D_{n}\right),\left(E_{1}, E_{2}, \ldots E_{n}\right), \ldots\left(Y_{1}, Y_{2}, \ldots Y_{n}\right)
$$

All other stakeholders $=\mathrm{D}, \mathrm{E}, \ldots \mathrm{Y}$ with their conservation strategies

The $(1 \ldots \mathrm{n})$ are different strategies employed by conservationists to convince other stakeholders to support conservation. Other stakeholders may have their own strategies Yi. 
Figure 4: Stakeholder strategies

\begin{tabular}{|c||c|c|c|c|c|c|}
\cline { 2 - 7 } \multicolumn{1}{c|}{} & \multicolumn{6}{c|}{$\begin{array}{c}\text { Communities, local organizations, stakeholders } \\
\text { (implementers) }\end{array}$} \\
\hline $\begin{array}{c}\text { Conservationists, } \\
\text { donors or countries }\end{array}$ & B1,D1 & B2,D2 & B3,D3 & B4,D4 & B5,D5 & B6,D6 \\
\cline { 2 - 7 } & C1,E1 & C2,E2 & C3,E3 & C4,E4 & C5,E5 & C6,E6 \\
\hline
\end{tabular}

This is a simple game theory table showing how biodiversity stakeholders play conservation games. For instance when conservationists come forward with strategy (B1), other stakeholders counter that strategy (D1); when conservationists come up with strategy (B2), the other player counters with (D2). The winner of the game finally is the player who gets highest benefits. There are situations when there can be a tie.

\subsection{Institutional relationships}

The systems theory facilitated this study in examining the extent that the use of the Internet by national and local institutions. I analyzed both how programs are connected from global settings to the local level and vice versa in terms agency and organizational relationships. Specifically, I tried to find out the availability of information- sharing structures across all levels. Also, how global program initiatives bring about changes at national level and finally to local levels. This was necessary to try and capture policy links, legislation and various initiatives that may go into a programmatic relationship from the global to local levels between governments and conservation organizations. 
The degree of non-compliance at global level with the goals of the CBD cannot be explained if there is no proper understanding of implementation challenges at local and national government levels. There has to be a system of both information sharing and coordination. This study makes an argument that low level capacities or non-compliant with CBD goals is partly the lack of effective engagement of local communities where actual implementation takes place. Implementation of biodiversity protection programs is a complex process of bringing together a combination of events and institutions all the time. These events include the various international, regional and national conferences involving governments, NGOs and private sector corporations all meant to facilitate organizational learning through interaction and information sharing.

The Convention created two Information Technology (IT) sharing tools, the Clearing House Mechanism (CHM) and the Global Biodiversity Information Facility (GBIF). The CHM is a place for national governments and partners to openly share information as well as promote and facilitate technical scientific cooperation (www.cbd.int). The GBIF was created in 2001 to provide free and open access to global biodiversity data via the Internet to foster scientific research and development globally and to support public use of such data. International Conservation Non-Governmental Organizations also created the Biodiversity Conservation Information Systems (BCIS). The GBIF, CHMs and BCIS are structures that can be replicated by all members of the CBD.

Countries are encouraged to develop their own information sharing tools for effective engagement of local institutions, supporting collaboration and coordination of conservation programs (CBD, 2006). The CBD website (www.cbd.int) acts as the central 
node. However, the national information systems seem to face numerous organizational and institutional challenges.

\subsubsection{Biodiversity protection coordination problems}

Most of the problems facing biodiversity protection originate from insufficient information sharing structures as well as lack of data and coordination between different institutions and sectors. The work done at conferences simply sets the agenda and countries are left on their own to implement those agendas. There have to be clear systems providing universally-accessible data and information that is fully integrated at national levels and that link local implementation to international compliance. This need not be just a mere linkage but also a way to influence various authorities, facilitate the pursuit of conservation goals, and help in the allocation of resources, and measurement of outcomes.

The use of information technology has revolutionized the traditional methods of public involvement by leveraging the collective interests of society in order to design conservation solutions with communities at local levels (Lei, 2013). Various conservation organizations are able to establish relationships with both governments and local institutions, which get strengthened using the systems approach. The systems approach provides structures for stakeholder involvement with greater transparency, sufficient information and learning (Save, 2002). Table 11 below shows how the systems theory facilitates outcomes at local, national and international levels. 
Table 11: Functional systems levels

\begin{tabular}{|c|c|c|c|}
\hline & Shared meaning & Participation & Outcomes \\
\hline Local & $\begin{array}{l}\text { Public awareness } \\
\text { Public education, } \\
\text { Communication, } \\
\text { experimentation, } \\
\text { Institutionalization, } \\
\text { best practices, } \\
\text { common objectives }\end{array}$ & $\begin{array}{l}\text { Economic incentives, } \\
\text { regulations, } \\
\text { Decision-making, } \\
\text { Decision } \\
\text { implementation, } \\
\text { dissenting views } \\
\text { incorporated, change of } \\
\text { mental models }\end{array}$ & $\begin{array}{c}\text { Empowerment, } \\
\text { implementation, internal } \\
\text { consistency, feedback } \\
\text { mechanisms, dialogue, } \\
\text { problem definition, } \\
\text { consensus, accepted } \\
\text { regulations, available } \\
\text { options, knowledge } \\
\text { integration, community } \\
\text { transformation, } \\
\end{array}$ \\
\hline National & $\begin{array}{l}\text { Building public } \\
\text { trust, Stakeholder } \\
\text { priorities, causes of } \\
\text { problems, seeing } \\
\text { actions and } \\
\text { systematic effects, } \\
\text { Policy options and } \\
\text { boundaries }\end{array}$ & $\begin{array}{l}\text { Problem identification, } \\
\text { problem focus, feedback } \\
\text { tools for learning, } \\
\text { intervention tools, } \\
\text { information sharing } \\
\text { tools, }\end{array}$ & $\begin{array}{l}\text { Documentation and } \\
\text { analysis, goals, plans, } \\
\text { reports, data, policy } \\
\text { levers, points of } \\
\text { intervention, greater } \\
\text { transparency, clarity of } \\
\text { limitations, strong } \\
\text { regulations }\end{array}$ \\
\hline International & $\begin{array}{c}\text { Conferences, } \\
\text { planning, reporting }\end{array}$ & $\begin{array}{l}\text { Information sharing, } \\
\text { CHMs, document } \\
\text { depository, learning }\end{array}$ & $\begin{array}{l}\text { Improved coordination, } \\
\text { improved management, } \\
\text { more consensus, }\end{array}$ \\
\hline
\end{tabular}

Table 11 above shows activities that have to be undertaken at different levels in society in order to develop an effective conservation system. The local, national and global levels require specific activities to disseminate information so as to improve the shared meaning in conservation and participation. It is out of the level of participation with clear outcomes that there can be a working system.

$G_{c}=S_{m}+P_{n}+D_{a}$ 15

Where: $G_{c}=$ Global compliance

$$
S_{m}=\text { Shared meaning }
$$




$$
\begin{aligned}
& P_{n}=\text { Participation } \\
& D_{a}=\text { Data }
\end{aligned}
$$

Stave (2002) argues that traditional methods used to involve the public in general such as information campaigns, facilitated discussions and public hearings frequently leave stakeholders dissatisfied. These traditional methods are essentially a one-way communication from experts to members of the public with information that is not well explained how it meets community interests. The key assumption made here was that the use of information technology (IT) will facilitate the engagement of multiple stakeholders to predictably reduce implementation barriers and increase outcomes. The following themes were identified and used to explain the extent information systems facilitate compliance at all levels: 1) Shared meaning 2) Participation; and 3) Data. These themes provided the coding references which were guided by the links to all types of information and data found in the CBD and national CHMs.

Quantitative measurement for these themes were generated from the number coded references to each theme and were used to rank how successful systems approach has contributed to biodiversity protection and compliance with CBD goals.

\subsubsection{Stakeholder shared meaning in biodiversity management}

Environmental resources are public goods and therefore environmental policies are part of the public interest issues. Many of the problems that arise in conservation of biodiversity are not because there is no knowledge but rather because of lack of shared meaning by all stakeholders in the system (Stave, 2002). Environmental protection policy 
decisions straddle various societal values. There are no set standards on how to assign value to different policy outcomes in different settings. Stakeholders in biodiversity have differing interests and competing goals in terms of their specific needs. Information technology has facilitated behavioral changes in information-enabled society and has infused both learning and understanding (Lei, 2013).

Public policies continue to evolve over a long period of time after they are legislated. Sometimes, these policies are often in a state of self-contradiction and often end up sending conflicting signals to society (Friedrich \& Mason, 1940). If there is no clear and shared meaning, implementation in this kind of relationships will be difficult if not impossible. For most individuals, Organizations and Corporations, the pursuit private interest is the upmost priority, making biodiversity problems secondary.

\subsubsection{Stakeholder participation in biodiversity management}

Greater participation by more stakeholders improves the quality of environmental decision-making as a result of integration of local, administrative and scientific knowledge (Reed, 2008). Participation in the execution and implementation by many stakeholders and administrative arm of governments renders policy a continuous process constantly in a state of flux making it almost impossible to state with precision what the policy is at a specific time in a specific policy environment (Pressman \& Wildavsky, 1984). In conservation, three types of participation are identified (Reed, 2008): i) research driven ii) development driven iii) planner-centered and iv) people-centered. Planner-centered participation focuses more on outcomes while people-centered is 
concerned with empowering stakeholders to define and meet their environmental needs (Reed, 2008).

\subsection{Information sharing and communication tools}

It is unclear exactly how individuals, communities and local governments are experiencing biodiversity protection programs at local levels. The degree of noncompliance at the global level with the goals of the Convention on Biodiversity (CBD) can only be explained when there is a good understanding of implementation challenges at the local and national government levels. My argument here is that partly the problem is the lack of effective engagement of local communities where actual implementation takes place. The Convention uses two Information Technology (IT) sharing tools to engage governments, the Central Clearing House Mechanism and the Global Biodiversity Information Facility. Countries are encouraged to develop their own information sharing tools for effective engagement of local institutions. The CBD website (www.cbd.int) acts

as the central node. There should be national nodes in every country that connect to local level implementation.

Table 12 below shows responses regarding how countries prioritize national interest, how individual make decisions based on immediate benefits and the extent that private organizations look to profits as their priority. Most people from across the world agree that biodiversity conservation is not a priority across government and private sector institutions, there are more people that agree as can be seen across D and E in table 11 above. This shows how biodiversity protection means different to different sectors. 
Table 12: The extent to which biodiversity protection is given priority

\begin{tabular}{|l|l|l|l|l|l|l|l|}
\hline Responses & Rank & $\begin{array}{l}\text { Western } \\
\text { Europe }\end{array}$ & $\begin{array}{l}\text { Eastern } \\
\text { Europe }\end{array}$ & Asia & $\begin{array}{l}\text { Latin } \\
\text { America }\end{array}$ & Africa & $\begin{array}{l}\text { Middle } \\
\text { East }\end{array}$ \\
\hline \multirow{4}{*}{$\begin{array}{l}\text { National interests often } \\
\text { take precedence. }\end{array}$} & $\mathrm{A}$ & 8 & 6 & 18 & 6 & 0 & 0 \\
\cline { 2 - 8 } & $\mathrm{B}$ & 2 & 6 & 35 & 13 & 8 & 20 \\
\cline { 2 - 8 } & $\mathrm{C}$ & 11 & 22 & 30 & 13 & 4 & 0 \\
\cline { 2 - 8 } & $\mathrm{D}$ & 30 & 22 & 137 & 23 & 21 & 40 \\
\cline { 2 - 8 } & $\mathrm{E}$ & 51 & 39 & 254 & 39 & 67 & 40 \\
\hline \multirow{4}{*}{$\begin{array}{l}\text { Individuals tend to make } \\
\text { decisions based on }\end{array}$} & $\mathrm{A}$ & 3 & 6 & 30 & 3 & 0 & 0 \\
\cline { 2 - 8 } & $\mathrm{B}$ & 6 & 0 & 45 & 3 & 4 & 20 \\
\cline { 2 - 8 } & $\mathrm{C}$ & 7 & 0 & 32 & 3 & 4 & 0 \\
\cline { 2 - 8 } & $\mathrm{D}$ & 36 & 39 & 181 & 13 & 33 & 20 \\
\cline { 2 - 8 } & $\mathrm{E}$ & 48 & 50 & 199 & 71 & 58 & 60 \\
\hline \multirow{4}{*}{$\begin{array}{l}\text { Economic profits of } \\
\text { organizations or regions } \\
\text { are prioritized and } \\
\text { environmental } \\
\text { considerations are not }\end{array}$} & $\mathrm{A}$ & 2 & 6 & 44 & 3 & 0 & 0 \\
\cline { 2 - 8 } & $\mathrm{B}$ & 7 & 0 & 61 & 0 & 0 & 20 \\
\cline { 2 - 8 } & $\mathrm{C}$ & 2 & 6 & 37 & 0 & 4 & 0 \\
\cline { 2 - 8 } & $\mathrm{D}$ & 31 & 28 & 147 & 16 & 17 & 20 \\
\cline { 2 - 8 } & $\mathrm{E}$ & 57 & 56 & 206 & 77 & 75 & 60 \\
\hline
\end{tabular}

Source: Asahi Glass Foundation

A: Strongly disagree B: Somewhat disagree C: Neither (I don`t know) D: Somewhat agree E: Strongly agree

Table 13 below puts together data to show how national dynamics and influence global management of biological resources. At national level, decisions are heavily influenced by political, business and organizational interests and therefore the needs of the whole society become secondary as At the international level, decision are made by consensus which often leans more to what countries want. 
Table 13: Influence of national decisions on global conservation

\begin{tabular}{|c|c|c|c|c|c|c|c|}
\hline Responses & Rank & $\begin{array}{l}\text { Western } \\
\text { Europe }\end{array}$ & $\begin{array}{l}\text { Eastern } \\
\text { Europe }\end{array}$ & Asia & $\begin{array}{l}\text { Latin } \\
\text { America }\end{array}$ & Africa & $\begin{array}{l}\text { Middle } \\
\text { East } \\
\end{array}$ \\
\hline \multicolumn{8}{|l|}{ National Systems } \\
\hline \multirow{5}{*}{$\begin{array}{l}\text { National decision-making } \\
\text { systems prioritize national } \\
\text { interests; policies that } \\
\text { optimize the whole are } \\
\text { become secondary. }\end{array}$} & $\mathrm{A}$ & 4 & 0 & 16 & 14 & 0 & 0 \\
\hline & $\mathrm{B}$ & 7 & 0 & 17 & 10 & 5 & 30 \\
\hline & $\mathrm{C}$ & 7 & 13 & 36 & 5 & 5 & 30 \\
\hline & $\mathrm{D}$ & 40 & 31 & 203 & 33 & 32 & 0 \\
\hline & $\mathrm{E}$ & 42 & 56 & 212 & 33 & 58 & 60 \\
\hline \multirow{5}{*}{$\begin{array}{l}\text { National decisions influenced } \\
\text { by political, business, and } \\
\text { organizational interests and do } \\
\text { not reflect the will of the } \\
\text { public, who shoulder the } \\
\text { environment. }\end{array}$} & $\mathrm{A}$ & 2 & 0 & 12 & 10 & 0 & 0 \\
\hline & B & 5 & 0 & 24 & 0 & 0 & 0 \\
\hline & $\mathrm{C}$ & 11 & 13 & 40 & 10 & 11 & 0 \\
\hline & $\mathrm{D}$ & 38 & 38 & 173 & 14 & 32 & 20 \\
\hline & E & 44 & 50 & 240 & 62 & 58 & 80 \\
\hline \multirow{5}{*}{$\begin{array}{l}\text { Changes in national policy } \\
\text { face great resistance (inertia), } \\
\text { and as } \\
\text { such it tends to stay with } \\
\text { business as usual. }\end{array}$} & A & 4 & 0 & 13 & 5 & 0 & 0 \\
\hline & $\mathrm{B}$ & 7 & 6 & 32 & 14 & 11 & 0 \\
\hline & $\mathrm{C}$ & 11 & 25 & 80 & 0 & 11 & 0 \\
\hline & D & 24 & 38 & 220 & 38 & 32 & 20 \\
\hline & $\mathrm{E}$ & 55 & 31 & 147 & 43 & 47 & 80 \\
\hline \multicolumn{8}{|l|}{ International Systems } \\
\hline \multirow{5}{*}{$\begin{array}{l}\text { International organizations } \\
\text { like the U.N. are affected by } \\
\text { the will of countries, and do } \\
\text { not } \\
\text { optimize the whole. }\end{array}$} & $\mathrm{A}$ & 2 & 0 & 11 & 10 & 5 & 0 \\
\hline & $\mathrm{B}$ & 9 & 0 & 26 & 0 & 0 & 0 \\
\hline & $\mathrm{C}$ & 7 & 19 & 46 & 10 & 5 & 0 \\
\hline & $\mathrm{D}$ & 18 & 25 & 150 & 38 & 47 & 40 \\
\hline & $\mathrm{E}$ & 84 & 86 & 210 & 43 & 42 & 60 \\
\hline \multirow{5}{*}{$\begin{array}{l}\text { Voting system at the U.N. } \\
\text { with its adherence to the } \\
\text { fundamental } \\
\text { principle of unanimous } \\
\text { consent, makes decision- } \\
\text { making difficult. }\end{array}$} & $\mathrm{A}$ & 2 & 6 & 21 & 5 & 0 & 0 \\
\hline & $\mathrm{B}$ & 4 & 6 & 38 & 5 & 0 & 20 \\
\hline & $\mathrm{C}$ & 9 & 13 & 72 & 14 & 0 & 20 \\
\hline & $\mathrm{D}$ & 22 & 38 & 191 & 33 & 47 & 0 \\
\hline & $\mathrm{E}$ & 84 & 38 & 107 & 38 & 53 & 60 \\
\hline \multirow{5}{*}{$\begin{array}{l}\text { International organizations } \\
\text { like the U.N. are not provided } \\
\text { enforcement powers or other } \\
\text { forceful methods of } \\
\text { coordination. }\end{array}$} & A & 4 & 0 & 13 & 14 & 0 & 0 \\
\hline & B & 2 & 13 & 45 & 10 & 5 & 0 \\
\hline & $\mathrm{C}$ & 9 & 13 & 61 & 0 & 5 & 0 \\
\hline & $\mathrm{D}$ & 27 & 25 & 185 & 24 & 32 & 40 \\
\hline & $\mathrm{E}$ & 58 & 44 & 136 & 48 & 58 & 60 \\
\hline \multirow{5}{*}{$\begin{array}{l}\text { Systemic and organizational } \\
\text { reforms are needed, but have } \\
\text { not been implemented. }\end{array}$} & A & 4 & 0 & 4 & 10 & 0 & 0 \\
\hline & B & 5 & 13 & 46 & 5 & 5 & 0 \\
\hline & $\mathrm{C}$ & 29 & 19 & 80 & 5 & 32 & 0 \\
\hline & $\mathrm{D}$ & 36 & 38 & 207 & 57 & 21 & 60 \\
\hline & $\mathrm{E}$ & 25 & 31 & 107 & 19 & 42 & 40 \\
\hline
\end{tabular}

Source: Asahi Glass Foundation 


\subsubsection{Local and national information sharing capacity}

Using NVivo10, a content qualitative analysis of NBSAPs, national reports, analysis of information obtained from government, international and local organizations websites was done. This was mainly to see the key emerging conservation themes and the contexts in which various key words are used. A word frequency was done to produce a tag cloud of the most commonly used words in each of the documents and compare the messages being conveyed. Specifically, this analysis set out to identify the input from local levels, cooperation between all sectors, decision making and the types of decisions made, information sharing and communication tools.

Institutions put in place for purposes of biodiversity protection exist at multiple levels. Policies drawn at global level are meant for adoption by national governments. Once these policies are modified and adopted to the national level, they have to be passed down to local levels for implementation. There has to be a shared meaning of these policies at all levels and across all institutions for them to be accepted for implementation. A shared meaning of rules, regulations and policies help to strengthen national enforcement of international treaties. As long as international treaties lack sovereign authority to enforce laws, they have very little impact at implementation levels (Hathaway, 2005). Shared meaning in this hypothesis means going beyond participation to place externally generated goals and objectives in the context of local needs.

This is where the role of the state apparatus becomes central, as it is the responsibility of the government to provide direction, legitimization and information to its citizens (Adams \& Hutton, 2007). One of the claims made by biodiversity protection 
experts is the contribution of biodiversity protection to poverty alleviation. How poverty alleviation is viewed at both national and local levels from the perspective of biological resources protection remains controversial. While there are many people who strongly believe that biodiversity protection constrains development, there are many that believe it is not and is therefore a good tool for poverty alleviation (Turner et al., 2012). There are also many people that believe in sustainable use argument in biodiversity protection while there are some that argue that sustainable use argument is presented to postpone the conservation problems (Porter \& Brown, 1991).

There is a clear lack of sufficient analysis and information to inform decision makers and policy on the contribution of biodiversity protection in social and economic development (Turner, 2012). This study therefore tried to uncover and explain the shared understanding using information from the existing national plans, reports and the literature. The CBD goals and emerging conservation policies at the local levels in the light of national and global conservation agendas require to be carefully bridged.

Examining the existing literature points toward a clear lack of shared understanding in the language used, policy processes and sharing the benefits from biodiversity. The role of government is to create binding regulations that mandate all stakeholders to act responsibly in the course of their business towards environmental protection. Governments build structures and networks that recruit expertise needed for effective intervention on issues that are considered most important (Stampfer et al., 2010). At the same time, governments have also been known to play what is known as symbolic politics (Davidson, Frickel \& Edelman, 1964), where countries develop rhetorical strategies designed to manufacture and reinforce public's convictions that 
biological resources protection is being competently addressed when in fact the opposite is true. Developments over the last two decades of trying to implement the goals of the $\mathrm{CBD}$ reveal some major disconnection between what is said and what is actually being implemented at the local levels (Davidson \& Frickel, 2004).

Biodiversity protection needs to be legitimated across all sectors with relevant rules and laws supported by prevailing social norms, traditional, charismatic or bureaucratic leadership (Weber, 1968). Sound organizational ethics where biodiversity protection interests take center stage can only thrive where all stakeholders share the meaning and are guided through use strong tougher enforcement mechanisms (Oliver, 1991).

\subsubsection{Local input to national policy development}

There is overreliance by national institutions on international experts to develop domestic policies and also on international non-governmental organizations (NGOs) in the implementation of conservation programs worldwide (Basurto, 2008). International experts on policy making do not often understand local conditions. Although NGOs have been portrayed as providing better avenues for more participation and less bureaucratized approaches that allow the meeting peoples' needs with greater efficiency and at lower costs, recent studies have shown that this is not always true (Chapin 2004; Igoe and Kelsall 2005; Basurto, 2008).

It has also been established that international NGOs cannot be classified as part of the civil society as they are not membership based, governed or financed and therefore 
cannot play a representative role (Abramson 1999; Gaventa 1999; Nelson 1995; Fowler, 2000). This leaves governments as key players in facilitating more participation and thus input from local communities. Although partnerships with the international community are extremely important for purposes of accessing financial resources and scientific information (Basurto, 2008), best policies are formulated using local institutions.

\subsection{Opportunity costs of biodiversity protection}

According to the global Footprint Network, wastes generated from the consumption of natural resources can be measured, quantified and tracked by using the amount of land that is required to maintain those (Borucke et al. 2012). Human demand is expressed in the form of an ecological footprint on global natural resources where supply is compared to demand based on biological hectares available to every person. When demand exceeds supply, biological resources start to be degraded. Compliance measurement should therefore include the difference between available biological resources and the level of consumption/use in each country. Countries that are consistently in a biological resources deficit should be classified least complied regardless of their quality of planning and reporting. Minimum level of compliance should be defined starting from a situation when the supply of biological resources is either equal or greater that consumption as expressed in the equation below.

Opportunity costs arise from restrictions imposed on the use of land, forest and water resources that are set aside for conservation purposes. These restrictions may involve stopping communities from converting land to the use of their choice or are

allowed limited acceptable usage. Communities therefore forfeit all future streams of 
income from the land that is restricted (Kaphengst et al. 2011; Chomitz, 2005). Restrictions on land use can be measured using foregone income. However, when land is converted to serve industry and manufacturing facilities that pollute the environment, opportunity costs are on the side of the environment. Estimating such costs is extremely difficult and opportunity costs in biodiversity degradation are this type of costs. Industry has been known to use environmental resources that come from biodiversity and dispose off waste to the environment at no cost.

Opportunity costs $\left(O p_{c}\right)$ of biodiversity protection $(\$ / \mathrm{ha})$ were estimated based on total costs $\left(T_{c}\right)$ of conservation less external funding $\left(E_{f}\right)$ and also less national budgetary allocation to conservation. If the final answer is positive, owners of biological resources would be expected to incur that cost. If the final answer is negative, the cost of conservation is fully covered and communities or private sector organizations will not incur opportunity costs $\left(O P_{c}\right)$.

$$
O p_{c}=\left(T_{c}-E_{f}-B_{a}\right)
$$

For each country, total opportunity costs $\left(T O P_{c}\right)$ will be the number of hectares in biological deficit/surplus times the value of positive opportunity cost. For countries in biodiversity deficit, opportunity cost estimates was based on complete conservation of the number of hectares in deficit. In other words, an equivalent of the total number of hectares in deficit need to brought into outright protection in the same country, if not cooperate and support such conversion in another country. For all other countries, a partial conversion was used to estimate opportunity costs. This is because unless these 
countries continue to pay attention to conservation, they are most likely to also end up in biodiversity deficit.

$$
T O P_{c}=\left(B R_{\text {available }}-B R_{\text {consumed }}\right) O P_{c}
$$

\subsubsection{Opportunity cost estimation}

Estimating opportunity costs of protecting global biodiversity is necessary for appropriate planning, fundraising and implementation of targeted conservation strategies. However, there exists no sufficient biodiversity cost data on leading to conservation organizations promoting conservation strategies with no costs and budgets (Frazee et al., 2003). Some of the information needed for opportunity cost estimates includes lost revenue arising from foregone use of natural resources, as well as costs of capacity building for local conservation institutions. Data on foregone opportunity costs of biodiversity protection does not exist.

Based on available biological resources measured in hectares and level of use for each country, opportunity costs were estimated in this research.

Opportunity $=$

\{Available biological Resources - Level of use of biological Resources\} X Cost per hectare.

$$
O p=\left(A_{b r}-U_{b r}\right) X C_{p h}
$$

\subsubsection{Opportunity cost compensation mechanism}


One of the objectives of this research was not really to estimate the opportunity costs but rather to show that it needs to be the core component in defining compliance with the CBD goals. Current consumption and degradation of the quality of biodiversity far outstrips available quantity and quality of biological resources (Myers et al., 2000). The gap between funding opportunities and biodiversity conservation targets in most areas is rather growing wider than closing (Kaphengst et al., 2011). Increasing financial resources is critical to successful conservation but it will require innovative approaches such as the inclusion of opportunity costs in conservation efforts (Kaphengst et al., 2011). Accurate estimates of opportunity costs and total costs of conservation leads to a more focused approach to the areas of the greatest need thus enabling informed decision making and efficiency in the allocation of financial resources (Kaphengst et al., 2011).

Protecting biodiversity is always in conflict with human activities and economic development as unless human activities are restricted, they lead to habitat loss, fragmentation and loss of biodiversity. Restricting human activities using only legislative, legal or physical restrictions leaves people worse off economically (Bull et al., 2013). There is therefore the need for appropriate compensation mechanisms to people for lost economic opportunities if they get subjected to any restriction in the way they want to use natural resources to meet their basic needs.

\subsubsection{Types of compensation schemes}

There are two types of compensation mechanisms (Plumb et al., 2012; Kate et al., 2011): i) opportunity cost compensation and ii) biodiversity offset schemes. Opportunity cost compensation is an equity based approach that applies to people directly. It is a 
mechanism where those who benefit from environmental services should bear the burden of paying those who would incur some sort of cost to provide those services (Atisa et al., 2014). Offset schemes are slightly different from opportunity cost approach. Offset schemes are designed to link biodiversity conservation with development activities with an aim of improving ecological outcomes alongside development (Bull et al., 2013).

According to Bull et al. (2013), compensation to offset opportunity costs as well as offset schemes helps to link conservation with many other sectors that negatively impact upon biological resources with sectors that protect these resources. There are 45 countries globally that now have mandatory opportunity cost compensation legislation for biodiversity and compensation mechanism are being developed in another 27 (Bull et al. 2013; Madsen et al. 2011). Although compensation approach has been conceptually attractive, it comes with numerous challenges at implementation stages (Bull et al. 2013; Gibbons \& Lindenmayer, 2007; Bekessy et al., 2010).

Once opportunity costs are determined, compensation to offset conservation costs otherwise known as foregone benefits of use of biodiversity can be more targeted to both people and specific resources. This can be seen in situations where people get paid for agreeing not to use a natural resource or when a piece of land is purchased for conservation purposes (Kaphengst et al., 2011). This is necessary if it is expected that such use would exceeds the ecological boundary of that specific place.

\subsubsection{Biodiversity Offset Schemes}

Biodiversity offset schemes are compensation mechanisms designed to maintain or improve environmental values despite the negative impact outcomes as countries 
pursue development (Bull et al. 2013; Kiesecker et al. 2009; Lindenmayer, 2007). This literature argues that biodiversity offsets address negative environmental impacts after efforts to minimize impacts and appropriate mitigation actions have been implemented. There are four steps that lead to biodiversity offsets: avoid, minimize, restore and offset or mitigate. These four steps help to balance negative environmental impacts of development with positive environmental gains to maintain or improve environmental outcomes (Bull et al. 2013; Kiesecker et al. 2009).

Biodiversity offset schemes stand to benefit development industries, the government and conservation efforts. Industries with offset schemes are more likely to be granted license for new operations with little or no resistance from the public. Offsets provide a mechanism through which government regulators encourage industry to contribute to conservation thus enabling broader, deeper and large-scale conservation (Kiesecker et al., 2009). Despite paper and policy compliance, as long as industrial development continues to erode biological resources, countries need to re-examine their definition of compliance. It is important that environmental impacts of development are balanced by no net-loss of biodiversity.

\subsection{Decision making in biodiversity protection}

Decision making can make significant contribution to effective policy formation when a combination of expert knowledge and ordinary citizens work together. Policy formulation and problem-solving by public administrators draws from various criteria and rules as a basis for choosing from many alternatives (Lindblom, 1959). Grounds for decision making in public organizations are based on partisan mutual adjustments, 
incrementalism and value clarification (Lindblom, 1959). No one organization or level within institutions is able to produce optimal decision making outcomes. National policy for biodiversity protection needs local inputs as well as international inputs for decision outcomes that would move a country toward higher compliance with the CBD goals.

Decision making can be seen as a pendulum that swings across a broad range of interests, values and hierarchies in and outside of organizations. Best decisions are made after an extraordinary inquiry into relative values held by staff members and the society to settle at the one that offers greatest value (Lindblom, 1959). Although decision making is the function of the executive in an organization (Barnard, 1938), selection of available and best alternatives and values needed to attain a specified objective calls for allowance for a great deal of inquiry from lower levels and also other stakeholders (Barnard, 1938; Mockler, 1968).

There are many big and influential organizations whose activities have direct profound negative effects on the environment but have not been engaged constructively in integrating environmental impacts into their business decisions (WWF, 2005). Organizations are guided by economic self-interest to the extent that they are not likely to adopt biological diversity protection initiatives if these do not meet their own profitability criteria (Regan, 1998). Corporations focus more on efficiencies required to maximize shareholder value where the key drivers of organizational behavior are competitive pressures, market demand, and supply issues (Banerjee, 2008). Conservation decision need to tap into private and other stakeholder organizations so as to make policies that take into account all interests. 
Organizational control, decision making and planning for specified objectives is best achieved by combining a diverse set of specializations and values from within and outside of the organization. Organizations are best managed when they are viewed as a form of information network with the flow of information providing decision makers at different management levels with information needed to make decisions of all types (Mockler, 1968). Decisions are made in a dynamic and interactive environment. The systems approach facilitates for more comprehensive information, faster, at the point and in the form it is needed to make better decisions (Mockler, 1968). Use of systems theory in processing and transmitting information makes organizations aware of their internal and external environment leading to consideration of political and social values in their decision making process (Mokler, 1968).

Street-level bureaucrat theory argues for allowing more discretionary decision making to low level implementers of public policies. Public organizations should seek contribution from street-level bureaucrats when formulating policies. Changing regulations that affect the way street-level bureaucrats do their business without their input to satisfy a section of the policy interests can easily run into conflict with the intended policy objectives. Discretionary decision may look insignificant, but collectively they determine the texture of the relationship between the citizens and the government (Watson, case 2). Policies should be adopted after taking into account regard to the existing sum of human knowledge concerning all aspects of biodiversity conservation and existing preferences in the community. 


\section{CHAPTER IV}

\section{DATA ANALYSIS AND RESULTS}

\subsection{Data analysis and determination of compliance}

Chapter four was developed in line with the four hypothesis formulated to guide this study and is divided into five sections. The first section presents the qualitative analysis of key findings and the specific internal capacities within countries. The second section presents the analysis of critical factors that influence compliance and implementation of international environmental treaties. This is then followed by compliance analysis using the score card methodology on NBSAPs and national reports. Compliance analysis by way of cooperative games follows, and the last section examines opportunity costs of conservation.

\subsection{Introduction}

Both qualitative and quantitative methodologies were employed to examine compliance. Specifically, qualitative methods were used to try and define compliance as is already defined but with more details in the form of numbers. The qualitative compliance findings were translated and scored on a scale of 0 to 100 percent against each criterion that was identified in chapter 3. Although it is the responsibility of each country to conserve biodiversity within its jurisdiction, the universal nature of biodiversity requires cooperation across countries. To examine such cooperation across 
countries, game theory approach was used. In addition, effective implementation of any plan requires full participation of all stakeholders. Systems theory was used to analyze how various countries, conservation organizations and communities work together.

When cooperation does not work, stakeholders involved resort to consensus building. Hove (2004) argues that participation is a continuum between consensusoriented and compromise-oriented negotiation processes aimed at making adjustments to stakeholder interests. Emphasis on consensus obscures adjustments that stakeholders make in conservation decisions (Colyvan et al. 2011). I argue that participation need to be designed so that rather than have stakeholders make adjustments to their interests, which eventually leads to less than optimal decisions, they need to cooperate and agree on the best collective outcome from a set of available strategies.

Game theory was employed to show the differences on compliance outcomes between when countries cooperate and when they go through consensus to agree to use specific conservation strategies. Compliance levels developed based on the 20 criteria were regarded as strategies because the criteria used to determine compliance essentially show how strong a country is in implementing specific protection initiatives. Putting figures to compliance levels has not been tried by any study before. In this chapter, therefore, I have further developed methods that were proposed in the previous chapter to be able to see how countries comply at various levels and what should go into compliance. 


\subsection{Theoretical findings}

The use of game and systems theories was ideal so as to distinguish the idea of consensus building and cooperation. There can be major differences when decisions are made under a managed consensus and when stakeholders cooperate. Consensus is always never attained and, therefore, stakeholders have to find compromises (Hove, 2004). In the coordination of various biodiversity conservation activities to improve overall compliance, a consensus building model is not sufficient. There are possibilities that some stakeholders would lose out while others gain.

The systems theory on the other hand was used in trying to elaborate how government and various organizations identify problems and the nature of solutions developed to address each specific problem. Analytical findings from both government and conservation organization activities were compared to determine similarities and differences. It was expected that the more similarities, the higher the compliance outcomes and vice versa.

The aim of the CBD is to create a shared network of all countries to improve global compliance simultaneously without making any one country worse off. Various combinations of strategies that were assumed if effectively addressed in planning will increase compliance payoffs without reducing the payoffs of participating countries were identified. 


\subsection{Qualitative Analysis of NBSAPs, National Reports and NCHMs}

The use of qualitative analysis of key documents provided the best way to see how compliance and implementation is done by countries. Various passages from the plans and national reports were examined to see specific ideas that these documents were conveying. Passages with similar ideas, phenomenon, or activities were grouped together into nodes. The primary documents that were used to gather relevant implementation and compliance data were the National Biodiversity Strategy Action Plans (NBSAPs), the fourth national progress report submitted to the $\mathrm{CBD}$ and online information found on the websites of international and local organizations. The study used NVivo10 for qualitative document analysis to search, query and code specific texts with information referring to specific conservation issues. The key questions that guided coding of texts from these documents were: What is going on? What are countries doing? What are the documents telling us? (Gibbs, 2007).

A query to identify the most commonly used words was conducted. Most of the conservation words found to be commonly used were searched to see the context or exact information they were conveying in the passages where they appeared. A coding process to put similar passages together into a node was done. From these nodes, various categories and conservation themes started to emerge. Codes are essence capturing and essential elements of a research story that when clustered together according to similarity facilitate to see connections (Saldan, 2013). 
For purposes of obtaining information regarding local level implementation, codifying and categorization was done to re-group and link specific themes to local implementation, national policies and global strategies. A third cycle of coding to generate conservation strategies, policies, collaboration, and stakeholder participation at various levels of conservation structures was conducted. Queries using key words to see emerging themes (Saldana, 2013) were run. Emerging themes and information patterns were tabulated for easier conceptualization.

The key theme that kept emerging from various plans and reports that connected many aspects of conservation was the word "capacity". There is either too little capacity within countries to contribute towards meaningful compliance or too much capacity in a few countries to continue to overexploit biological resources beyond levels where they can replenish themselves.

Table 14: Frequency of use of the word capacity by key documents

\begin{tabular}{|l|l|l|l|}
\hline & Country & NBSAP & $4^{\text {th }}$ National Report \\
\hline 1 & Brazil & 0 & 71 \\
\hline 2 & Jamaica & 55 & 44 \\
\hline 3 & Mexico & 12 & 59 \\
\hline 4 & Canada & 13 & 49 \\
\hline 5 & UK & 26 & 36 \\
\hline 6 & Netherlands & 16 & 12 \\
\hline 7 & Switzerland & 12 & 19 \\
\hline 8 & Poland & 4 & 10 \\
\hline 9 & Kenya & 13 & 76 \\
\hline 10 & South Africa & 61 & 118 \\
\hline 11 & D R Congo & 9 & 22 \\
\hline 12 & Ghana & 13 & 49 \\
\hline 13 & India & 40 & 87 \\
\hline 14 & Jordan & 45 & 64 \\
\hline 15 & Indonesia & 55 & 37 \\
\hline 16 & Australia & 29 & 42 \\
\hline
\end{tabular}

Source: estimated using information from the Convention on Biodiversity Website 
This section explores various contexts in which the word "capacity" is used to bring an understanding of exactly how various countries are prepared in both the formulation and implementation of biodiversity conservation programs.

The use of the word "capacity" was examined in the context of national and local supportive capacities from existing plans and national reports. Context analysis of the word "capacity" to see how it was used and what it meant when used in various contexts. A country's capacity in biodiversity conservation takes into account all instruments necessary to increase a country's ability to carry out conservation work, whether equipment, information, knowledge or training (Kenya $4^{\text {th }}$ National Report, 2006).

The Kenya $4^{\text {th }}$ National Report (2006) argues that capacity building is a central element in the implementation of biodiversity goals as well as in aiding in the successful design and implementation of conservation goals at all levels and sectors. The specific objectives of NBSAPs include the strengthening of national and local institutions, and community capacity for sustainable conservation of biodiversity, including the safe utilization of biotechnology (CBD, 2002). Inadequate resources and capacity constraints slow implementation of conservation plans. The breadth and depth of all types of capacities available would give an indication to how successfully the goals of biodiversity protection are being implemented.

Tables $15 \mathrm{a}$ through $15 \mathrm{~d}$ present summaries of the contexts in which the word "capacity" was used by NBSAPs and country reports. 


\subsubsection{NBSAPs and the $4^{\text {th }}$ National Report for North and Latin America}

Table 15a: Context in which the word capacity is used - Americas

\begin{tabular}{|c|c|c|}
\hline Country & NBSAP & $4^{\text {th }}$ National Report \\
\hline Brazil & 0 & $\begin{array}{l}\text { Capacity building }- \text { Humans, } \\
\text { Institutional, Funding, Technological, } \\
\text { Ecosystems, } \\
\text { Communication, Conservation and } \\
\text { Infrastructure }\end{array}$ \\
\hline Jamaica & $\begin{array}{l}\text { Local communities, Resources management, } \\
\text { National institutions, Technical, Scientific, } \\
\text { Regenerative, Carrying capacity, Risk } \\
\text { assessment, Knowledge, Taxonomy, Alien } \\
\text { Species, Human, Climate Change, Law } \\
\text { enforcement, Management, Financial assistance, } \\
\text { implementation, Research \& Training, Capital } \\
\text { resources, Planning, National, Lead agencies, } \\
\text { Living Modified Organisms (LMOs), Fisheries } \\
\begin{array}{l}\text { Division, Monitoring, Biosafety, CHMs, } \\
\text { Biological data, Protected Areas, Resource } \\
\text { managers }\end{array}\end{array}$ & $\begin{array}{l}\text { Capacity building }- \text { Assessments, } \\
\text { carrying, Local, Ecosystems, Financial, } \\
\text { Technical, Planning, Implementation, } \\
\text { Scientific, Institutional, Conservation, } \\
\text { Research, Coordination, Human, } \\
\text { Marine and Recreational areas and } \\
\text { Planning }\end{array}$ \\
\hline Mexico & $\begin{array}{l}\text { Increased human, Institutional and financial } \\
\text { capacity, Information availability, decision } \\
\text { making, control, monitor and mitigate and local } \\
\text { capacities }\end{array}$ & $\begin{array}{l}\text { Human, People, Scientific, Research, } \\
\text { Budgetary, Institutional, Technological, } \\
\text { Monitoring, Decision making, local, } \\
\text { funding, analysis, }\end{array}$ \\
\hline Canada & $\begin{array}{l}\text { National and international data base, Carrying } \\
\text { capacity, Earth, Ever-growing demand, } \\
\text { Ecological carrying capacity, Management, } \\
\text { Museums, Institutions, Data \& Information, } \\
\text { Dissemination, Economics \& Ecological } \\
\text { capacity, Support to other countries, LDCS, } \\
\text { Planning, Implementation, Shared responsibility }\end{array}$ & $\begin{array}{l}\text { Adaptive, Ecosystems, Agricultural } \\
\text { lands, Wildlife, Assessment, Response, } \\
\text { Marine life, Economic, Capacity } \\
\text { building, Carrying, Development, } \\
\text { Human, Reporting, Different levels of } \\
\text { government, Agencies }\end{array}$ \\
\hline
\end{tabular}

Table $15 \mathrm{~b}$ below shows the contexts in which the word capacity was used by countries sampled from Europe. 


\subsubsection{NBSAPs and the $4^{\text {th }}$ National Report for Europe}

Table 15b: Context in which the word capacity is used - Europe

\begin{tabular}{|c|c|c|}
\hline Country & NBSAPs & $4^{\text {th }}$ National Reports \\
\hline UK & $\begin{array}{l}\text { Agricultural stability, Invasive } \\
\text { Species, Collections in } \\
\text { Environmental, Carrying capacity, } \\
\text { Resources management, Exceeding limits, } \\
\text { Ecosystems, Forest capacity, Over- } \\
\text { fishing, Targeted decommissioning } \\
\text { program, Linkages, Botanic gardens, } \\
\text { Productive, Support to other governments, } \\
\text { NGOs, Awareness, Funding, } \\
\text { Implementation }\end{array}$ & $\begin{array}{l}\text { Capacity building, Develop/Build, } \\
\text { Adaptive, Climate Change, Scientific, } \\
\text { Reproductive, Habitats, Ecosystems, } \\
\text { People, Institutions, Financial, Technical, } \\
\text { Local, Cooperation, implementation, } \\
\text { Awareness }\end{array}$ \\
\hline Netherlands & $\begin{array}{l}\text { Knowledge sharing, Sustainable forestry, } \\
\text { Good governance, Management, } \\
\text { Ecosystems, Poor countries, Programs, } \\
\text { Resilience, Protected Areas, Ecological } \\
\text { Networks, Fishing fleets, Developing } \\
\text { countries, Fish meal \& Fish oil chain, } \\
\text { Water management, Knowledge networks, } \\
\text { Shared responsibility, managers. }\end{array}$ & $\begin{array}{l}\text { Indigenous/local communities, Parties, } \\
\text { Capacity building, Financial, Human, } \\
\text { Scientific, Technical, Implementation, } \\
\text { Capacity as an indicator }\end{array}$ \\
\hline Switzerland & $\begin{array}{l}\text { Climate Change, Implementation, } \\
\text { Protected Areas, Participatory planning, } \\
\text { Knowledge management, Nature to renew } \\
\text { itself, Performance of forests, Resilience, } \\
\text { Natural regeneration, Alien Species, } \\
\text { Ecosystems }\end{array}$ & $\begin{array}{l}\text { Glaziers/water holding, production, } \\
\text { capacity building, indigenous/Local } \\
\text { communities, Technology transfer, } \\
\text { Networking, Scientific, Financial, } \\
\text { Communications, Ecosystems, Technical, } \\
\text { implementation, Parties, Switzerland, } \\
\text { Cartagena Protocol, Technical/Scientific } \\
\text { Cooperation, Knowledge, Programmes. }\end{array}$ \\
\hline Poland & 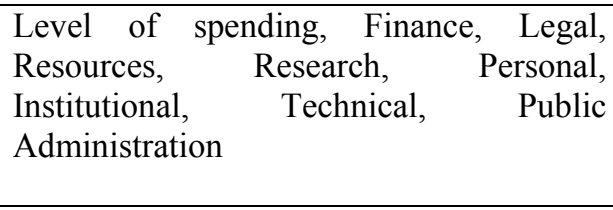 & $\begin{array}{l}\text { Financial, Gene banks, collections of } \\
\text { botanical/zoological gardens, Capacity } \\
\text { building, Public, Fishing, Catch, } \\
\text { Ecosystems, Parties, Financial, Human, } \\
\text { Scientific, Technical, Planning. }\end{array}$ \\
\hline
\end{tabular}

Source: NBSAPs and reports of these countries 


\subsubsection{NBSAPs and the $4^{\text {th }}$ National Report for Africa}

Table 15c: Context in which the word capacity is used - Africa

\begin{tabular}{|c|c|c|}
\hline Country & NBSAPs & $4^{\text {th }}$ National Reports \\
\hline Kenya & $\begin{array}{l}\text { Institutional, Linkages, Law } \\
\text { enforcement agencies, Collaboration } \\
\text { \& Networking, Coordination, Kenya } \\
\text { Wildlife Service, Programs, Training, } \\
\text { Bioprospecting, } \\
\text { Biotechnology, National, } \\
\text { Technology Transfer }\end{array}$ & $\begin{array}{l}\text { Planning, financial, human, scientific, } \\
\text { Technology transfer, National, Institutional, } \\
\text { Managers, Support to fisheries, wildlife and } \\
\text { birds, Capacity Building, Community, } \\
\text { stakeholders, local resources, Poverty, } \\
\text { Coordination, Funding, Land degradation, } \\
\text { Education, Research, Assessment, } \\
\text { Implementation gaps, Information, storage } \\
\text { and retrieval, Law enforcement agencies, } \\
\text { National ICT, Taxonomic works and } \\
\text { surveys, NGOs and CBOs, Gene banks, } \\
\text { Ecosystems, Parties }\end{array}$ \\
\hline $\begin{array}{l}\text { South } \\
\text { Africa }\end{array}$ & $\begin{array}{l}\text { Institutional, Constraints, Local } \\
\text { governments, Research, Universities, } \\
\text { Councils, Institutions, Adaptive, } \\
\text { Agencies, Community empowerment, } \\
\text { Ecosystems, Management, Climate } \\
\text { change, Financial, Local level, Staff } \\
\text { Retention, Data, Human, Planning, } \\
\text { Partnerships, Habitats, Economic, } \\
\text { Environmental, NGOs, Assessment, } \\
\text { Implementation, Programs, CBOs, } \\
\text { HIV/AIDS, Funding, Programs, } \\
\text { Trans-boundary, Carrying capacity, } \\
\text { Negotiations, Biotechnology, GMOs, } \\
\text { Monitoring and Risk Assessment, } \\
\text { Technology, PA Networks, Biosafety }\end{array}$ & $\begin{array}{l}\text { Human, Capacity building, Lack of capacity, } \\
\text { Enforcement, Research, Monitoring, } \\
\text { National, Programs, Municipalities, Local, } \\
\text { Planning, Protected area systems, Future } \\
\text { priorities, } \\
\text { Compromised ecosystems, Climate Change, } \\
\text { Flooding, Water quality, Institutional, } \\
\text { Legislation, Agencies, Compliance } \\
\text { monitoring, Uneven capacities, Resources, } \\
\text { Stakeholders, Mainstreaming, Parties, } \\
\text { Cartagena Protocol, Overcoming constraints }\end{array}$ \\
\hline D R Congo & $\begin{array}{l}\text { Management, Protected Areas, Local } \\
\text { communities, Funding, Law } \\
\text { enforcement, Legal, Institutional }\end{array}$ & $\begin{array}{l}\text { Low skills, production, Financial, Technical } \\
\text { support, Carrying capacity, National, } \\
\text { Institutional, Capacity building, } \\
\text { Management, Gaps - management structures } \\
\text { and individuals, Implementation, Technical, } \\
\text { Climate Change, Biosafety, Communication, } \\
\text { CHMs, Poverty, Internal Revenues, } \\
\text { Financial, Assessments, Internal wars and } \\
\text { Cartagena Protocol. }\end{array}$ \\
\hline Ghana & $\begin{array}{l}\text { Community participation, } \\
\text { Management, Carrying capacity, } \\
\text { Akosombo dam, Scientific data, } \\
\text { Information, Institutions, National \& } \\
\text { Local levels, Assessment, Human } \\
\text { capacity, Fire prevention and control. }\end{array}$ & $\begin{array}{l}\text { Inadequate management, GIS, CERGIS, } \\
\text { Building/Strengthening institutions, Capacity } \\
\text { building, Financial support from DCs, } \\
\text { Carrying capacity, management, Ecosystems, } \\
\text { Parties, Cartagena Protocol, National-Level, } \\
\text { Technical/Scientific Cooperation, Training, } \\
\text { Planning, Protected areas, Knowledge \& } \\
\text { Skills, Participation of Local/Indigenous } \\
\text { communities, Fringe communities, District } \\
\text { Assemblies, Agricultural Production, Land } \\
\text { Management. }\end{array}$ \\
\hline
\end{tabular}


\begin{tabular}{|l|l|l|}
\hline & \\
\hline
\end{tabular}

\subsubsection{NBSAPs and the $4^{\text {th }}$ National Report for Asia}

\section{Table 15d: Context in which the word capacity is used - Asia}

\begin{tabular}{|c|c|c|}
\hline Country & NBSAPs & $4^{\text {th }}$ National Reports \\
\hline India & $\begin{array}{l}\text { Institutional, National, Human, Strengthen, } \\
\text { Grassroots level, On-job training, Invasive } \\
\text { Alien Species, Climate Change, Financial } \\
\text { Assistance, Natural regeneration of rivers, } \\
\text { Monitoring, Enforcement, Taxonomy, } \\
\text { Biosystems, New technologies, Local, } \\
\text { Carrying capacity, New generation of } \\
\text { taxonomists, Awareness, Biotechnological, } \\
\text { Production, Scientific Management, } \\
\text { Conservation, Risk Assessment, Genetically } \\
\text { Modified Organisms, Biosafety, } \\
\text { Communication, Manpower, Infrastructure, } \\
\text { Implementation }\end{array}$ & $\begin{array}{l}\text { Gaps, Constraints, National, Regional, Local, } \\
\text { Communities, Capacity building, Micro- } \\
\text { enterprise, Self-help groups, Biosafety, } \\
\text { Education, Awareness, Coordination, } \\
\text { Institutional, Legal Framework, Risk } \\
\text { evaluation/management, Evaluations, } \\
\text { Taxonomic, Ecosystems, Financial, Human, } \\
\text { Scientific, Technical, Implementation, } \\
\text { Planning, Management, Protected Areas, } \\
\text { Regulations, Inter-Ministerial, Online data } \\
\text { base, New Technologies, Genetically } \\
\text { Modified Foods, Enabling policy \& } \\
\text { Legislation, Partnerships and Stakeholders, } \\
\text { Local people, Center for excellence in } \\
\text { Madras, Coastal systems, Farmers, }\end{array}$ \\
\hline Jordan & $\begin{array}{l}\text { Institutional, Productive, Ecological, } \\
\text { Carrying capacity, Bio-transformation, } \\
\text { Tolerance to environmental stress, Law } \\
\text { enforcement, Cooperation, Management, } \\
\text { Local ecologists, Information, Data, Wildlife } \\
\text { Reserves, Local communities, Authorities, } \\
\text { Coordination, Technical, Staff, Monitoring, } \\
\text { Animal care, Ecosystems, Infrastructure and } \\
\text { services, Development, Rangelands, } \\
\text { Economic valuation, Technical training, } \\
\text { Agencies, Funding, Implementation, Micro- } \\
\text { biology, Land-use practices, Safe \& healthy } \\
\text { foods, Local species, Stakeholders }\end{array}$ & $\begin{array}{l}\text { National, Communication, Administrative, } \\
\text { Biological, Technical, } \\
\text { Universities, Carrying capacity, Planning, } \\
\text { Environmental, Institutional, Knowledge } \\
\text { management, Development programs, } \\
\text { Awareness, Local conditions/communities, } \\
\text { Decision making, NGOs \& CBOs, Capacity } \\
\text { building, Taxonomic research, Production, } \\
\text { Local civil society organizations, } \\
\text { Networking, Climate change, } \\
\text { Implementation, Education and training, } \\
\text { Resource mobilization. }\end{array}$ \\
\hline & $\begin{array}{l}\text { Institutional, Implementation, Management, } \\
\text { Institutions, Carrying capacity, Effect of } \\
\text { salinity on animals, Ground water, Pollution, } \\
\text { Education, Communication, National, Local, } \\
\text { Timber industry, Forest management, } \\
\text { Overexploitation, Data, Technical, Natural } \\
\text { resources, Economic growth, Laws \& } \\
\text { regulations, Negotiation, Awareness, } \\
\text { Compliance, Fundraising, Partnerships }\end{array}$ & $\begin{array}{l}\text { Capacity constraints, Sectoral programs, } \\
\text { Planning, Carrying capacity, exceeded } \\
\text { capacities, capacity building, Institutional, } \\
\text { Communication, NGOs, Local governments, } \\
\text { Negotiations, Fundraising, National, } \\
\text { Indigenous, Local communities, } \\
\text { Management, Ecosystems, Financial, } \\
\text { Human, Technical, Assessments, Valuation, } \\
\text { Forest rangers, Implementation, Parties. }\end{array}$ \\
\hline Australia & $\begin{array}{l}\text { Food production, Ecosystem resilience, } \\
\text { Finite capacity, Human activities, Individual } \\
\& \text { Collective, Productive, Survival, } \\
\text { Underlying capacity, Earth's capacity, } \\
\text { Climate Change, National biodiversity } \\
\text { accounting, Local, Territorial, Regional, } \\
\text { Private sector, Indigenous engagement, } \\
\text { Emissions accounting, NAILSMAN, Land } \\
\text { management, Back-on-Track, Corporate } \\
\text { planning, Land use planning, Community }\end{array}$ & $\begin{array}{l}\text { Gaps in policy research, Corals destruction, } \\
\text { Land managers, Finite capacity, Capacity } \\
\text { building, Nature vegetation cover, Loss of } \\
\text { taxonomic workforce, NGOs, Asia-Pacific } \\
\text { forestry funding, Workshops, Technology } \\
\text { transfer, Maritime Surveillance, Protecting } \\
\text { Maritime Resources, Adaptive, Ecosystems, } \\
\text { Financing, Parties, Human, Scientific } \\
\text { cooperation, Short of skills, Assessments, } \\
\text { Implementation, Community engagement. }\end{array}$ \\
\hline
\end{tabular}




\begin{tabular}{|l|l|l|}
\hline & $\begin{array}{l}\text { Networks, Program, Ecological knowledge, } \\
\text { Resource degradation, Self-Regeneration. }\end{array}$ & \\
\hline
\end{tabular}

Other key emerging themes were put together and used as criteria for evaluating compliance and implementation at local levels. This was how the 20 criteria mentioned earlier were established. Because actual conservation activities are done at local levels and within sectors that exploit natural resources, it was possible to analyze what countries are doing and what these documents were saying. Key words surrounding these emerging themes were determined to be ideal criteria to be used to measure compliance levels at the global, national and local levels.

\subsection{Factors that most influence global compliance}

Information in Table 16 represents responses from a survey conducted in the year 2013 by the ASAHI Glass Foundation where people were asked to indicate which factors they thought most influence compliance and implementation. Before zooming into specific factors in individual countries that are being examined in this study, a global analysis has been done to see where and how the sampled countries under study share an understanding of overall global conservation.

Table 16: Factors that most influence compliance and implementation

\begin{tabular}{|l|l|l|l|l|l|l|}
\hline Factors & $\begin{array}{l}\text { Western } \\
\text { Europe }\end{array}$ & $\begin{array}{l}\text { Eastern } \\
\text { Europe }\end{array}$ & Asia & $\begin{array}{l}\text { Latin } \\
\text { America }\end{array}$ & Africa & $\begin{array}{l}\text { Middle } \\
\text { East }\end{array}$ \\
\hline $\begin{array}{l}\text { Problems in communicating } \\
\text { Information }\end{array}$ & 19 & 23 & 107 & 34 & 36 & 33 \\
\hline Pursuit of economic Profit & 74 & 69 & 409 & 76 & 73 & 56 \\
\hline Global economic system & 74 & 69 & 241 & 63 & 39 & 44 \\
\hline $\begin{array}{l}\text { Problems in decision making } \\
\text { Systems }\end{array}$ & 47 & 62 & 261 & 51 & 58 & 56 \\
\hline $\begin{array}{l}\text { Governance problems } \\
\text { Lack of technical resources }\end{array}$ & 58 & 46 & 246 & 51 & 64 & 78 \\
\hline
\end{tabular}




\begin{tabular}{|l|l|l|l|l|l|l|}
\hline Total & 277 & 273 & 1388 & 282 & 288 & 300 \\
\hline
\end{tabular}

Source: ASAHI Glass Foundation, 2012

Since 1992, the AGF has been conducting global research on environmental conservation. In 2013, the AGF sent out questionnaires to key conservation organizations, research universities and governments, and asked staff to rank issues that they thought were key impediments to environmental conservation in general. The way the language in the research was framed fits very well with the questions that are guiding this study. As can be seen from table 16, in Western Europe, 19 people said communication was a critical factor. There were 74 people that said it was the pursuit of economic profit by private and public sector institutions. Also 74 people said it was the global economic systems, such as the measure of development using GDP, which tend to exclude many other aspects of development, such as the quality of our environment. There were 47 people that said it was decision making systems that were key impediments to compliance and implementation of conservation goals. What the decision making systems here means is who actually has the most power to influence what governments do. At the moment, powerful political, businesses and other private organizational interests wield more power and tend to influence decisions away from favoring environmental concerns.

Governance problems were also highlighted as critical factors by 58 people. Governance here covered many factors, such as the slow response by countries in fulfilling their commitments to conservation, political priorities and transparency in decision making by various organs of government, and the public and private sectors. Only five people cited lack of technical resources as a critical factor impeding implementation. Issues highlighted in this question were technologies that would help to 
reduce overconsumption of resources including energy. Western Europe is comprised of the world's most developed nations that are well endowed technologically and therefore this view cannot apply to most of the countries.

The same explanations apply to Eastern Europe, Asia, Africa, Latin America and the Middle East.

\subsubsection{Factors that most influence local level implementation}

Table 17 below shows the relationship between compliance and various primary variables. Using data from the Global Footprint Network, the following linear regression were obtained for sixteen countries. The dependent variable was the average biological capacity of all the sixteen countries. It was assumed that there is a direct relationship between biological capacity and these specific independent variables.

Except for forest resources at 5\% level, all other variables have significant impact on the biological capacity. The population, networking (meaning coordination of various agencies), community institutions and the international community, croplands, grazing, and levels of carbon in the atmosphere have significant effects on biological capacity. Built-up areas, which are comprised of urbanization, constructions and road networks, were also found highly significant.

However, biodiversity conservation cannot be classified as a linear, cause-andeffect relationship. Total activities that affect biodiversity and the total conservation efforts interact in ways that cannot possibly be classified as linear. Conservation activities and institutional relationships, therefore, need to be examined from the lens of a whole system. 
Table 17: Significance of primary factors that most influence implementation

\begin{tabular}{|c|c|c|c|c|c|}
\hline \multicolumn{2}{|c|}{ Regression Statistics } & & & & \\
\hline Multiple R & 0.978 & & & & \\
\hline $\begin{array}{l}\text { R Square } \\
\text { Adjusted R }\end{array}$ & 0.957 & & & & \\
\hline Square & 0.907 & & & & \\
\hline Standard Error & 1.507 & & & & \\
\hline Observations & 16.000 & & & & \\
\hline \multicolumn{6}{|l|}{ ANOVA } \\
\hline & $D f$ & SS & MS & $F$ & Significance F \\
\hline Regression & 8 & 351.615 & 43.95 & 19.34 & 0.00 \\
\hline Residual & 7 & 15.91 & 2.27 & & \\
\hline \multirow[t]{2}{*}{ Total } & 15 & 367.52 & & & \\
\hline & Coefficients & Standard Error & t Stat & P-value & Lower 95\% \\
\hline Intercept & 5.726 & 1.829 & 3.131 & 0.017 & 1.402 \\
\hline Population (Ms) & -0.004 & 0.002 & -1.900 & 0.099 & -0.008 \\
\hline Network & 10.630 & 1.924 & 5.524 & 0.001 & 6.080 \\
\hline Cropland & 15.820 & 3.265 & 4.846 & 0.002 & 8.100 \\
\hline Grazing & -6.770 & 2.326 & -2.911 & 0.023 & -12.269 \\
\hline Forest & -3.643 & 3.099 & -1.176 & 0.278 & -10.971 \\
\hline Fish & -20.251 & 10.020 & -2.021 & 0.083 & -43.945 \\
\hline Carbon & -3.830 & 0.819 & -4.674 & 0.002 & -5.767 \\
\hline Built-up & -83.377 & 13.083 & -6.373 & 0.000 & -114.312 \\
\hline
\end{tabular}

Adjusted R squared is $91 \%$ meaning that the model is well explained by the independent variables.

Biological capacity was measured in hectares per person. Population was given in millions; network was measured in the number of institutions and organizations that work together. Although not so significant, a unit rise in population leads to a reduction in biological capacity by an equivalent of 0.004 hectares per person. A unit rise of the number of conservation networks improves biological capacity by 10.63 hectares per person. A rise in one hectare of cropland according to this analysis improves biological 
capacity by 15.8 hectares. This was not the expected outcome. A rise by one hectare of grazing land reduces biological capacity by 6.8 hectares per person. An equivalent of one hectare increase in fishing grounds leads to reduced biological capacity by an equivalent of 20 hectares of fish resources. One unit rise of carbon in the atmosphere reduces biological capacity by about four hectares per person. One hectare increase in the land taken up by buildings and other constructions reduces biological capacity by an equivalent of 83 hectares per person.

\subsubsection{Analysis of compliance levels}

It is important to note that national compliance is not only a reflection of the strength of conservation policies and quality of conservation programs but also the readiness of local institutions. How ready and able local institutions are, depends on information dissemination, enforcement of conservation policies, training, incentives and perceived costs associated with such programs. It requires guidelines, education and long term multilevel strategies to build local capacities. Finally, program developers should get involved on a continuing basis to identify key attributes of a conservation program that gives best outcomes at minimum costs.

There are two national approaches to compliance: (i) countries comply because it is appropriate to do so and (ii) countries comply just to be seen doing good without actually fulfilling the requirements of a treaty (Hathaway, 2005). National compliance outcomes include creation of national and local institutions, changes in community's way of viewing biological resources, improved communication and collaboration, and emergence of epistemic communities. Adoption of a treaty without fulfilling its 
requirements may come about from lack of capacity, lack of political willingness, or because other issues are given higher priorities.

\subsubsection{Compliance outcomes}

The estimates of compliance were analyzed from the data obtained from the NBSAPS and National Reports. Data on local level compliance and implementation was expected to be obtained from National Clearing House Mechanisms (NCHMs) in each country. Countries have not developed NCHMs to serve the coordination and information sharing with all sectors and different stakeholders. There was, therefore, no data in the NCHMs to serve this need. Consequently, data from the AGF was used to estimate local level compliance and implementation.

Data obtained from AGF was constructed from the Likert scale statements that covered all aspects of local level implementation. These aspects of local implementation included communication, decision making, societal values, traditions, economic vs environmental considerations and priorities of biological resources. The percentage number of respondents, who held the view that implementation at local levels was going on well and that it was above a certain threshold level, was used as a measure of local compliance.

Table 18 below shows average compliance across specific compliance criteria as well as local level compliance. National compliance based 15 of the 20 criteria established from data obtained from the NBSAPs and national reports were $56 \%$. These 15 criteria were selected as they were very similar to the AGF responses used in 
estimating local compliance. This was done for comparison purposes to see the difference between national and local compliance.

These were statements that disagreed that there were problems with local implementation and have been re-stated in table 18 to fit the exact views of respondents.

Table 18: National and local compliance

\begin{tabular}{|c|c|c|c|}
\hline $\begin{array}{c}\text { CBD - Information from } \\
\text { documents }\end{array}$ & $\begin{array}{c}\text { Compliance } \\
\text { level }\end{array}$ & $\begin{array}{l}\text { AGF Data - Information from } \\
\text { survey data }\end{array}$ & $\begin{array}{c}\text { Compliance } \\
\text { Level }\end{array}$ \\
\hline $\begin{array}{l}\text { National Biodiversity } \\
\text { Strategy Action Plans }\end{array}$ & 31 & $\begin{array}{l}\text { Ability to comprehend } \\
\text { information }\end{array}$ & 12 \\
\hline National Reports & 79 & Adequate Information & 18 \\
\hline Clearing House Mechanisms & 81 & Education and training & 8 \\
\hline $\begin{array}{l}\text { The nature and type of } \\
\text { language used by plans }\end{array}$ & 51 & $\begin{array}{l}\text { Consideration of future } \\
\text { generations }\end{array}$ & 18 \\
\hline National Capacity & 53 & $\begin{array}{l}\text { Balanced economics and } \\
\text { Environmental Decision }\end{array}$ & 10 \\
\hline Local capacity & 53 & $\begin{array}{l}\text { National Decisions reflecting } \\
\text { local conditions }\end{array}$ & 6 \\
\hline $\begin{array}{l}\text { Surveys, data and local } \\
\text { studies }\end{array}$ & 40 & Societal and Cultural practices & 10 \\
\hline $\begin{array}{l}\text { Depth \& Scope of plans and } \\
\text { reports }\end{array}$ & 61 & $\begin{array}{l}\text { Organizational and institutional } \\
\text { reforms }\end{array}$ & 10 \\
\hline $\begin{array}{l}\text { Goals set by countries in their } \\
\text { plans }\end{array}$ & 62 & $\begin{array}{l}\text { Acceptance in changes to } \\
\text { national policies }\end{array}$ & 9 \\
\hline $\begin{array}{l}\text { Objectives - How realistic are } \\
\text { the objectives }\end{array}$ & 66 & Coordination & 12 \\
\hline $\begin{array}{l}\text { Institutions created to protect } \\
\text { biodiversity protection }\end{array}$ & 61 & Sustainable lifestyles & 32 \\
\hline Funding allocations & 46 & $\begin{array}{l}\text { Ability to recognize } \\
\text { environmental conditions }\end{array}$ & 25 \\
\hline $\begin{array}{l}\text { Legislation that biodiversity } \\
\text { protection }\end{array}$ & 51 & $\begin{array}{l}\text { Making decisions that equally } \\
\text { support conservation }\end{array}$ & 12 \\
\hline Clear timelines in the plans & 49 & $\begin{array}{l}\text { Willingness to conserve } \\
\text { biodiversity freely }\end{array}$ & 17 \\
\hline Total & 784 & Total & 199 \\
\hline Average & $56 \%$ & Average & $14 \%$ \\
\hline
\end{tabular}


The criteria that reflect local level implementation were selected from both the Convention on Biodiversity (CBD) data as well as data from the AGF. As can be seen from table 17 above, overall national compliance is at $35 \%$. This confirms most of the fears expressed in the literature that biodiversity degradation has continued to accelerate over time. At $35 \%$ compliance means that only $35 \%$ of all activities that people do go towards improving biodiversity protection. It also means that about $65 \%$ of all human activities at the national level go towards both over-exploitation and degradation of biological resources.

The next step in the analysis was to test hypothesis one by examining the level of support and types of support indicators. Some of these indicators include decision support mechanisms to local levels and societal priorities that either support more or less of conservation, communication, local practices and cultural influences. Table 18 below presents the percentages on how different respondents agreed to or disagreed to the given statements.

It is clear from table 18 above that $79 \%$ of the respondents feel that other national interests take precedence over conservation. About $83 \%$ felt that individuals make decisions based on immediate benefits that are often not about the protection of biological resources. It was also found from the respondents that there is more priority given to other societal needs, communication is not well targeted and that decisions are made to satisfy immediate needs and not long-term conservation objectives.

On average, about $73 \%$ of these respondents in table 18 were of the opinion that all the 17 statements on the table support less conservation but support other activities 
more. Compliance has been estimated to be at $35 \%$ in table 18 . This confirms the first hypothesis that International and national conservation initiatives fall short of conservation outcomes, and because of inadequate support to local institutions where actual implementation takes place, global compliance with CBD goals is low.

Table 19: Confirmation of hypothesis one

\begin{tabular}{|c|c|c|c|}
\hline & Statements & Disagree & Agree \\
\hline 1 & $\begin{array}{l}\text { Other National interests often take precedence over } \\
\text { environmental conservation }\end{array}$ & 13 & 79 \\
\hline 2 & Individual make decisions based on immediate benefits & 12 & 83 \\
\hline 3 & $\begin{array}{l}\text { Easily comprehensible information is not communicated from } \\
\text { conservation experts to the public }\end{array}$ & 12 & 80 \\
\hline 4 & $\begin{array}{l}\text { Environmental experts focus communication of information too } \\
\text { heavily upon political decision makers, failing to reach the public }\end{array}$ & 26 & 53 \\
\hline 5 & $\begin{array}{l}\text { Political decision makers do not communicate information from } \\
\text { environmental experts to the public }\end{array}$ & 9 & 80 \\
\hline 6 & $\begin{array}{l}\text { Public does not value the information provided by environmental } \\
\text { experts unless disaster occurs in their vicinity }\end{array}$ & 15 & 77 \\
\hline 7 & $\begin{array}{l}\text { Non-profit organizations overemphasize Communications efforts } \\
\text { on political decision makers }\end{array}$ & 17 & 50 \\
\hline 8 & $\begin{array}{l}\text { Minimum environmental education level is necessary for } \\
\text { understanding of environmental information but is lacking }\end{array}$ & 8 & 79 \\
\hline 9 & $\begin{array}{l}\text { The economic profits of a corporation/organization/regions are } \\
\text { prioritized so much that environmental considerations are not } \\
\text { taken into account }\end{array}$ & 15 & 80 \\
\hline 10 & Absence of reference towards natural and different life forms & 13 & 74 \\
\hline 11 & $\begin{array}{l}\text { Societal and cultural practices and bases that place importance on } \\
\text { "common good," like environment, are lacking or fragile. }\end{array}$ & 10 & 81 \\
\hline 12 & $\begin{array}{l}\text { Societal practices and traditions that value the weak, including } \\
\text { environment, are few and far between. }\end{array}$ & 15 & 65 \\
\hline 13 & $\begin{array}{l}\text { At most, people have capacity to recognize environmental } \\
\text { conditions and effects on local level, but are incapable of } \\
\text { recognizing problems globally }\end{array}$ & 25 & 61 \\
\hline 14 & $\begin{array}{l}\text { Human decision-making process is based on self-preservation; it } \\
\text { does not consider happiness of others or of future generations }\end{array}$ & 18 & 64 \\
\hline 15 & $\begin{array}{l}\text { Human nature to care for others is overwhelmed by behavioral } \\
\text { principles based on economic considerations }\end{array}$ & 12 & 77 \\
\hline 16 & $\begin{array}{l}\text { The value systems that respect one's own environment and daily } \\
\text { economic activities are inconsistent with each other }\end{array}$ & 11 & 74 \\
\hline \multirow[t]{2}{*}{17} & $\begin{array}{l}\text { Current lifestyles based on large consumption of energy cannot } \\
\text { be abandoned }\end{array}$ & 32 & 76 \\
\hline & Average & $16 \%$ & $73 \%$ \\
\hline
\end{tabular}


Table 19 above shows the percentage of people that disagreed and that agreed that existing local conservation efforts cannot drive compliance to higher levels. The percentage of people that think local initiatives are good were only $16 \%$. A total of 1009 people responded to these statements. The $16 \%$ level does really drive down compliance level when an average is estimated with the national and CBD levels.

Table 20: Overall global compliance by all countries

\begin{tabular}{|c|c|c|c|c|}
\hline Countries & $\begin{array}{l}\text { Paper } \\
\text { Compliance } \\
\%\end{array}$ & $\begin{array}{l}\text { Policy } \\
\text { Compliance } \\
\%\end{array}$ & AGF Data & $\begin{array}{l}\text { Local } \\
\text { compliance } \\
\%\end{array}$ \\
\hline Canada & 67 & 86 & Ability to comprehend information & 12 \\
\hline Mexico & 67 & 46 & Adequate information & 18 \\
\hline Jamaica & 67 & 48 & Education and training & 8 \\
\hline Brazil & 73 & 49 & Consider future generations & 18 \\
\hline UK & 80 & 77 & $\begin{array}{l}\text { Balanced economics and } \\
\text { environment }\end{array}$ & 10 \\
\hline Switzerland & 67 & 75 & $\begin{array}{l}\text { Decisions reflecting local } \\
\text { conditions }\end{array}$ & 6 \\
\hline Netherland & 67 & 72 & Societal and cultural practices & 10 \\
\hline Poland & 80 & 34 & $\begin{array}{l}\text { Organizational and institutional } \\
\text { reforms }\end{array}$ & 10 \\
\hline Ghana & 60 & 30 & $\begin{array}{l}\text { Acceptance to changes brought by } \\
\text { national policies }\end{array}$ & 9 \\
\hline DR Congo & 73 & 24 & Coordination & 12 \\
\hline Kenya & 33 & 23 & Sustainable lifestyles & 32 \\
\hline S. Africa & 40 & 36 & $\begin{array}{l}\text { Ability to recognize environmental } \\
\text { conditions }\end{array}$ & 25 \\
\hline India & 73 & 54 & $\begin{array}{l}\text { Making decisions that support } \\
\text { conservation }\end{array}$ & 12 \\
\hline Indonesia & 73 & 40 & $\begin{array}{l}\text { Willingness to conserve } \\
\text { biodiversity freely }\end{array}$ & 17 \\
\hline Jordan & 27 & 29 & Total & 199 \\
\hline Australia & 73 & 75 & & \\
\hline $\begin{array}{l}\text { Total \% } \\
\text { Global } \\
\text { Compliance }\end{array}$ & $\begin{array}{l}\text { Average - } \\
63.75\end{array}$ & $\begin{array}{l}\text { Average - } \\
\quad 49.88\end{array}$ & Average & $14 \%$ \\
\hline
\end{tabular}


The Table 20 above shows compliance levels for each country at paper, policy and local levels. The average paper compliance is $63.75 \%$, policy compliance is $49.88 \%$ and local implementation is compliant at a mere $14 \%$.

The paper compliance column represents the percentage level that each country has met with the CBD requirements. The UK and Poland had the highest compliance at $80 \%$. What this means is that they have submitted more reports and revised their NBSAPs more than other countries. Jordan had the lowest compliance at $27 \%$, followed by Kenya at $33 \%$ and South Africa at $40 \%$. These countries have made minimum revisions to their NBSAPs and submitted the least number of reports. On average, international compliance is about $64 \%$.

The Policy compliance column was estimated using the 20 criteria that were established from the literature, plans and national reports. Canada had the highest compliance at $86 \%$ and Kenya was lowest at $23 \%$. Nationally, the average compliance was about $50 \%$ when looking at policy alone.

Country compliance column is the average of paper and policy compliance. The global compliance without local level implementation was 57\%. Compliance data on local level implementation is missing from Table 20 above Local level compliance was estimated separately using data from AGF. This data contained responses to a 5-point Likert scale questionnaire. where people were to either a Local level compliance has been analyzed using organizational and stakeholder cooperation and implementation strategies using game theory. 
Table 21 below presents some of the critical factors that influence the management and implementation of biodiversity goals. These factors were scored between zero and $100 \%$. Columns one, two and three show the percentage performance of each country based on the number of NBSAPs and National Reports submitted to the CBD and the creation of National Clearing House Mechanisms. Columns four through 15 are part of the 20 criteria used to evaluate compliance by countries. Only 11 out of the 20 criteria have been used here, first because of space and secondly, these 11 are the core variables that influence compliance and guide implementation.

The columns show the average compliance level by each factor for all countries. The bottom row presents average compliance by each factor. The rows show the average compliance for each country across various factors. The last right column presents the average compliance by each country. Overall compliance by these countries measures up to only $49 \%$. Based on these factors, Canada had the highest compliance at $70 \%$. United Kingdom and Australia had compliance with CBD goals at 67\%. Kenya, Jordan and Democratic Republic of Congo had the least compliance at $31 \%, 33 \%$ and $33 \%$ respectively. With respect to individual factors, the NBSAPs that are supposed to be the roadmap for compliance and implementation comply only up to $31 \%$. Surveys and data collection activities comply at only $40 \%$, funding at $46 \%$ and setting timelines at $49 \%$.

Compliance based on paper and policy levels does not really tell the whole story. It is therefore necessary to find ways of analyzing local level implementation to be able to present a true reflection of actual compliance level. 
Table 21: Compliance level by 15 out of the 20 criteria

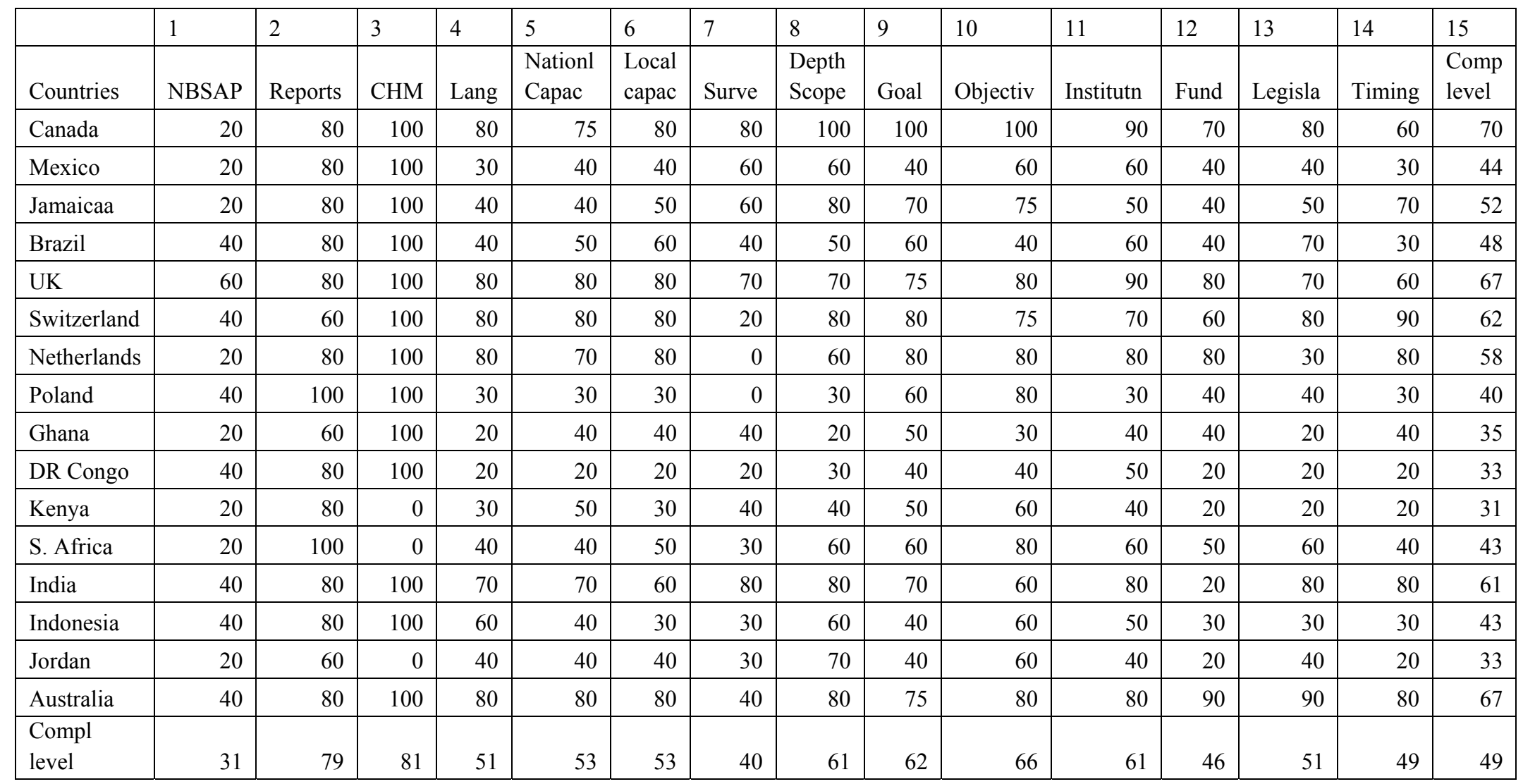

Source: Calculations estimated using information from NBSAPs, National Country Reports, and Clearing House Mechanisms

The criteria where a country has highest compliance was assumed also to be an area of the highest strength and therefore its best strategy in a cooperative game. 


\subsection{International relations theory analysis}

Goldsmith and Posner (2005) argue that international theory is designed to support states in pursing their own interests on the international stage. Many international treaties also treat all countries as equals when in reality they are not. This is clearly demonstrated in Table 21 above where compliance levels by each country across various criteria are so different. Governments are unwilling to commit to international treaties when doing so does not serve national interests.

National implementation and compliance is a total whole of conservation activities taking place at local levels within a country. This also includes how well countries are performing at a continuum from planning through capacity building to monitoring and evaluation at national levels. In this continuum is the rest of all other criterion used to measure compliance in my study. For international relations theories to effectively be seen to coordinate governments, they must be able to internally coordinate national activities to satisfy global interest. This is not practically and politically feasible.

My study examined the effectiveness of the international relations theory by using compliance levels in Table 21 above. These compliance levels can be viewed as issues of global concern and therefore provide excellent case studies on how countries make decisions on what qualifies for support from outside of the country. The following assumptions were made in order to establish international working relationships between countries 
1. Compliance levels established through scores given to each criterion shows the level of conservations support needs for each criteria.

2. When governments cooperate, they should support each other in areas where they both have highest compliance so that the overall average compliance remains high.

For explanation purposes, compliance levels on national capacities (NC), local capacities (LC), funding levels within each country (FG), and the strength of environmental legislation (LN) were selected to compare the UK and Brazil. The same explanations can apply to the rest of the sample of countries.

Figure 5. United Kingdom and Brazil cooperative relationship

\begin{tabular}{|l|l|l|l|l|l|}
\hline & & \multicolumn{4}{|c|}{ Brazil } \\
\hline & & NC & LC & FG & LN \\
\hline \multirow{4}{*}{ UK } & NC & 80,50 & 80,60 & 80,40 & 80,70 \\
\cline { 2 - 6 } & LC & 80,50 & 80,60 & 80,40 & 80,70 \\
\cline { 2 - 6 } & FG & 80,50 & 80,60 & 80,40 & 80,70 \\
\cline { 2 - 6 } & LN & 70,50 & 70,60 & 70,40 & 70,70 \\
\hline
\end{tabular}

Suppose the UK and Brazil decide to cooperate in the management and implementation of key initiatives to help the two countries move to higher compliance. Except legislation (LN), the UK has higher compliance in national capacities (NC), local capacities (LC) and funding capacities (FG) than Brazil. If Brazil, therefore, were to approach the UK and ask for support, it will most likely ask to be supported financially (FG). This is the strategy where it has the lowest compliance at $40 \%$ and therefore stands to gain the most. On the other hand, if the UK were to approach Brazil and ask to support 
Brazil's conservation efforts, it will most likely want to support local capacity, which is at $60 \%$, because this is where the UK will incur the least cost/effort. If the two countries were to be brought together by a third party and asked to cooperate, they may want to negotiate and settle at a strategy where the UK does not spend too much, and where Brazil does not benefit too little. They may go through a negotiation process and arrive at a consensus where the UK most likely agrees to support Brazil's national capacity, which is at $50 \%$. This shows how each country's national interests influence international relations.

The expected outcomes from these relationships were as follows: (1) If the UK is to agree to support Brazil by funding its conservation activities, average compliance between the two countries will be $60 \%$ (average of $80 \%+40 \%$ ). (2) If the UK agrees to support Brazil's local capacity building efforts, average compliance will be $70 \%$ (average of $80 \%+60 \%$ ). (3) If the UK agrees to support national capacity building efforts through negotiation, average compliance will be $65 \%$ (average of $80 \%+50 \%$ ).

In biodiversity conservation, the aim is basically to try to minimize relationships that lead to the lowest compliance. The strategy that would lead to a higher compliance is if the UK supported local capacity building efforts. As currently structured, international relations theories have no way of guiding countries to settle for best outcomes from a relationship. In addition, governments never go through what I call selfevaluation to establish and rank national needs so that a targeted support is possible. 


\subsubsection{Game theory analysis}

Game theory helps to explain the conflicting interests in biodiversity protection from an organization's perspective in more practical ways. In any type of work, there are the two expected outcomes: successful implementation of programs or failed program implementation. Success or failure is a relative measure of an outcome which, in the context of biodiversity protection, is heavily influenced by stakeholder interests. Both success and failure help to identify strategies with Pareto-inefficient Nash equilibrium, meaning a situation where conservation is less than optimal. A Pareto-optimal situation is one where it is not possible to improve the condition of one player without making another player worse-off (Villasante \& Sumaila, 2010).

For biodiversity protection, all countries should, therefore, develop policy mechanisms and strategies to move compliance towards closer to optimal levels, otherwise known as Pareto-efficient outcomes. Nash equilibrium is the optimal outcome, such that no player can do better by unilaterally deviating from the current course of action or strategy (Frank \& Sarkar, 2010). To be able to put implementers and donors of biodiversity protection in the context of a game, they are also referred to here as players.

\subsubsection{Analysis of conservation in game theory}

My study presents a simple two-agent type of relationship between an implementer (country, agency, organization or local institution) of CBD goals and a donor (another country, national government supporting local levels, or an international organization). Under game theory, implementation of biodiversity protection strategies 
can take the form of either cooperative or non-cooperative strategies. Cooperative games exist when players have a collective common interest on the outcomes of a game. With proper negotiations and consensus building, cooperative strategies bring about more efficient outcomes. Non-cooperative games, also known as competitive games, exist where players are entirely motivated by self-interest gains (Villasanet \& Sumaila, 2010). Non-cooperative game strategies lead to inefficient outcomes.

A modified two-agent, game-theoretic analysis approach used by Frank and Sarkar (2010) was used to construct conservation strategies in Figure 6 below. Figure 6 also includes the structure of prisoner's dilemma in game theory. "I" represents strategies of implementers on the rows, while "F" represents strategies of donors on the columns. "I" stands for implement (cooperate), while "-I" stands for does not implement (defect). As for the columns, "F" stands for fund (cooperate), and "-F" stands for does not fund (defect). The letter "B" stand for the benefits gained from using biodiversity, "S" stands for the subsidies (funds) given to support biodiversity protection and " $\alpha$ " represents the fraction of benefits to the society after implementing a conservation program. The first entry in Figure 6 is for donors (F), and the second entry is for implementers (I).

Figure 6: Two conservation players with prisoner's dilemma

\begin{tabular}{|c|c|c|c|}
\hline & & \multicolumn{2}{|c|}{ CBD Implementers } \\
\hline & & Implement (I) & Does not Implement $(-\mathrm{I})$ \\
\hline \multirow{2}{*}{ 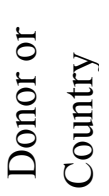 } & Fund $(\mathrm{F})$ & (i) $(\mathrm{B}-\mathrm{S}),(\alpha \mathrm{B}+\mathrm{S})$ & (ii) $(-\mathrm{B}-\mathrm{S}),(\mathrm{B}+\mathrm{S})$ \\
\hline & Does not Fund $(n-F)$ & (iii) $\mathrm{B}, \alpha \mathrm{B}$ & (iv) $-\mathrm{B}, \mathrm{B}$ \\
\hline
\end{tabular}

I , $-\mathrm{I}=$ implement, not implement, F, $-\mathrm{F}=$ Fund or not fund 
$0 \leq \alpha \leq$. Where $\alpha=$ fraction of benefits remaining after implementation.

Expected outcomes:

i. The Fund and Implement (F, I) strategy leads to an outcome where donors benefit because their funding is used in conservation, but their financial resources are reduced by $(-\mathrm{S})$. The amount that donors use in this case is equivalent to foregone benefits by the community who implement conservation activities. This can be classified as compensation to local levels. Implementers overall benefits are equal to the total of the fraction of benefits received from biodiversity after implementation $(\alpha \mathrm{B})$ and the compensation received from donors $(+\mathrm{S})$. This shows a cooperative situation where both stakeholders benefit.

ii. The Fund and does not implement $(\mathrm{F},-\mathrm{I})$ strategy is a situation where donors give funding but implementation is not done. Donors, therefore, lose financially $(-\mathrm{B})$ by compensating $(-\mathrm{S})$ to implementers for a service not delivered. Implementers benefit from full use on biodiversity (B) as well as compensation $(+\mathrm{S})$ from donors. This is the worst outcome for donors but very good for implementers, especially if they do not care about conservation.

iii. The does not Fund and Implement (-F, I) strategy arises when donors fail to provide funding, but implementation is still done. Donors benefit by B, as implementation is effected without funding. Implementers lose out on the benefits from biodiversity as they have access to only a fraction $(\alpha B)$ after implementation. This is the best outcome for donors, but it is bad for 
implementers because their benefits of biodiversity are reduced with no compensation.

iv. Does not fund and does not implement $(-\mathrm{F},-\mathrm{I})$ is a strategic combination when donors give no funding and implementers do not implement conservation policies. From the eyes of the CBD, biodiversity continues to be depleted (-B) while implementers enjoy the full benefits of biodiversity (B). This is the situation Frank and Sarkar (2010) describe as the prisoner's dilemma. Most biodiversity conservation activities can be classified under prisoner's dilemma.

\subsubsection{The Prisoner's Dilemma in conservation}

Prisoner's dilemma arises when both implementers and donors decide that their individual interests are more important than the collective responsibility of protecting biodiversity. Donors are better off not spending their money to reduce overconsumption, while implementers are also better of using more of biodiversity. The benefits of biodiversity to the whole society are well understood, but often times donors find it either expensive or not in their immediate interest to support other countries or regions that are rich in these resources. On the other hand, when local regions find that the costs of conservation are higher than the immediate benefits, they will not implement conservation activities. Both donors and implementers, therefore, have an incentive to free-ride.

From Figure 6 above, the most favorable outcomes for implementers is not implement (- I) while donors go ahead and fund $(\mathrm{F})$. As for donors, their most favorable 
outcome is implementers implement (I) and they (donors) withhold their funding (-F). When, $\mathrm{B}>\mathrm{S}$, there are more biodiversity benefits to the society than the cost of implementation. At the same time, when the society feels they are better off to not implement conservation programs, -I strategy is better than I strategy; donors need to cooperate with implementers. Also, if $(B+S)>(\alpha B+S)$, benefits after implementation are lower and, therefore, donors and implementers need to cooperate. However, when B $>\alpha \mathrm{B}$, implementers will defect. For the donor country, $-\mathrm{F}$ is superior or individually rational whether the implementing country implements $\mathrm{CBD}[\mathrm{B}>-\mathrm{B}-\mathrm{S}]$ or not $[-\mathrm{B}>(-$ $\mathrm{B}-\mathrm{S})]$

\section{Assumptions}

1. $\alpha \mathrm{B}+\mathrm{S}>\mathrm{B}$

2. $S>(1-\alpha) B$

The key question is: why do countries end up with low compliance due to nonimplementation of CBD goals even in the presence of donor support? The answer depends on the type of cooperation between countries and the payoff structure. Application of game theory helps to navigate through both the thinking and the nature of self-interest that countries have on the use of biodiversity. Implementing countries find non-compliance more rational in their self-interest irrespective of what donor countries can do, leading to low compliance. However, if the two countries collectively strive for cooperation through negotiation and compensation, the outcome will be Pareto-efficient. This need to be supported with a situation where donor funds are greater than the opportunity costs of conservation, such as when $S>(1-\alpha) B$. reword 
Finally, support to conservation activities globally falls far below conservation needs. At the same time, local communities and institutions have none or limited alternatives to their basic needs. Systems theory was therefore deigned going forward to try and analyze specific country and organizational capacities to provide solutions to the prisoner's dilemma.

\subsection{Systems theory}

Although the United Nations (UN) has delegated policy-making and implementation of biodiversity goals to governments, international conservation organizations are leading governments in conservation programs internally. Borrowing from the "representative bureaucracy" theory, international organization's power to mold national governments to be more responsive to implementation of biodiversity protection programs is an important consideration. The need to understand government capacities in all aspects of biodiversity protection in order to address the weaknesses specifically, and strengthen the high capacity areas, is likely to improve implementation and lead to higher overall compliance. On the other hand, governments also should have access to the decision making processes of conservation organizations, as this is likely to lead to some forms of trust, socialization experiences that easily shape others' values, and would facilitate collective decision making.

In order to define the most efficient form of collaboration between governments and conservation institutions, it is necessary to know the least complied parts of conservation as this is where more effort is needed. Capacities can only be seen from the level of success or failure in performing specific tasks. By focusing on capacities that 
governments have on one hand and how conservation organizations can improve them produces more efficient outcomes.

\subsubsection{Governments and NGOs collaboration outcomes}

The next major question examined is the extent that nonprofits and international organizations work with governments in the implementation of biodiversity protection policies. To explain collaboration outcomes based on compliance levels, international organizations' conservation strategies in the most biodiversity rich countries were examined to find their main focus and priorities in these countries. This was done to establish how international organizations' missions, values and goals are both aligned to improve the weakest policies of countries as well as provide a roadmap for countries to inform conservation initiatives in individual countries.

There are three approaches to implementation here: (i) international organizations draw agreements with governments that allow them to implement conservation programs on their own; (ii) international organizations identify the problem and ask governments to find ways of implementing policies that would remove the problem; (iii) organizations create a partnership with governments and implement conservation programs jointly. The first two approaches are the most popular, and this is where the problem lies. Without direct partnerships and collaboration with governments, it is extremely difficult to see weaknesses in governments and therefore be able to give support to address those specific weaknesses. The organizations that were found to have the greatest capacities and currently working in most of the sampled countries were: World Wildlife Fund (WWF), International Union for Conservation of Nature (IUCN), Conservation 
International (CI), and the United Nations Environmental Programme (UNEP). Activities of these organizations were therefore evaluated against the weaknesses identified in governments with highest biodiversity hotspot regions.

Many organizations often come together, discuss, and go away hoping that what has been agreed upon will be implemented without discussing the process. In this process, the key to successful implementation is the nature of the contract that establishes relationships between various organizations. Contracts between conservation institutions should have both short and long-tern solutions because that is how conservation problems arise. 
Table 22a: Government and NGOs collaboration in the DRC

\begin{tabular}{|c|c|c|c|}
\hline \multirow{2}{*}{$\begin{array}{l}\text { Areas of lowest conservation } \\
\text { compliance }\end{array}$} & \multicolumn{3}{|c|}{ Key focus areas by Conservation Organization } \\
\hline & World Wildlife Fund & $\begin{array}{l}\text { International Union for } \\
\text { Conservation of Nature }\end{array}$ & Conservation International \\
\hline $\begin{array}{l}\text { Problems: Low quality of the NBSAPs } \\
\text { given the vague and non-committal } \\
\text { language. The timelines for all the goals } \\
\text { and objectives is not specified. In } \\
\text { addition the goals and objectives as } \\
\text { stated do not adequately address the } \\
\text { conservation challenges. The depth of } \\
\text { NBSAPs is rather shallow and their } \\
\text { scope fails to cover all critical and } \\
\text { underlying conservation barriers. The } \\
\text { desired conservation outcomes have not } \\
\text { been clearly established. } \\
\text { The National capacities - institutional, } \\
\text { scientific and social are low. There are } \\
\text { no adequately trained local } \\
\text { conservationist personnel. Coordination } \\
\text { of conservation activities across sectors } \\
\text { and jurisdictions is weak and national } \\
\text { support to local level institutions of } \\
\text { does not exist. Local reports do not } \\
\text { exist in the NCHM. Public-private } \\
\text { partnerships are very weak. }\end{array}$ & $\begin{array}{l}\text { Problems identified include: } \\
\text { Poaching, very little research } \\
\text { in this region, logging } \\
\text { concessions, hunting, river } \\
\text { pollution and sedimentation, } \\
\text { land degradation, erosion and } \\
\text { desertification. } \\
\text { WWF has focused on: } \\
\text { reducing illegal offtake of } \\
\text { wildlife, partnering for new, } \\
\text { effective and sustainable } \\
\text { protected areas, } \\
\text { Advancement of green } \\
\text { economy and building } \\
\text { durable mechanisms to } \\
\text { conserve biodiversity, and } \\
\text { that forests and carbon. }\end{array}$ & $\begin{array}{l}\text { Problems: Illegal bushmeat trade } \\
\text { and habitat degradation, political } \\
\text { instability, widespread poverty, } \\
\text { wildlife poaching, deforestation, } \\
\text { mining, poor water quality, } \\
\text { agriculture and logging. There are } \\
\text { no adequate environmental } \\
\text { institutions, no adequate funding } \\
\text { for conservation, government is } \\
\text { not able to enforce environmental } \\
\text { laws, big gap between legislation } \\
\text { and practice. Missing } \\
\text { mechanisms to coordinate } \\
\text { cooperation between various } \\
\text { sectors, } \\
\text { Assessment of at risk species of } \\
\text { both plants and animals, assisting } \\
\text { with the development of Ape } \\
\text { conservation plans, and works in } \\
\text { close collaboration with ministry } \\
\text { of environment, nature } \\
\text { conservation \& tourism. } \\
\text { Conducting studies to identify } \\
\text { critical threats to gorillas, } \\
\text { chimpanzees and their habitats. }\end{array}$ & $\begin{array}{l}\text { Problems: Habitat destruction, } \\
\text { conversion of forest lands to } \\
\text { agriculture, and pastures, fuel- } \\
\text { wood, unsustainable logging, } \\
\text { great dependence on natural } \\
\text { resources by communities, } \\
\text { Conservation International has } \\
\text { developed partnerships with } \\
\text { local communities to improve } \\
\text { human well-being while } \\
\text { conserving natural resources, } \\
\text { design strategies to mitigate } \\
\text { causes of forest loss, identify } \\
\text { main agents and drivers of } \\
\text { deforestation. } \\
\text { Emissions from Deforestation } \\
\text { and Forest Degradation (REDD), }\end{array}$ \\
\hline
\end{tabular}


Table 22b: Government and NGOs collaboration in Indonesia

\begin{tabular}{|c|c|c|c|}
\hline \multirow{2}{*}{$\begin{array}{c}\text { Areas of lowest conservation } \\
\text { compliance }\end{array}$} & \multicolumn{3}{|c|}{ Key focus areas by Conservation Organization } \\
\hline & World Wildlife Fund & $\begin{array}{l}\text { International Union for } \\
\text { Conservation of Nature }\end{array}$ & Conservation International \\
\hline $\begin{array}{l}\text { Both national and local institutions } \\
\text { are weak. Capacity building activities } \\
\text { are not well targeted and are not } \\
\text { adequate. The country does not } \\
\text { conduct enough surveys, research } \\
\text { and data collection activities. The } \\
\text { goals and objectives developed in the } \\
\text { plan documents are not deep enough } \\
\text { to tackle the underlying conservation } \\
\text { barriers and are also not broad } \\
\text { enough to address all biodiversity } \\
\text { resources. Funding opportunities are } \\
\text { limited and funds allocated to } \\
\text { conservation are extremely low. } \\
\text { Institutional capacity building at both } \\
\text { national and local levels is very low. } \\
\text { Coordination between local and } \\
\text { national institutions is poor. } \\
\text { Legislation is weak, support to local } \\
\text { level institutions is weak, monitoring } \\
\text { and evaluation of implementation } \\
\text { almost non-existent. National } \\
\text { conservation institutions are not fully } \\
\text { developed. Local reports do not exist } \\
\text { at national level CHMs. } \\
\text { Public-Private Partnerships are not } \\
\text { strong. }\end{array}$ & $\begin{array}{l}\text { WWF's mission is to stop the degradation } \\
\text { of the planet's natural environment and to } \\
\text { build a future in which humans live in } \\
\text { harmony with nature. Pulp and paper } \\
\text { Industries and oil palm plantations are the } \\
\text { leading causes of rapid rates of } \\
\text { deforestation. } \\
\text { WWF therefore supports sustainable } \\
\text { management of ecosystems and promotes } \\
\text { community welfare management efforts. } \\
\text { It has called upon the pulp and oil palm } \\
\text { industries to work with the government to } \\
\text { conserve elephant habitats. } \\
\text { WWF has conducted studies on Palm Oil } \\
\text { management, Elephants protection in } \\
\text { collaboration with local institutions. } \\
\text { Has facilitated the creation of smallholder } \\
\text { palm oil production certification program } \\
\text { that is geared towards the sustainable } \\
\text { management palm oil plantations. } \\
\text { Forests protection through pushing the } \\
\text { Asia paper \& Pulp company to stop } \\
\text { clearing forests and peatlands to allow an } \\
\text { assessment of their conservation and } \\
\text { carbon values. }\end{array}$ & 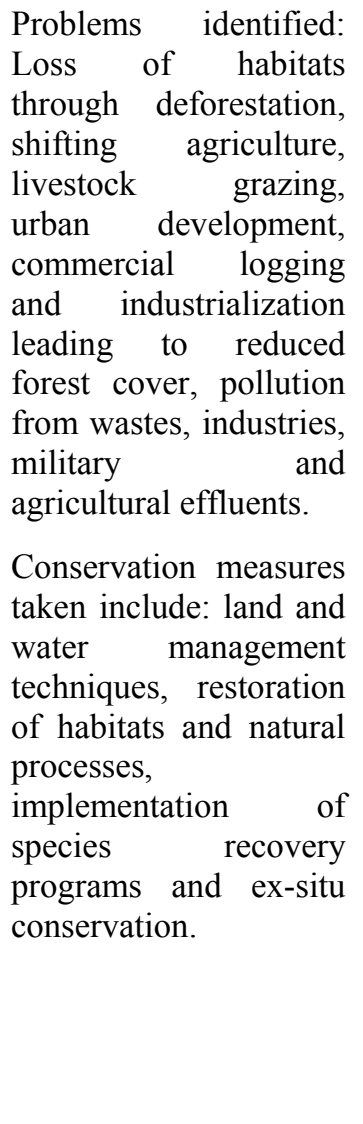 & $\begin{array}{l}\text { Problems: Over-exploitation of } \\
\text { marine resources, poor coastal } \\
\text { development, poor planning, } \\
\text { water pollution, air pollution, un- } \\
\text { processed waste from factories, } \\
\text { over-fishing, global ocean } \\
\text { acidification. Other problems } \\
\text { relate to deforestation, } \\
\text { greenhouse gas emissions. } \\
\text { CI has been helping local } \\
\text { governments to develop } \\
\text { environmental assessments, } \\
\text { spatial planning, works with } \\
\text { public and private sectors to train } \\
\text { farmers to improve the quality } \\
\text { and quantity of agricultural } \\
\text { products. Assisitng farmers with } \\
\text { sustainable farming techniques, } \\
\text { educating local people to } \\
\text { improve participation in } \\
\text { conservation, natural resources } \\
\text { management, conducts public } \\
\text { awareness campaigns. Currently } \\
\text { working with public and private } \\
\text { sectors to implement integrated } \\
\text { watershed management to } \\
\text { protect forests and water supply. }\end{array}$ \\
\hline
\end{tabular}


Table 22c: Government NGOs collaboration in Brazil

\begin{tabular}{|c|c|c|c|}
\hline \multirow{2}{*}{$\begin{array}{c}\text { Areas of lowest conservation } \\
\text { compliance }\end{array}$} & \multicolumn{3}{|c|}{ Key focus areas by Conservation Organization } \\
\hline & World Wildlife Fund & $\begin{array}{c}\text { International Union } \\
\text { for Conservation of } \\
\text { Nature }\end{array}$ & Conservation International \\
\hline $\begin{array}{l}\text { The quality of NBSAPs is low } \\
\text { due to non-committal language } \\
\text { used and lack of realistic } \\
\text { timelines for stated } \\
\text { conservation activities. } \\
\text { Funding opportunities are both } \\
\text { limited and extremely low. } \\
\text { The National and local } \\
\text { institutional capacities are } \\
\text { weak, their coordination is } \\
\text { poor and national support to } \\
\text { local level institutions is not } \\
\text { good enough. There are no } \\
\text { strong legislations. The } \\
\text { country lacks the capacity to } \\
\text { carry out monitoring and } \\
\text { evaluation. Both reports and } \\
\text { national plans have no } \\
\text { information regarding surveys, } \\
\text { research and data collection. } \\
\text { There are no local reports and } \\
\text { data. }\end{array}$ & $\begin{array}{l}\text { Problems identified as barriers to conservation are: } \\
\text { the lack of allied planning, weak governance } \\
\text { systems, and failure to comply with environmental } \\
\text { legislation. Others include high demand for natural } \\
\text { resources as a result of population growth, } \\
\text { alarming rate of deforestation, water pollution, } \\
\text { logging, mining and agricultural expansion. } \\
\text { WWF supports the government to establish } \\
\text { conservation budgets of } 0.5 \% \text { of GDP per year, } \\
\text { guide private companies to follow environmental } \\
\text { laws and seeks innovations to help reduce use of } \\
\text { natural resources especially water. Expansion } \\
\text { investment in human resources to expand } \\
\text { knowledge, It conducts studies, fosters public } \\
\text { policies, monitoring of wild species, establishment } \\
\text { of ecological corridors and improvement of the } \\
\text { management of protected areas. } \\
\text { Encourages the creation and expansion of } \\
\text { protected areas, responsible use and sustainable } \\
\text { management of natural resources, promotion of } \\
\text { environmental and social standards, technical and } \\
\text { community capacities. }\end{array}$ & $\begin{array}{l}\text { IUCN is doing } \\
\text { ecological restoration } \\
\text { in Brazil. Helping the } \\
\text { government with } \\
\text { establishment of } \\
\text { protected areas. } \\
\text { IUCN is also } \\
\text { facilitating better } \\
\text { coordination between } \\
\text { institutions. }\end{array}$ & $\begin{array}{l}\text { Problems: Expanding road } \\
\text { networks, building of dams, } \\
\text { deforestation, climate change, } \\
\text { development, and violent land } \\
\text { conflicts. } \\
\text { CI works to protect land and } \\
\text { cultural traditions, strengthens } \\
\text { surveillance and institutional } \\
\text { capacities to indigenous } \\
\text { associations, provides economic } \\
\text { alternatives to logging, supports } \\
\text { logistical needs for both } \\
\text { surveillance and data collection. } \\
\text { Has created a fund to support } \\
\text { long-term conservation, this } \\
\text { fund facilitates monitoring and } \\
\text { land protection, development of } \\
\text { sustainable economic activities, } \\
\text { and capacity building to local } \\
\text { organizations. }\end{array}$ \\
\hline
\end{tabular}




\subsubsection{Application of systems theory}

Tables 22a to 22c can be better explained using the systems theory. Biodiversity protection weaknesses that exist in governments, those identified by conservation organizations, and how these problems are collectively or singularly addressed is a systems driven approach. It is clear that there is no uniformity between the real challenges found in governments and what conservation organizations want to do. For successful implementation and improved compliance, international conservation organizations should first try to understand government systems in the context capacities, governance challenges, and then try to develop their programs from the positions of governments.

In the Democratic Republic of Congo, some of the key national biodiversity protection challenges are the low quality of NBSAPs, low national capacities, few and weak national agencies, weak legislation, and poor coordination between various sectors. The country lacks data on biological resources, and little or no studies/surveys are being conducted. Conservation organizations are not addressing challenges that this government seems to face, but rather, have chosen to address direct causes of biodiversity degradation.

Indonesia is also having problems with low national and local capacities, poor national coordination, low quality NBSAPs, weak legislation, and not fully developed national institutions. On the other hand, conservation organizations have focused on conservation through emphasis on sustainable management, land and water management techniques, restoration of habitats, environmental assessments, and integrated watersheds 
management. There is no clear systems linking conservation organizations to government initiated programs.

Brazil is facing a systems breakdown between biodiversity protection challenges identified at the government level and what conservation organizations are doing. The quality of NBSAPs is low, there is limited and insufficient funding to support biodiversity protection, there is poor inter-agency coordination, there is no data, and very little support to local level institutions. Conservation organizations are trying to institute allied planning, asking the government to allocate funding to natural resources protection, investing in human resources to educate and raise awareness, and asking private companies to follow environmental laws. These organizations are also conducting ecological restoration activities, helping establish more protected areas, and protecting land and cultural traditions.

It was clear from this analysis that the exact nature of conservation problems that arise within governments, communities and conservation organizations can be viewed as autonomous independent systems. For better management of conservation problems, a concerted action that brings all these efforts together to develop a whole system, rather than separate systems, would lead to better implementation and higher compliance. As can be seen from these tables, conservation problems identified within government are different from what conservation organizations want to address. Protecting biological resources requires a multi-dimensional relationship on the basis of a shared understanding of the nature of specific problems and the meaning of policies designed to address such problems. This confirms the third hypothesis because the approaches taken 
by various stakeholders toward conservation are different, and interpretation is different, thus leading to low compliance with $\mathrm{CBD}$ goals.

Organizations are best managed when they are viewed as a form of information network - with the flow of information providing decision makers at varying management levels with information needed to make decisions of all types (Mockler, 1968). Development of systems in management is viewed as one way that efficiently meets the demands on public institutions, lowers administrative costs and improves service delivery (Myeong \& Choi, 2010). Public institutions use systems approach to reduce uncertainty and ambiguity about goals and cause-effect relationships during the time of implementation. The CBD needs to find ways that link conservation efforts by all stakeholders in biodiversity protection to improve efficiency and avoid duplication.

Management of biological resources is a complex process of balancing immediate benefits with long-term conservation goals and political priorities (Wang, 2004). Generation of relevant information and data sharing is crucial to reaching an optimal balance of various stakeholder interests (Simon, 1977). Systems theory helps to find answers to questions on how globally designed biodiversity protection programs fit into the needs of local situations, as well as effective relationships between global and local institutions (Deming, 1986). The purpose of an institution according to the living systems theory is to reach a desired steady state where institutions are effective and their existence to continue to meet specified goals is guaranteed (Wang, 2004). 


\subsection{Local level implementation}

My study relied on secondary global data gathered by AGF to help examine local compliance and implementation. The data was constructed on a 5-point Likert scale starting with "A" strongly disagree, "C" I do not know, and "E" strongly agree with various statements relating to local level compliance. The AGF (2012) notes that there are communication problems, and therefore, conditions of the global environment are poorly understood at local levels. Additional data generated from qualitative analysis and supplemented with numerical data from Global Footprint Network was used. Quantitative analysis is more about numbers. It is a way of trying to explore what the numbers representing specific data are saying, and what can be concluded about such numbers.

\subsubsection{Local level compliance}

In addition to the communication problems, the public needs to be educated, their conservation capacity needs to be developed, and they need funding for local conservation activities. This is so they can understand and be able to implement conservation programs that either stop or begin to reverse biodiversity degradation. Education, funding and capacity building come in the context of national government support to local governments and institutions (Lo \& Fryxel, 2005; Van Rooij \& Lo, 2010). In the study conducted in Guangzhu, China, Lo et al. (2012) found out that a lack of adequate political and administrative support by the national government at all levels seriously undermines regulatory effectiveness and implementation at local levels. 
Table 23: Analysis of local level implementation

\begin{tabular}{|c|c|c|c|c|c|c|c|}
\hline Responses & Rank & $\begin{array}{l}\text { Western } \\
\text { Europe }\end{array}$ & $\begin{array}{l}\text { Eastern } \\
\text { Europe }\end{array}$ & Asia & $\begin{array}{l}\text { Latin } \\
\text { America }\end{array}$ & Africa & $\begin{array}{l}\text { Middle } \\
\text { East }\end{array}$ \\
\hline \multirow{5}{*}{$\begin{array}{l}\text { Easy to comprehend info info } \\
\text { is not communicated from } \\
\text { conservation experts to the } \\
\text { public }\end{array}$} & $\mathrm{A}$ & 9 & 0 & 7 & 0 & 8 & 6 \\
\hline & B & 13 & 0 & 24 & 7 & 8 & 9 \\
\hline & $\mathrm{C}$ & 4 & 17 & 31 & 0 & 0 & 6 \\
\hline & $\mathrm{D}$ & 39 & 17 & 132 & 43 & 17 & 41 \\
\hline & $\mathrm{E}$ & 35 & 50 & 100 & 43 & 58 & 36 \\
\hline \multirow{5}{*}{$\begin{array}{l}\text { Conservationists focus } \\
\text { communication too heavily } \\
\text { upon political decision } \\
\text { makers, failing to reach the } \\
\text { public }\end{array}$} & $\mathrm{A}$ & 4 & 0 & 15 & 0 & 8 & 0 \\
\hline & B & 17 & 17 & 68 & 14 & 17 & 33 \\
\hline & $\mathrm{C}$ & 22 & 0 & 77 & 14 & 8 & 33 \\
\hline & $\mathrm{D}$ & 39 & 50 & 76 & 29 & 33 & 33 \\
\hline & $E$ & 17 & 17 & 36 & 36 & 25 & 0 \\
\hline \multirow{5}{*}{$\begin{array}{l}\text { Political decision makers do } \\
\text { not communicate information } \\
\text { from environmental experts to } \\
\text { the public }\end{array}$} & A & 4 & 17 & 3 & 0 & 0 & 0 \\
\hline & $\mathrm{B}$ & 9 & 17 & 10 & 14 & 0 & 0 \\
\hline & $\mathrm{C}$ & 17 & 0 & 63 & 0 & 0 & 0 \\
\hline & $\mathrm{D}$ & 35 & 17 & 137 & 21 & 58 & 67 \\
\hline & $E$ & 35 & 50 & 77 & 64 & 33 & 33 \\
\hline \multirow{5}{*}{$\begin{array}{l}\text { Public does not value the } \\
\text { information provided by } \\
\text { environmental experts unless } \\
\text { disaster occurs in their } \\
\text { vicinity. }\end{array}$} & $\mathrm{A}$ & 0 & 33 & 10 & 0 & 0 & 0 \\
\hline & $\mathrm{B}$ & 26 & 17 & 22 & 7 & 0 & 0 \\
\hline & $\mathrm{C}$ & 9 & 0 & 31 & 14 & 8 & 0 \\
\hline & $\mathrm{D}$ & 35 & 50 & 138 & 29 & 25 & 67 \\
\hline & $\mathrm{E}$ & 30 & 0 & 88 & 50 & 58 & 33 \\
\hline \multirow{5}{*}{$\begin{array}{l}\text { Non-profit organizations } \\
\text { overemphasize } \\
\text { Communications efforts on } \\
\text { political decision makers. }\end{array}$} & $\mathrm{A}$ & 9 & 0 & 5 & 0 & 0 & 0 \\
\hline & $\mathrm{B}$ & 22 & 17 & 59 & 14 & 8 & 0 \\
\hline & $\mathrm{C}$ & 35 & 33 & 107 & 14 & 33 & 33 \\
\hline & $\mathrm{D}$ & 22 & 33 & 90 & 50 & 33 & 67 \\
\hline & $E$ & 13 & 17 & 27 & 14 & 17 & 0 \\
\hline \multirow{5}{*}{$\begin{array}{l}\text { Certain education level is } \\
\text { necessary for understanding } \\
\text { of environmental information, } \\
\text { and environmental education } \\
\text { is lacking. }\end{array}$} & $\mathrm{A}$ & 4 & 0 & 3 & 0 & 0 & 0 \\
\hline & B & 13 & 0 & 34 & 7 & 0 & 0 \\
\hline & $\mathrm{C}$ & 13 & 17 & 39 & 21 & 8 & 0 \\
\hline & $\mathrm{D}$ & 48 & 33 & 111 & 14 & 25 & 33 \\
\hline & $\mathrm{E}$ & 22 & 50 & 105 & 57 & 58 & 67 \\
\hline \multirow{5}{*}{$\begin{array}{l}\text { The economic profits of a } \\
\text { corporation, organization, } \\
\text { or a region are prioritized so } \\
\text { much that environmental } \\
\text { considerations are not taken } \\
\text { into account. }\end{array}$} & A & 2 & 0 & 6 & 44 & 3 & 0 \\
\hline & B & 7 & 0 & 0 & 61 & 0 & 20 \\
\hline & $\mathrm{C}$ & 2 & 4 & 6 & 37 & 0 & 0 \\
\hline & $\mathrm{D}$ & 31 & 17 & 28 & 147 & 16 & 20 \\
\hline & $\mathrm{E}$ & 57 & 75 & 56 & 206 & 77 & 60 \\
\hline
\end{tabular}

A: Strongly disagree B: Somewhat disagree C: Neither (I don't know) D: Somewhat agree E: Strongly agree

Source: ASAHI Global Foundation, 2012 
Local government agencies and other local institutions may be lacking in sufficient capacities in the form of trained manpower and financial resources, thus making them inadequately prepared to enforce and implement desired conservation policies. Other internal obstacles include poor coordination with other stakeholders, poor communication, poor management practices, and conflicting objectives (Lo et al., 2012). Table 23 above highlights problems that exist when the public does not sufficiently understand what needs to be done, and the different levels of understanding between politicians, policy makers and conservation organizations.

Analysis of this kind of data helps to put into perspective the relationships between different stakeholders in conservation. This helps to strengthen areas that need attention and identify obstacles that hinder implementation. This table also presents specific elements of local compliance on a 5-point Likert scale from "Strongly Disagree" to "Strongly Agree."

\subsubsection{Reconciling conservational initiatives from local to global levels}

One of the key challenges facing the international community is the ability to tell how individuals, communities and local governments are experiencing biodiversity protection programs at local levels. The degree of non-compliance with the CBD goals can therefore best be explained by an understanding of actual implementation efforts at local and national government levels. It is at local settings that government regulations/laws that govern the society are most felt, frameworks for political relationships are developed and where specific policies and practices are implemented. Priorities at these levels need to be synchronized towards satisfying "common goods" 
Any plan that promotes biodiversity protection at local levels should be developed with the main objective of changing people's perceptions, improving local knowledge, and creating specific institutions to manage biological resources (Alexander, 2005). This calls for biodiversity protection to be pursued simultaneously at three levels, global, national/country and local levels. Involvement of local institutions and communities in the design and program implementation is only possible if people at local levels know what the government and conservation experts are doing.

Table 24: Perceptions on compliance and implementation at local levels

\begin{tabular}{|c|c|c|c|c|c|c|c|}
\hline Factors/Statements & Rank & $\begin{array}{l}\text { Western } \\
\text { Europe }\end{array}$ & $\begin{array}{l}\text { Eastern } \\
\text { Europe }\end{array}$ & Asia & $\begin{array}{l}\text { Latin } \\
\text { America }\end{array}$ & Africa & $\begin{array}{l}\text { Middle } \\
\text { East }\end{array}$ \\
\hline \multirow{5}{*}{$\begin{array}{l}\text { Societal and cultural } \\
\text { practices that place } \\
\text { importance on "common } \\
\text { good," like environment, } \\
\text { are lacking or fragile. }\end{array}$} & $\mathrm{A}$ & 2 & 0 & 4 & 5 & 5 & 0 \\
\hline & $\mathrm{B}$ & 9 & 0 & 44 & 0 & 18 & 0 \\
\hline & $\mathrm{C}$ & 9 & 6 & 59 & 14 & 0 & 0 \\
\hline & $\mathrm{D}$ & 47 & 69 & 209 & 52 & 47 & 40 \\
\hline & $\mathrm{E}$ & 31 & 25 & 119 & 24 & 32 & 60 \\
\hline \multirow{5}{*}{$\begin{array}{l}\text { Societal practices and } \\
\text { traditions that value the } \\
\text { weak, including } \\
\text { environment, are few and } \\
\text { far between. }\end{array}$} & A & 0 & 6 & 6 & 5 & 0 & 0 \\
\hline & B & 11 & 0 & 67 & 10 & 32 & 0 \\
\hline & $\mathrm{C}$ & 20 & 31 & 70 & 24 & 16 & 20 \\
\hline & $\mathrm{D}$ & 47 & 31 & 190 & 48 & 16 & 80 \\
\hline & $\mathrm{E}$ & 18 & 25 & 78 & 10 & 37 & 0 \\
\hline \multirow{5}{*}{$\begin{array}{l}\text { At most, people have } \\
\text { capacity to recognize } \\
\text { environmental conditions } \\
\text { and effects on local level } \\
\text { but not globally. }\end{array}$} & A & 7 & 6 & 19 & 0 & 0 & 0 \\
\hline & $\mathrm{B}$ & 15 & 38 & 99 & 10 & 16 & 20 \\
\hline & $\mathrm{C}$ & 13 & 0 & 72 & 19 & 11 & 20 \\
\hline & $\mathrm{D}$ & 38 & 38 & 151 & 38 & 42 & 20 \\
\hline & $\mathrm{E}$ & 25 & 13 & 96 & 29 & 32 & 40 \\
\hline \multirow{5}{*}{$\begin{array}{l}\text { Human decision-making } \\
\text { process is based on self- } \\
\text { preservation and not } \\
\text { consider happiness of others } \\
\text { or of future generations. }\end{array}$} & A & 5 & 0 & 21 & 5 & 5 & 0 \\
\hline & $\mathrm{B}$ & 13 & 6 & 79 & 19 & 16 & 0 \\
\hline & $\mathrm{C}$ & 13 & 19 & 90 & 14 & 11 & 20 \\
\hline & $\mathrm{D}$ & 45 & 44 & 187 & 33 & 26 & 60 \\
\hline & $\mathrm{E}$ & 22 & 31 & 59 & 24 & 42 & 20 \\
\hline \multirow{5}{*}{$\begin{array}{l}\text { Human nature to care for } \\
\text { others is overwhelmed by } \\
\text { behavioral principles based } \\
\text { on economic } \\
\text { considerations. }\end{array}$} & A & 0 & 0 & 12 & 10 & 0 & 0 \\
\hline & B & 7 & 6 & 54 & 10 & 5 & 0 \\
\hline & $\mathrm{C}$ & 11 & 19 & 62 & 5 & 11 & 0 \\
\hline & $\mathrm{D}$ & 47 & 38 & 196 & 29 & 42 & 60 \\
\hline & E & 33 & 38 & 98 & 43 & 42 & 40 \\
\hline
\end{tabular}

Source: ASAHI Global Foundation, 2012

A: Strongly disagree B: Disagree C: Neither (I don’t know) D: Agree E: Strongly agree 
Inability to engage local communities makes it difficult to bring about change to local perceptions needed in order to understand the value of protecting biodiversity (Myeong \& Choi, 2010).

Table 25: Perceptions on compliance and implementation at national and international levels

\begin{tabular}{|c|c|c|c|c|c|c|c|}
\hline Factors/Statements & Rank & $\begin{array}{l}\text { Western } \\
\text { Europe }\end{array}$ & $\begin{array}{l}\text { Eastern } \\
\text { Europe }\end{array}$ & Asia & $\begin{array}{l}\text { Latin } \\
\text { America }\end{array}$ & Africa & $\begin{array}{l}\text { Middle } \\
\text { East }\end{array}$ \\
\hline \multicolumn{8}{|l|}{ National Systems } \\
\hline \multirow{5}{*}{$\begin{array}{l}\text { National decisions } \\
\text { influenced by political, } \\
\text { business, and organizational } \\
\text { interests and do not reflect } \\
\text { the will of the public, who } \\
\text { shoulder the environment. }\end{array}$} & A & 2 & 0 & 12 & 10 & 0 & 0 \\
\hline & $\mathrm{B}$ & 5 & 0 & 24 & 0 & 0 & 0 \\
\hline & $\mathrm{C}$ & 11 & 13 & 40 & 10 & 11 & 0 \\
\hline & $\mathrm{D}$ & 38 & 38 & 173 & 14 & 32 & 20 \\
\hline & $\mathrm{E}$ & 44 & 50 & 240 & 62 & 58 & 80 \\
\hline \multirow{5}{*}{$\begin{array}{l}\text { Changes in national policy } \\
\text { face great resistance } \\
\text { (inertia), and as such it } \\
\text { tends to stay with business } \\
\text { as usual. }\end{array}$} & A & 4 & 0 & 13 & 5 & 0 & 0 \\
\hline & $\mathrm{B}$ & 7 & 6 & 32 & 14 & 11 & 0 \\
\hline & $\mathrm{C}$ & 11 & 25 & 80 & 0 & 11 & 0 \\
\hline & $\mathrm{D}$ & 24 & 38 & 220 & 38 & 32 & 20 \\
\hline & $\mathrm{E}$ & 55 & 31 & 147 & 43 & 47 & 80 \\
\hline \multicolumn{8}{|l|}{ International Systems } \\
\hline \multirow{5}{*}{$\begin{array}{l}\text { International organizations } \\
\text { like the U.N. are affected by } \\
\text { the will of countries, and do } \\
\text { not optimize the whole. }\end{array}$} & A & 2 & 0 & 11 & 10 & 5 & 0 \\
\hline & $\mathrm{B}$ & 9 & 0 & 26 & 0 & 0 & 0 \\
\hline & $\mathrm{C}$ & 7 & 19 & 46 & 10 & 5 & 0 \\
\hline & $\mathrm{D}$ & 18 & 25 & 150 & 38 & 47 & 40 \\
\hline & $\mathrm{E}$ & 84 & 86 & 210 & 43 & 42 & 60 \\
\hline \multirow{5}{*}{$\begin{array}{l}\text { Voting system at the U.N. } \\
\text { with its adherence to the } \\
\text { principle of unanimous } \\
\text { consent, makes decision- } \\
\text { making difficult. }\end{array}$} & $\mathrm{A}$ & 2 & 6 & 21 & 5 & 0 & 0 \\
\hline & B & 4 & 6 & 38 & 5 & 0 & 20 \\
\hline & $\mathrm{C}$ & 9 & 13 & 72 & 14 & 0 & 20 \\
\hline & $\mathrm{D}$ & 22 & 38 & 191 & 33 & 47 & 0 \\
\hline & $\mathrm{E}$ & 84 & 38 & 107 & 38 & 53 & 60 \\
\hline \multirow{5}{*}{$\begin{array}{l}\text { International organizations } \\
\text { like the U.N. are not } \\
\text { provided enforcement } \\
\text { powers or use of forceful } \\
\text { methods of coordination. }\end{array}$} & $\mathrm{A}$ & 4 & 0 & 13 & 14 & 0 & 0 \\
\hline & $B$ & 2 & 13 & 45 & 10 & 5 & 0 \\
\hline & $\mathrm{C}$ & 9 & 13 & 61 & 0 & 5 & 0 \\
\hline & $\mathrm{D}$ & 27 & 25 & 185 & 24 & 32 & 40 \\
\hline & $\mathrm{E}$ & 58 & 44 & 136 & 48 & 58 & 60 \\
\hline \multirow{5}{*}{$\begin{array}{l}\text { Systemic and organizational } \\
\text { reforms are needed, but } \\
\text { have not } \\
\text { been implemented. }\end{array}$} & $\mathrm{A}$ & 4 & 0 & 4 & 10 & 0 & 0 \\
\hline & B & 5 & 13 & 46 & 5 & 5 & 0 \\
\hline & $\mathrm{C}$ & 29 & 19 & 80 & 5 & 32 & 0 \\
\hline & $\mathrm{D}$ & 36 & 38 & 207 & 57 & 21 & 60 \\
\hline & $\mathrm{E}$ & 25 & 31 & 107 & 19 & 42 & 40 \\
\hline
\end{tabular}

A: Strongly disagree B: Disagree C: Neither (I don’t know) D: Agree E: Strongly agree

Source: ASAHI Global Foundation, 2012 
Table 25 above presents statements that contain data on local level compliance and implementation. It is the number of people and what they think about these statements that generated numbers for quantitative analysis of local level compliance. It is possible to relate societal practices, decision-making and capacities to national policies and international organizations.

\subsection{Opportunity costs of biodiversity protection}

Table 26 contains data from the Global Footprint Network showing the available biological resources and the level of use by each of the countries that were analyzed. This data provided information that was used to run regression analysis to determine the significance of various factors that most influence compliance and implementation. 
Table 26: Status on biological resources as of 2008

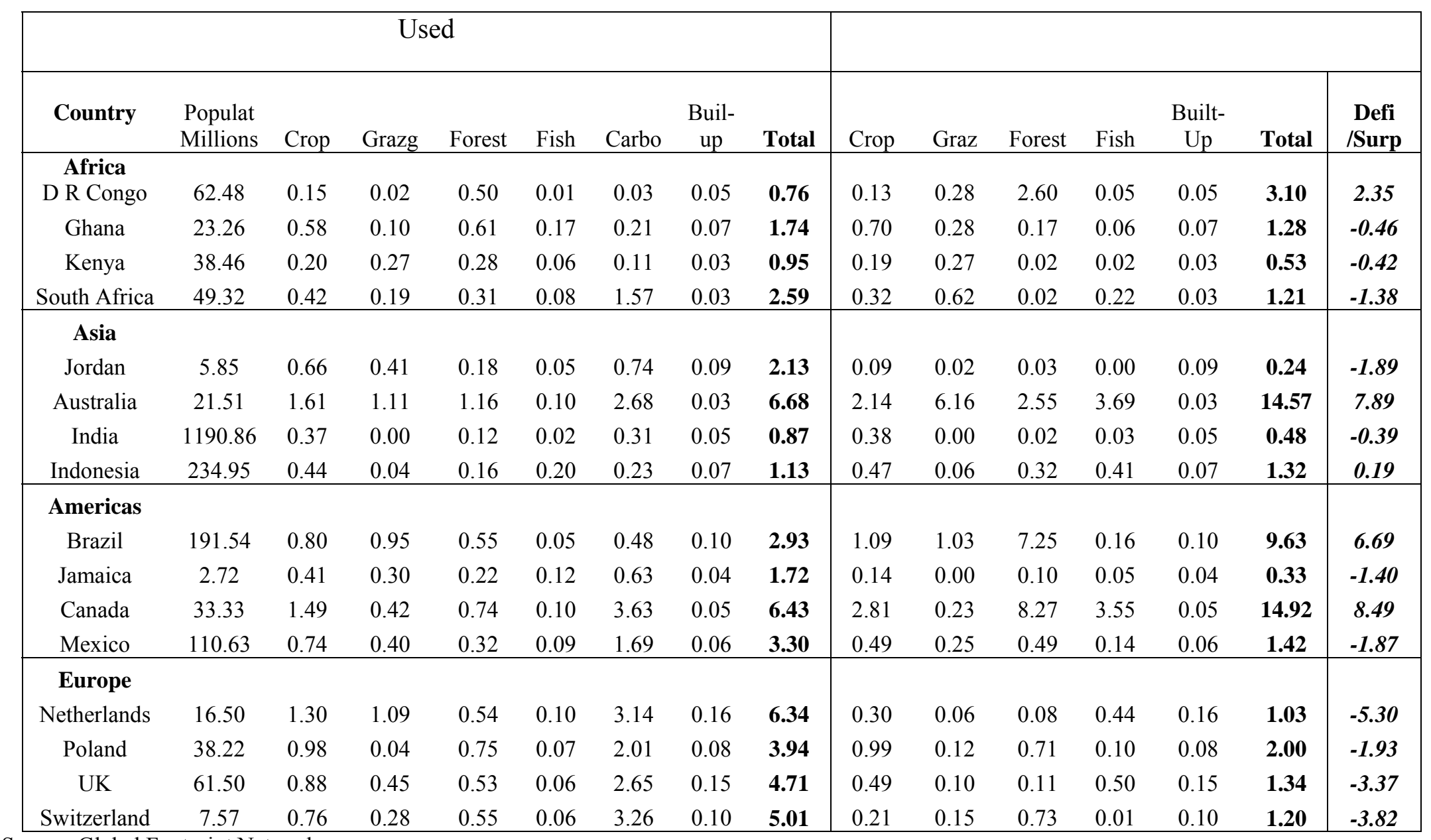

Source: Global Footprint Network 


\subsubsection{Estimation of opportunity cost compensation}

Table 27 below shows the different levels of biological capacity each country. Information on the level of biological resources in each country though true in many respects still requires a deeper interpretation on the deficit and surplus levels. This is necessary so that the real biological capacity picture is clear for each country. From the literal observation, the Democratic Republic of Congo (DRC), Australia, Canada and Brazil are the only countries with a surplus of biological capacity. The rest of the other countries are in biological resources deficit. Using size of land may not be the most efficient indicator of biological capacity because of different population densities.

Table 27: Opportunity cost and compensation estimates

\begin{tabular}{|l|l|l|l|l|l|}
\hline Country & $\begin{array}{l}\text { Deficit/Surplus } \\
\text { in Hectares } \\
1\end{array}$ & $\begin{array}{l}\text { Cost of land } \\
\text { per Hectare } \\
2(\mathrm{US} \$)\end{array}$ & $\begin{array}{l}\text { Total Deficit or } \\
\text { surplus in US\$ } \\
3=(1 \mathrm{X})\end{array}$ & $\begin{array}{l}\text { Total } \\
\text { Population in } \\
\text { Millions } \\
4=(2 X 3)\end{array}$ & $\begin{array}{l}\text { Biological } \\
\text { capacities } \\
5=(3 X 4) \\
\text { (US\$) }\end{array}$ \\
\hline D R Congo & 2.35 & 5000 & 11750 & 62.48 & 734140 \\
\hline Ghana & -0.46 & 6500 & -2990 & 23.26 & -69547.4 \\
\hline Kenya & -0.42 & 6500 & -2730 & 38.46 & -104995.8 \\
\hline S. Africa & -1.38 & 7000 & -9660 & 49.32 & -476431.2 \\
\hline Jordan & -1.89 & 11000 & -20790 & 5.85 & -121621.5 \\
\hline Australia & 7.89 & 5000 & 39450 & 21.51 & 848569.5 \\
\hline India & -0.39 & 3500 & -1365 & 1190.86 & -1625523.9 \\
\hline Indonesia & 0.19 & 3000 & 570 & 234.95 & 133921.5 \\
\hline Brazil & 6.69 & 1500 & 10035 & 191.54 & 1922103.9 \\
\hline Jamaica & -1.4 & 4500 & -6300 & 2.72 & -17136 \\
\hline Canada & 8.49 & 7000 & 59430 & 33.33 & 1980801.9 \\
\hline Mexico & -1.87 & 7000 & -13090 & 110.63 & -1448146.7 \\
\hline Netherlands & -5.3 & 10000 & -53000 & 16.5 & -874500 \\
\hline Poland & -1.93 & 8000 & -15440 & 38.22 & -590116.8 \\
\hline UK & -3.37 & 8000 & -26960 & 61.5 & -1658040 \\
\hline Switzerland & -3.82 & 8000 & -30560 & 7.57 & -231339.2 \\
\hline
\end{tabular}

Source: data from GFN and Real Estate companies in these countries 
The deficit/surplus data in hectares was obtained from table 26. The cost of land data in table 27 was obtained from real estate companies' websites via Google.com. These land costs are average costs of agricultural lands (both crops and grazing). The total deficit/surplus column was obtained by multiplying columns one and two (deficit/surplus X cost of land). Since biological capacity was measured in hectares per person, to obtain total opportunity costs therefore, I multiplied the total cost with the total population of each country as at 2008 to obtain figures in column five.

Estimation of compensation across countries was assumed should be based on the level of biological deficit a country has. All biodiversity deficit countries should support biodiversity protection activities in biodiversity surplus countries. The difficult with this scenario is that there are a lot of poor countries that have no capacity to support other countries but are in biodiversity deficit. Compensation for biodiversity protection may be a very difficult undertaking.

The DRC has a surplus equivalent to 2.35 hectares per person, Australia has 7.89 hectares per person, Brazil has 6.69 hectares per person and Canada has 8.49 hectares per person. Canada and Australia are extremely large countries with very small human populations. Since the units used to measure biological capacity is hectares per person, these countries are showing a surplus not because their biological resources protection programs are very superior but simply because of their size relative to human population.

As at 2008, Canada had a human population of 33.33 million people and is 1.17 bigger than Brazil which had a population of 191.54 million people. Canada is also 4.26 times bigger than DRC which had a population 62.48 million people, twice the 
population of Canada. Brazil is 1.11 bigger than Australia which had a population of 21.51 million people. Australia is bigger than DRC by 3.28 times. The status of biological capacity as presently measured cannot therefore be taken figuratively at face value.

The samples of countries selected from Europe all have a deficit in biological capacity. This does not mean that their biodiversity protection programs are in total disarray. It is merely a question of both lifestyle and levels of development. It is clear that the level of development of a country cannot be stopped and it cannot be reduced.

It is for this reason why it is important to estimate opportunity costs of conservation so as to determine the most appropriate compensation mechanisms. Some of the existing compensation schemes so far include off-set schemes, direct payments to those that have a surplus of biological resources to stop them from both over-exploitation, and facilitate sustainable use so that these are available to other people. These compensation mechanisms apply to both citizens within a country and also payment to countries that have a surplus.

The findings from table 27 can best be represented graphically as in figure 5 below. This figure shows all the countries that are in deficit (negative) and those that have a surplus (positive) supply of biological resources. Five out of the sixteen countries are in biological surplus section of the graph. The deficits are much more than surpluses. 
Figure 7: The status of each country's biological capacity

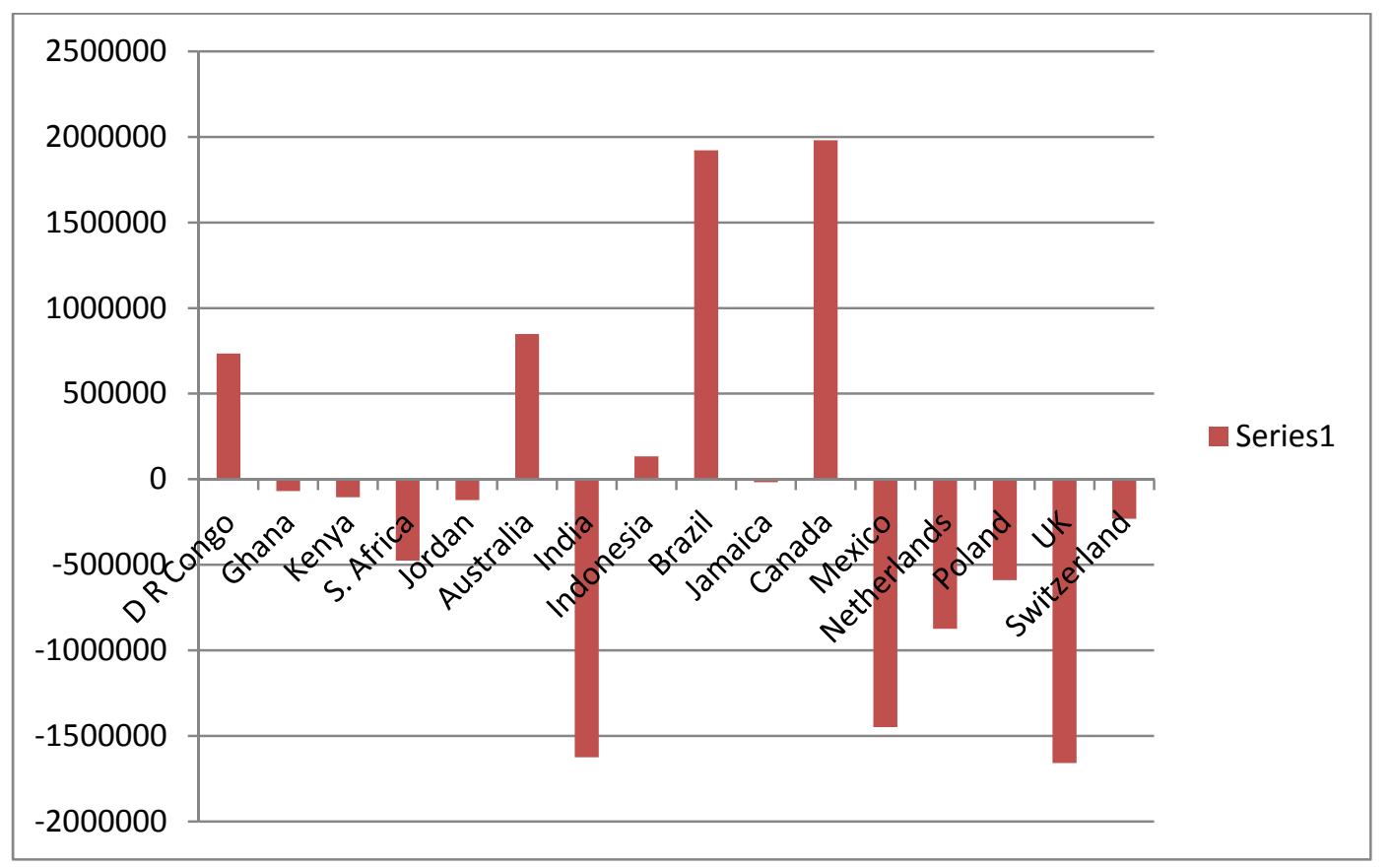

\subsubsection{Most appropriate compensation mechanisms}

The most appropriate compensation mechanisms should be programs that would compensate biodiversity rich countries the equivalent of the total of biological deficit in deficit countries. An underside to this approach is that biodiversity deficit countries might have their conservation capacities reduced further. This will be a bad outcome as it may lead to lower average global compliance. These findings do not provide a clear path to either rejecting or supporting the $4^{\text {th }}$ and final hypothesis which was stated as follows;

The use of appropriate compensation mechanisms to offset opportunity costs that would be incurred by those that supply biodiversity services will increase the 
probability of effective implementation and thus lead to higher compliance with CBD goals.

Compensation mechanisms can vary a lot both the country depending on the nature of the resource and cooperation between countries. Most compensation mechanisms take the form of financial resources. It is important to point out that compensation need not be purely in financial terms. There currently exists mechanisms that involve technological support, but a deeper analysis of the 20 criteria used to evaluate compliance reveals that compensation can take so many forms. Conservation needs cannot be restricted to financial terms alone.

\subsection{Implementation of the goals of the CBD}

The National Biodiversity Strategy and Action Plans (NBSAPs) prepared by countries are the primary biodiversity protection and policy documents guiding implementation. These are supposed to comprehensively cover all aspects on the conservation and sustainable use of biodiversity thus should facilitate better implementation and guide countries towards higher compliance. However, most of these NBSAPs fall short of a clear integration of many of the critical factors that most influence implementation and thus lead to low compliance.

The NBSAPs should include mechanisms to ensure that the capacity exists to implement projects, manage activities and monitor progress, including technology transfer. The plans should include regular monitoring and review, and follow adaptive management principles. 


\section{CHAPTER V}

\section{RESULTS AND DISCUSSION}

\subsection{Discussion of results}

Chapter five puts together the outcomes of this research to show both compliance and implementation challenges in the management of biological resources worldwide. The first section gives a summary of national capacity challenges of all countries that were examined. This is followed by a discussion on what is going on within and across countries. Explanations that try to reconcile the meaning of biodiversity protection across sectors are developed. Outcomes from game theory conservation strategies are discussed next. The chapter comes to a conclusion with findings from opportunity costs of biodiversity conservation.

\subsection{Introduction}

Conservation efforts aimed at enhancing biological resource protection within countries need to go beyond policy development at government level to include specific local level implementation programs. My study findings place local level implementation compliance level at a mere $14 \%$ and national policy level compliance at a modest 49.88\%. This is a big gap and is a clear demonstration that policies being developed at national level are not adequately supporting local level implementation. Development of national policies and plans are seen as first steps towards biodiversity protection, but these will remain just steps and mean very little if they do not get implemented. 
The target set by the CBD in 2002 to reverse biodiversity degradation by the year 2010 was not met by all countries (Barbault, 2010). Analysis of individual country plans and $4^{\text {th }}$ national reports also demonstrate a shortage of means, capacities and mechanisms to take national conservation policies to local levels for implementation. As long as there is no strong and active linkage between national policies and local implementation, biodiversity degradation will not be halted.

Research findings from ASAHI Glass Foundation (2012) found that communication from scientists and researchers to politicians, strategists and decision makers was not sufficient to promote changes in society for environmental protection. Most of the information is focused more on policy makers and less on implementers. Moreover, this information is not presented in a comprehensible format to the general public, hence it is not very appealing (ASAHI Glass Foundation, 2012). Further, research finds that once policy makers receive specific information, this information is not often communicated to the public or implementers and when, if it is at all communicated, the people at local levels do not have the capacity and training to comprehend it well. A certain minimum level of education is necessary for farmers and other stakeholders, at local levels, to fully understand conservation policies crafted at the global and national levels.

\subsection{Compliance and implementation capacity challenges}

There are several compliance and implementation challenges that emerged from analysis of data used in this study. First there are no clearly established cooperative strategies that can be categorized as either favorable or unfavorable across national 
boundaries or sectors. Within countries, it is clear how globally designed conservation policies get adapted to national priorities. What is not clear is how countries take these policies to local levels where actual implementation is done.

Virtually all NBSAPs demonstrate lack of adequate funding from both national governments and international donors for conservation programs. This leaves international organizations that come with their own funding to take the lead mostly at local levels. How these international organizations cooperate and work with local organizations is also not clear. Some national reports have shown that it is not everywhere that local institutions trust international organizations. The scale of the impact of international organizations on local implementation is difficult to measure.

\subsubsection{North and South America}

The Brazilian NBSAP in the CBD website does not use the word capacity. It is therefore difficult to tell exactly how Brazil has been planning for biodiversity protection capacities.

Jamaica NBSAP explains that most local communities lack capacities to carry out various types of integrated planning and management of biological resources. There are gaps in understanding conservation in general; thus a need for improved awareness raising, education and information sharing. There are ongoing risk assessments to determine carrying capacity for protected areas and sustainable use of wild Flora and Fauna. There are also capacity challenges at national policy level to reduce vulnerability of resources, conduct adaptive planning and institutional strengthening. The country is working at improving enforcement capacity, participating in global initiatives and is 
seeking financial and technical assistance to increase capacity to manage biological resources. The plan puts emphasis on the development of a specified strategic direction aimed at increasing capacity of human capital to be able to prepare, evaluate and implement environmental impact and risk assessment.

Mexico is still working on increasing human, institutional and financial capacity to meet biodiversity protection goals and needs, related to overall management. The country is also developing structures that provide information to people in decision making responsibility, for monitoring, control and mitigation of negative impacts.

Canada has an ongoing database capacities development that enables it to manage harmful Living Modified Organisms (LMO). Canada has put great emphasis on development of policies that reflect societal objectives and ecological carrying capacity of the planet. Canada supports research on ecological carrying capacity, works with national and international organizations to improve dialogue and communication, management and planning. The international community would need to assist some countries in their management capacities so that they can pursue economic activities in harmony with the Earth's biological capacity. Canada is cooperating with developing countries in capacity development toward biodiversity protection. The degree to which plans are able to enhance national capacities to conserve biological resources is seen as a measure of success.

\subsubsection{Europe}

\section{United Kingdom and the Republic of Northern Ireland}

The UK and the Republic of Northern Ireland draws lessons from historical agricultural development to place its NBSAP in context of current developments. The 
NBSAP argues that keeping of genetic variability is an extremely important social and economic resource as this is what enabled early man to develop crops and livestock which were a pre-requisite for settled agriculture. Continued development and global stability depends on the capacity to continue to maintain genetic variability. The plan explains that it is not desirable for invasive species to have the capacity to oust native species. Other aspects of capacities in the UK plan include the low financial capacity of zoos to maintain diverse collections and the land carrying capacity. Car travel in Great Britain for example has increased dramatically in the past 40 years and is projected to grow by a further $84 \%$ to $142 \%$ by 2025 . Accommodating such rate of growth through new capacity is likely to have a damaging impact on biodiversity, unless it is very carefully managed.

The government is working to ensure that forests are harvested in a way that allows capacity for renewal and is also trying to reduce over-capacity in fishing. The government is developing new capacity building courses such as those aimed at managing botanic gardens within the UK as well as providing support for capacity building and policy development in other countries. This is done through nongovernmental organizations (NGOs) whom the plan argues that in some countries provide the only national capacity to address environmental issues.

\section{Netherlands}

The Netherland's NBSAP puts more emphasis on sharing knowledge and capacity building for purposes of developing sustainable forestry, sustainable wood production and strengthening of governance and management. There is also emphasis to invest in sustaining the capacity of ecosystems to continue to provide goods and services 
especially in developing countries where most people are dependent on natural resources but lack the capacity to invest in sustainable management. Ecosystems have a certain level of resilience but persistent damage can lead to a dramatic decline in their capacity to continue providing environmental services. The Netherlands plan pays great attention to future conservation outcomes through supporting biodiversity protection by creating a strong capacity of ecological networks that can adapt to possible climate changes. Some of the key objectives include the promotion of sustainable fishing through innovations meant to reduce the fleet capacity under the European Fisheries Fund. The Netherlands government is also assisting developing countries to develop sustainable fisheries and capacity building in relation to biodiversity and water management, and support to international knowledge networks.

\section{Poland}

The Polish plan explains that the greatest conservation challenge in Poland is the country's low financial capacity. Poland does not have a good financial capacity to enable it to spend resources at a level corresponding to the needs of the conservation and sustainable use of biodiversity. A strong financial capacity is a pre-requisite for effective implementation of the CBD goals. In addition, Poland as a country clearly lacks the capacity to extend conservation to most needed areas such the marine environment. The country also does not have sufficient resources for improving research capacity.

\section{Switzerland}

The Swiss NBSAP has a well balanced approach to supporting national biodiversity conservation policies as well as to those of other countries. It is a government decision in line with Federal Council decision of 1 July 2008, to ensure the 
long-term conservation and promotion of biodiversity both in Switzerland and at global levels. The plan explains that connected habitats are a basic pre-requisite for ensuring that biodiversity is rich and has the capacity to remain resilient to climate change. There is a shared responsibility between the central government and its regions, and implementation is done in a participatory manner. Sustainable use of forest resources, the plan argues, contributes to the productive and performance capacity of the forest. Moreover, the resilience of forest ecosystem and sufficient habitat offers tranquility for wild animals. The word "capacity" is also used to describe the spreading capacity of invasive alien species, and their very high adaptability as well as competitive superiority.

\subsubsection{Africa}

\section{Kenya}

The Kenya NBSAP addresses concerns such as institutional capacities alongside biodiversity management incentives, research and training as well as impact assessments. The plan presents a clear proposal that capacity building should target law enforcement and regulatory agencies for the purposes of enhancing and streamlining implementation of environmental policies. The plan highlights the need to strengthen institutional systems for collaboration and establish linkages and networks to improve coordination. The plan also talks of capacity building in environmental economics, resource accounting, audit and valuation of biodiversity at tertiary levels. There is a need to strengthen bioprospecting capacity by equipping the national institutions to carry out research relevant to biotechnology, technology transfer, communication and linkages. The weaknesses 
identified in the Kenyan NBSAP include the low capacity for monitoring and evaluation, research and training, technical and scientific cooperation.

\section{Ghana}

The Ghanaian NBSAP is constructed as though biodiversity protection is for the international community's sake rather than as a national tool to protect national resources. The plan explains that capacity building is essential to ensuring an in-depth assessment of biological resources, promotion of community participation, strengthening the management of forests and protected areas. For instance, soil erosion has reduced the land carrying capacity, ground water re-charge and regeneration of vegetation in heavily settled areas. Further, the Akosombo dam's generation capacity is hindered by siltation.

There are initiatives to strengthen institutional capacities to gather and manage biodiversity scientific data and information. The plan talks of building human capacities at both local and national levels for assessment, conducting studies, ecosystems management through long and short-term training courses. There is a proposal to strengthen data and information management capacities to control and prevent fires for tourist areas and to stay within the resource carrying capacity.

\section{South Africa}

The word "capacity" was heavily used around institutional capacity building to conserve and prevent threats to biodiversity including capacity for sustainable use, access to benefit sharing, economic integration and poverty alleviation. However, there exists a financial and human resource capacity constraint at the government level. Specifically, the government lacks the ability to make negotiations, implement projects, monitor the implementation, offer effective participation and conduct risk assessments on Genetically 
Modified Organisms (GMOs), as well as manage protected areas. On the other hand, South Africa is home to well-established research capacity with a number of world renowned universities and scientific institutions that present good opportunities for biodiversity conservation research, development planning and community empowerment, as well as favorable environment for bio-prospecting.

Land degradation reduces the capacity for resources to regenerate. Across Africa, climate change is likely to accentuate social and ecological vulnerability and limit resources capacity to adapt to changes in ecosystem functioning. In order to implement policy and legislation effectively at local level, institutional and capacities need to be addressed. In addition, staff and expertise retention as well as awareness raising programs need to be developed. National and provincial agencies should develop common objectives, capacity sharing and joint accountability mechanisms for the management of habitats, and species across administrative boundaries. So many institutions play a role in biodiversity management thus a need for necessary capacity to collate data at genetic, species and ecosystem levels, planning and decision making. Various local levels should have the capacity to integrate biodiversity considerations into their spatial and economic planning. Moreover, they need to review environmental management programs and perform self-assessment to implement National Biodiversity Framework in relation to geographic and thematic priorities.

Non-Governmental and Community-Based Organizations are important partners in conservation and their capacity building is important. There is also mention of how HIV/AIDS impacts upon institutional capacities. The plan talks of strengthening capacity for international negotiation by developing common positions with other countries from 
the region. There is need for improved coordination of programs to build capacity across all relevant departments within the government.

\section{Democratic Republic of Congo (DRC)}

The analysis of the DRC NBSAP brings to light the key challenges of biodiversity protection that range from the feeling of isolation by national conservationists and trust on international organizations, in representing the views of local people to how political instability has dealt a big blow to conservation efforts. A lot of conservation challenges

are due to the civil wars that have plagued the country for close to five decades. The feeling of isolation comes from the fact that most conservation programs have not involved local experts and citizens. For instance, some of the key protected areas in the country were set up without consultation with local people which resulted in the eviction of local people without any form of compensation.

There are indications in the plan of strengthening the management capacity of existing protected areas and policy on national parks while taking into account concerns of local communities. The plan explains the need for institutional capacity building to manage funds as well as enforce legal provisions. The capacity to manage environmental conservation requires an effective legal and institutional framework, political will and local participation, awareness raising and private sector participation. The DRC is not well equipped in all these capacities and lacks structures to bring various sectors together. 


\subsubsection{Asia}

\section{India}

The Indian NBSAP highlights the need for appropriate institutionalization and human resource capacity building for all conservation ranging from capacities to implement measures for captive breeding to reducing constraints faced by various sectors. Sectors as forest sector manpower, management of river basins, grassroots levels to enable participatory decision-making and managing invasive alien species at different levels need to be strengthened financially, with communications and funding.

There are plans to help enhance the capacity of climate modeling in the country so people can understand the impacts of climate change on biodiversity at national and local levels. The country is also seeking technical and financial assistance from multilateral agencies for implementing the recommendations pertaining to mapping of ecologically sensitive areas along the coastline, control of pollution in the coastal waters from land based activities and capacity building and institutional development. Although the country has over a period of time developed a stable institutional structure for environmental management, there is still need to improve national capacities for biodiversity conservation and appropriate use of new technologies

\section{Jordan}

Jordan is currently building institutional capacities to implement the NBSAP. The Jordan NBSAP calls for respect of the environment's productive capacity. The plan begins with highlights of historical land uses saying that land resources have been exploited without regard to carrying capacity. The plan argues that there is now improved 
capacity building in areas of law enforcement and general environmental protection. Efforts aimed at building capacities of local ecologists and national capacity in conservation and management of biodiversity need to be stepped up. So far, inadequate technical and managerial capacity has been a hindrance to the development and implementation of protected area laws, policies and planning strategies. There is still need for local capacity building in the management of marine resources. The carrying capacity of many of the vegetated areas is way below current use for grazing animals as well as production capacities of many lands. Capacity to monitor alien species need improvement.

Although the carrying capacity of many areas has been exceeded, establishing limits is fraught with difficulties. Some areas such the embryonic eco-tourism market in Jordan could be developed and promoted to support biodiversity protection, there is no clear vision or the capacity to ensure that it is developed correctly. Rangelands are experiencing management difficulties and there is now a plan to build capacities of range managers. There is also a plan for building capacities for economic valuation of biodiversity. The country is putting in place a national and human capacity building structure to ensure a safe and healthy food and pharmaceutical products, and prevent transmission of diseases. Capacity building for the staff and stakeholders of the National Cleaner Production Center and Biotechnology is also being developed.

\subsection{Compliance within federally administered countries}

Large countries as well as small ones all seem to fit into one description - local and national institutional working relationships are weak and sometimes non-existent. 
National government agencies are weak and also in some countries too few to mount the level of effort that would implement strong conservation initiatives to drive the whole world towards higher compliance with CBD goals. Reports from local jurisdictions as well as key biodiversity hotspots are missing at national level. Support to local levels is weak both in funding as well as capacity building. Investment in human resources, appropriate technologies and institutional development is limited. Although Canada, India and Australia all have NCHMs, these have not been developed to effectively serve these countries.

\subsubsection{Countries with strong presence of conservation organizations}

The presence of international conservation organizations' headquarters in a country does not seem to have significant difference in compliance from other countries. One good example is Kenya that is home to the global UNEP headquarters and major regional headquarters of both WWF and IUCN. Kenya is one of the least compliant countries of the 16 countries analyzed. The Kenya NBSAP was not launched. It is not clear who drew the plan. The same plan has not been revised as required by the CBD. Other examples are Switzerland, Netherlands and the UK that have continued to overexploit their marine resources beyond levels that these can regenerate themselves. One interesting observation was that rather than these countries look to investing in conservation of national and local resources, they are supporting other countries to protect their resources. 


\subsubsection{High capacity countries and compliance levels}

High capacity countries are those that were seen as donors thus providing funding for other countries to do conservation. Compliance within these countries was therefore expected to be better than most countries. However, the findings from this study were disappointingly the opposite. High capacity countries face the same conservation challenges as low capacity countries of over-exploitation of biological resources. These countries not only over-exploit resources within their jurisdictions but also aid in the over-exploitation in other countries through international trade.

\subsubsection{Systems theory and information technology in conservation}

Very few governments have built an equivalent of GBIF at the national level. Some governments are not participating in the CHMs. Most are also not publishing their own data. Use of IT helps to relay information between different decision points to create an interactive environment between sectors, agencies and governments (Myeong \& Choi, 2010). An inclusive strategy encompassing implementation of IT interventions for

communication, data gathering, sharing and policy evaluation provides a feasible and reliable way forward in attaining better results in biodiversity conservation. When information and data gaps persist, effective policy implementation suffers, and costs of building consensus go up (Esty \& Ivanova, 2004).

The use of information technology across all levels is not developed in most countries. Even in countries that have the CHMs, these are merely documentation depository warehouses. They are static in the sense that the links do not have updated 
data, no local reports except a few that have been submitted to the CBD. There is not sufficient information to facilitate learning, and are not designed to engage all stakeholders effectively.

\subsection{Reconciling conservation initiatives for higher global compliance}

Compliance needs to be seen as a multi-level undertaking ranging from global, national to local level implementation. Conservation exists at three levels: global, national and local levels. Conservation issues are so different between these levels yet it is their sum that can either lead to better protection or continued biodiversity degradation. Furthermore, at these different levels, there are numerous sectors, all with very different interests. Against the perception that conservation programs are in conflict with both development and community needs, conservation initiatives need to be reconciled vertically across these levels and horizontally across all interests. Different stakeholders across sectors need to be made to feel that biodiversity conservation serves their needs as much it serves conservation interests. Only broad policies that address both conservation and stakeholder needs can achieve such a goal.

According to Wilshusen et al. (2002), the moral conservation argument supports the idea that the international community should act on behalf of nature in all countries. However, there is tension all the time between local and non-local interests. Findings from the analysis of NBSAPs, national reports and works of conservation organizations demonstrate how the same biodiversity problems are seen differently and how different solutions are offered to same problems by different stakeholders. There is a clear disconnect in the way conservationists work with governments as well as communities. 
There is need for an expanded dialogue between all stakeholders to help rank priorities, determine the level of commitment required across sectors and how to measure such commitments.

For many individuals, organizations, private sector institutions and governments, the pursuit of profits and economic development are of upmost priority and biodiversity conservation needs are secondary (AGF, 2012). The figure 8 below present findings from data of people interviewed globally on information how individuals, organizations and governments prioritize their interests. These findings do support the analytical findings from NBSAPs and various government national reports.

On average, about $80 \%$ of the respondents agree that other national interests take precedence over biodiversity protection. At the individual level, decisions are made based immediate benefits and economic considerations are given a higher priority over the needs of the environment. Respondents that felt that environmental considerations were given adequate attention across all sectors averaged about a mere $10 \%$.

Figure 8: Priorities of most sectors in society

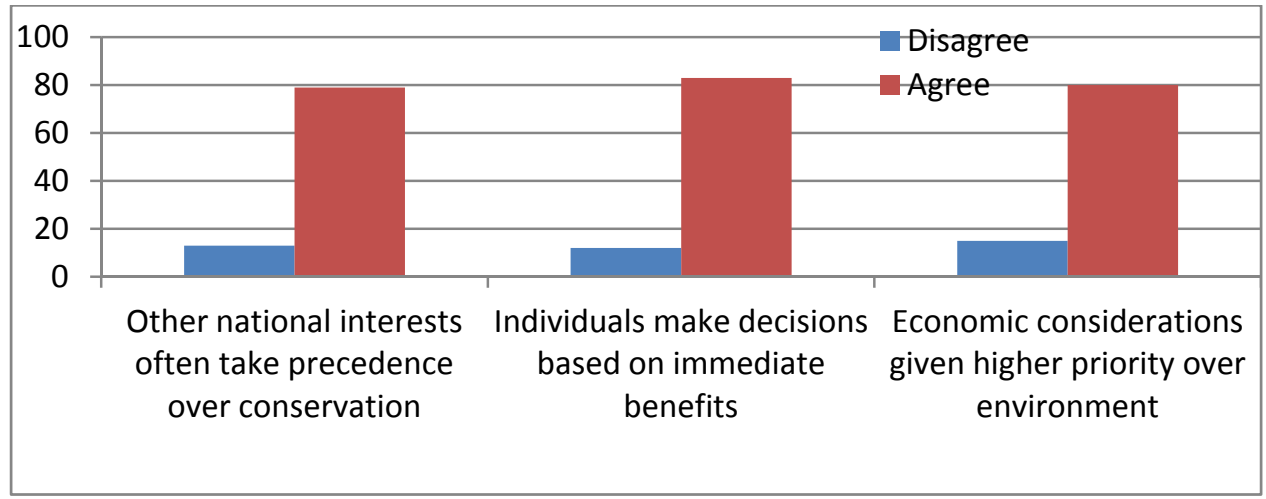

Source: Own Estimates using data from AGF 
Figure 9 below present findings from a Likert scale data about how countries make decisions and the limitations that they are likely to experience when making conservation decisions. This analysis also includes findings how international organizations facilitate the management of shared interests across countries and various sectors. Statements that generated these responses are found in table 28 below and were assigned numbers corresponding to the columns in figure 9 .

About $80 \%$ of the respondents agreed that national decisions are based on partial priorities that often relegate policies that optimize the whole to secondary considerations. More than $85 \%$ of respondents agreed that national decisions are heavily influenced by political, business and organizational interests which in most cases leave out the will of the public, who end up shouldering the costs of biodiversity degradation. About $78 \%$ of the respondents agreed that changes to environmental policies are often met with great resistance and as such, there is more support to the business as usual. More than $86 \%$ of interviewees agreed that International organizations are affected more by the will of countries thus fail to optimize their biodiversity protection goals alongside other national priorities. About $75 \%$ of the respondents also see a problem with the unanimous consensus principle especially with the United Nations system and agree that this leads to less than optimal decisions. There were more than $79 \%$ of the respondents that see the lack of international enforcement powers in the hands of international organizations as a source of weakness to global coordination. Finally, about $72 \%$ of the respondents felt that there is need for reforms in both systems and organizational structures so that new challenges as a result of environmental degradation can be taken into account. 
Figure 9: National decision making does not prioritize biodiversity protection

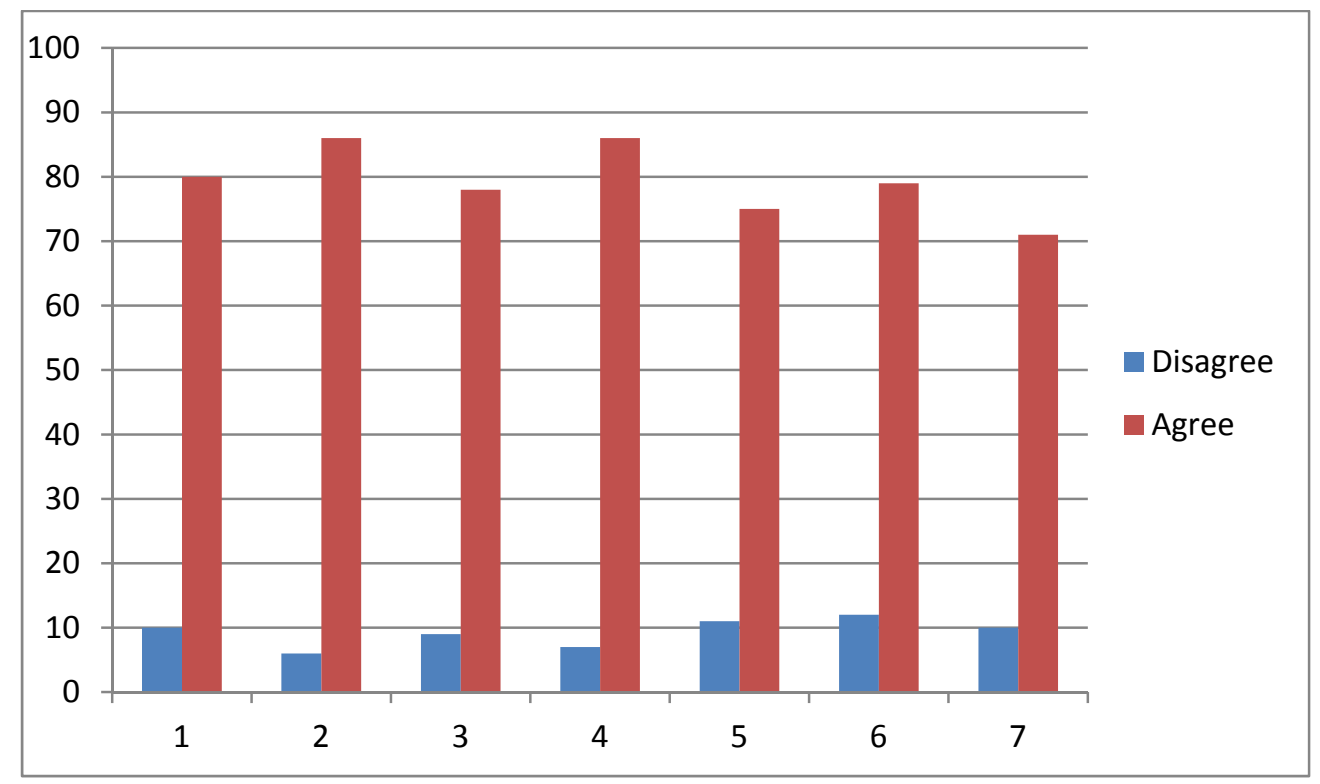

Sources: Own estimates using data from AGF

Table 28: National decisions give low priority to biodiversity protection

\begin{tabular}{|c|l|}
\hline Numbers & Description \\
\hline 1 & $\begin{array}{l}\text { National decision-making systems are based on partial optimization } \\
\text { prioritizing national interests; policies that optimize the whole become } \\
\text { secondary. }\end{array}$ \\
\hline 2 & $\begin{array}{l}\text { National decisions influenced by political, business, and organizational } \\
\text { interests and do not reflect the will of the public, who shoulder the } \\
\text { environment. }\end{array}$ \\
\hline 3 & $\begin{array}{l}\text { Changes in national policy face great resistance (inertia), and as such it } \\
\text { tends to stay with business as usual. }\end{array}$ \\
\hline 4 & $\begin{array}{l}\text { International organizations like the U.N. are affected by the will of } \\
\text { countries, and do not optimize the whole. }\end{array}$ \\
\hline 5 & $\begin{array}{l}\text { Voting system at the U.N. with its adherence to the fundamental principle } \\
\text { of unanimous consent, makes decision- making difficult. }\end{array}$ \\
\hline 6 & $\begin{array}{l}\text { International organizations like the U.N. are not provided enforcement } \\
\text { powers or other forceful methods of coordination. }\end{array}$ \\
\hline 7 & $\begin{array}{l}\text { Systemic and organizational reforms are needed, but have not been } \\
\text { implemented. }\end{array}$ \\
\hline
\end{tabular}

Source: Asahi Glass Foundation 
Figure 10 below was constructed using data that examined limitations to individual decision making at local levels. Information in the figure 10 takes into account the societal, cultural and behavioral scientific problems. The responses to the statements in table 29 below were used to generate figure four.

Up to $74 \%$ of the respondents to these statements agreed that there is no reference point for the natural environment as well as for the different life forms to aid in decision making at local/individual levels. About $81 \%$ agreed that local and cultural practices that give importance to "common resources" are lacking or weak. About $65 \%$ of the respondents agreed that local practices and traditions that value biological resources conservation are few and far in between. There were $61 \%$ respondents that said that most people have the capacity to recognize environmental conditions and effects on local levels but are not able to recognize the same problems globally. About $64 \%$ of the interviewees agreed that human decision making process is based on the "now" selfpreservation and does not consider that of future generations.

There was a statement that read "Human nature to care for others is overwhelmed by behavioral principles based largely on economic considerations". To this statement, $77 \%$ of respondents agreed. There were $74 \%$ respondents that agreed to the statement that value systems that respect one's own environment as well as daily economic activities are not consistent with each other. About $76 \%$ of the respondents agreed that current lifestyles based on large consumption of resources and energy cannot be abandoned. 
Figure 10: Support given to biodiversity protection is low

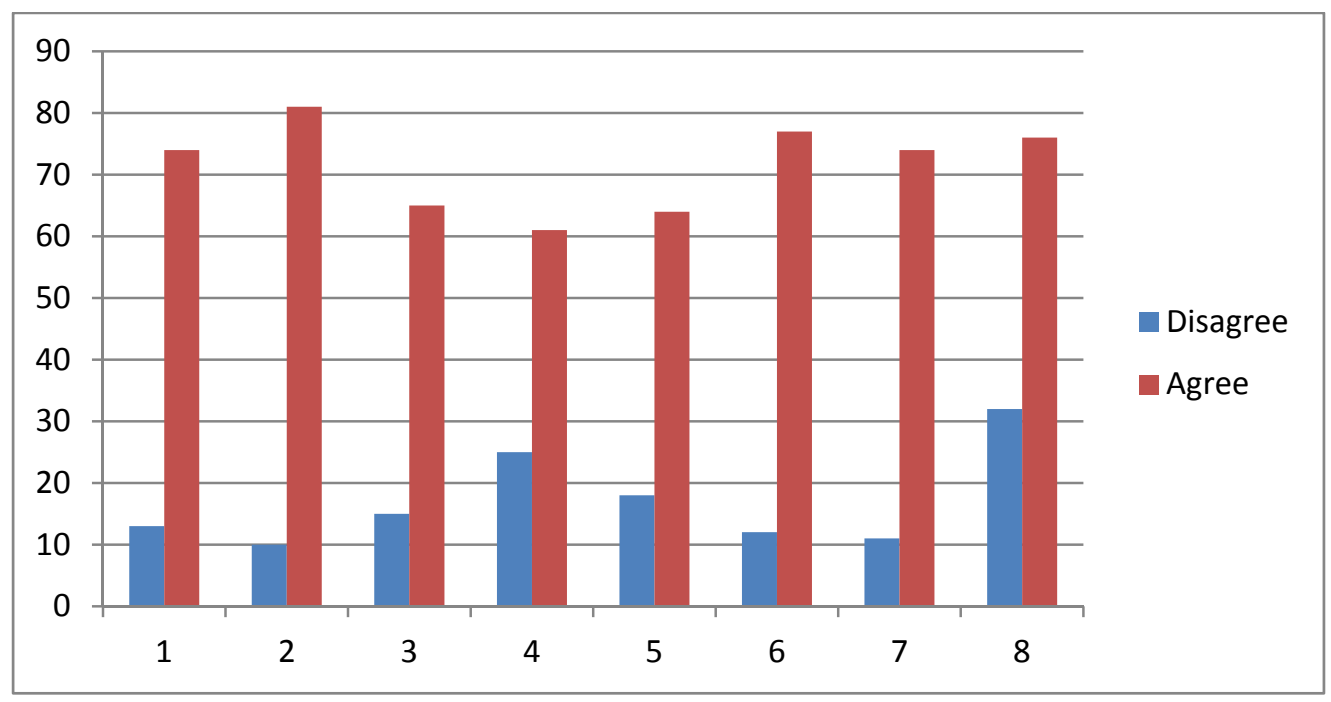

Columns one through to eight corresponds to the numbers assigned to the statements in table 29 below.

Table 29: Limitations to individual decision making at local levels

\begin{tabular}{|l|l|}
\hline Columns & Corresponding statements \\
\hline 1 & Absence of reverence towards the natural environment and life forms. \\
\hline 2 & $\begin{array}{l}\text { Societal and cultural practices and bases that place importance on "common } \\
\text { good," like environment, are lacking or fragile. }\end{array}$ \\
\hline 3 & $\begin{array}{l}\text { Societal practices and traditions that value the weak, including environment, } \\
\text { are few and far between. }\end{array}$ \\
\hline 4 & $\begin{array}{l}\text { At most, people have capacity to recognize environmental conditions and } \\
\text { effects on local level, but are incapable of recognizing problems globally. }\end{array}$ \\
\hline 5 & $\begin{array}{l}\text { Human decision-making process is based on self-preservation; it does not } \\
\text { consider happiness of others or of future generations. }\end{array}$ \\
\hline 6 & $\begin{array}{l}\text { Human nature to care for others is overwhelmed by behavioral principles } \\
\text { based on economic considerations. }\end{array}$ \\
\hline 7 & $\begin{array}{l}\text { Value systems that respect one's own environment and daily economic activity } \\
\text { are inconsistent with each other. }\end{array}$ \\
\hline 8 & Current lifestyles based on large consumption of energy cannot be abandoned. \\
\hline
\end{tabular}


Figure 11 below presents the percentage number of people that agreed and those that did agree to statements in table 30 . These were statements regarding communication between different levels and different sectors.

About $80 \%$ of the respondents agreed that information communicated from conservation experts is not easily comprehended by the public. Also, $53 \%$ of respondents agreed that communication from conservationists is geared more towards political decision makers rather than members of the public. Following the same statement, $80 \%$ of the people who responded agreed that political decision makers do not communicate conservation information given to them from conservationists to members of the public.

Figure 11: Communication in support of global biodiversity conservation is poor

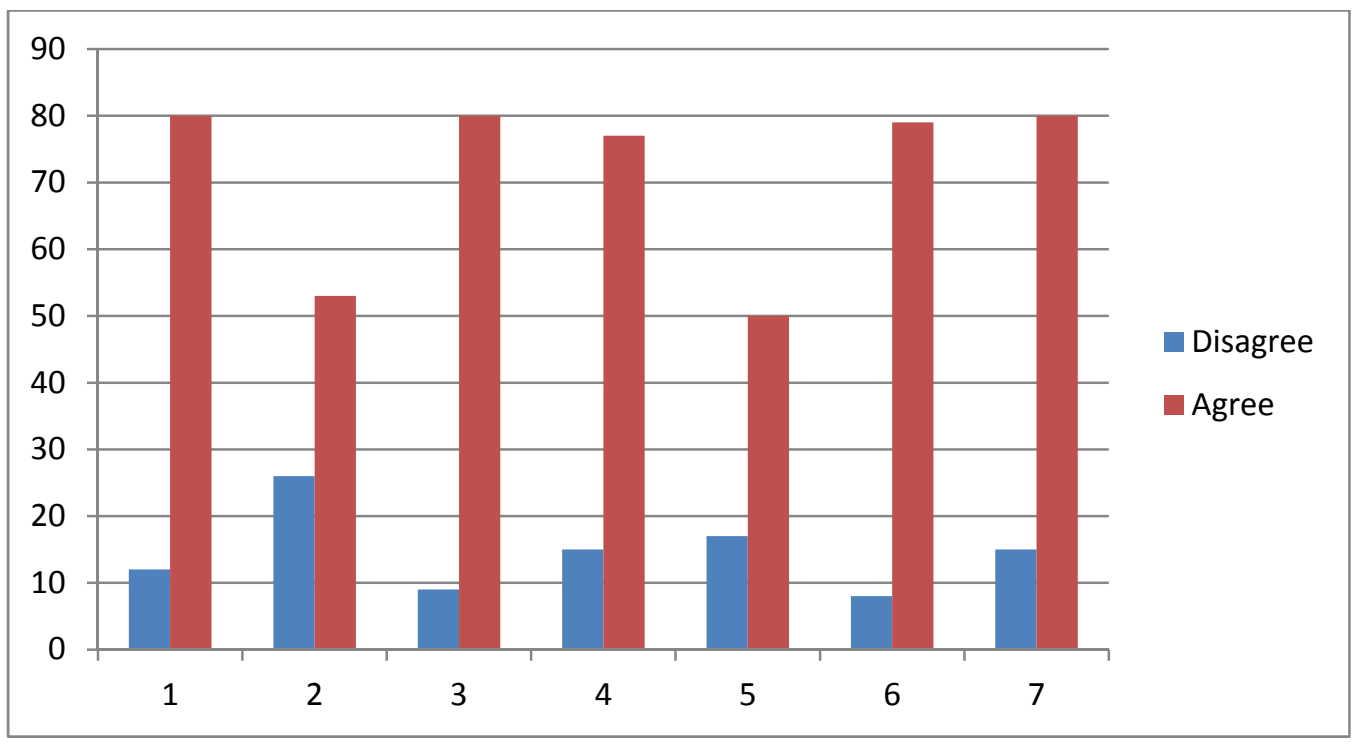

Another important piece of information was that about $77 \%$ of respondents agreed that members of the public do not value conservation information unless disaster occurs in their vicinity. About $50 \%$ of the respondents agreed that non-governmental 
organizations overemphasize communication with political decision makers. In communication, a certain level of education is necessary for members of the public to understand conservation needs. For this, $79 \%$ of the respondents agreed and $6 \%$ said this was not necessary. About $80 \%$ of interviewees also agreed that economic profits get a higher consideration in communication much more than environmental concerns.

Table 30 below presents the Likert scale statements used to generate figure 10 . The numbers before the statements correspond to the numbers assigned to the columns of the figure 10 .

Table 30: Communication and global understanding of biodiversity conservation

\begin{tabular}{|c|l|}
\hline Columns & Statements \\
\hline 1 & $\begin{array}{l}\text { Easily comprehensible information is not communicated from } \\
\text { conservation experts to the public }\end{array}$ \\
\hline 2 & $\begin{array}{l}\text { Environmental experts focus communication of information too heavily } \\
\text { upon political decision makers, failing to reach the public }\end{array}$ \\
\hline 3 & $\begin{array}{l}\text { Political decision makers do not communicate information from } \\
\text { environmental experts to the public }\end{array}$ \\
\hline 4 & $\begin{array}{l}\text { Public does not value the information provided by environmental experts } \\
\text { unless disaster occurs in their vicinity }\end{array}$ \\
\hline 5 & $\begin{array}{l}\text { Non-profit organizations overemphasize Communications efforts on } \\
\text { political decision makers }\end{array}$ \\
\hline 6 & $\begin{array}{l}\text { Certain education level is necessary for understanding of environmental } \\
\text { information, and environmental education is lacking }\end{array}$ \\
\hline 7 & $\begin{array}{l}\text { The economic profits of a corporation, organization, or a region are } \\
\text { prioritized so much that environmental considerations are not taken into } \\
\text { account. }\end{array}$ \\
\hline
\end{tabular}

Table 31 below shows a big difference between those that agree that aspects of biodiversity protection are good and those that disagree that conservation is not being implemented. Going by these findings, majority of the people seem to disagree that 
enough efforts, programs, effective decisions, good communication and capacities exist to reverse biodiversity degradation.

Table 31: Reconciling different levels and different sectors

\begin{tabular}{|c|c|c|c|}
\hline & $N=1009$ & Agree & Disagree \\
\hline \multirow{3}{*}{ Figure 1} & 1 & 13 & 79 \\
\hline & 2 & 12 & 83 \\
\hline & 3 & 15 & 80 \\
\hline \multirow{7}{*}{ Figure 2} & 1 & 10 & 80 \\
\hline & 2 & 6 & 86 \\
\hline & 3 & 9 & 78 \\
\hline & 4 & 7 & 86 \\
\hline & 5 & 11 & 75 \\
\hline & 6 & 12 & 79 \\
\hline & 7 & 10 & 71 \\
\hline \multirow{8}{*}{ Figure 3} & 1 & 13 & 74 \\
\hline & 2 & 10 & 81 \\
\hline & 3 & 15 & 65 \\
\hline & 4 & 25 & 61 \\
\hline & 5 & 18 & 64 \\
\hline & 6 & 12 & 77 \\
\hline & 7 & 11 & 74 \\
\hline & 8 & 32 & 76 \\
\hline \multirow{7}{*}{ Figure 4} & 1 & 12 & 80 \\
\hline & 2 & 26 & 53 \\
\hline & 3 & 9 & 80 \\
\hline & 4 & 15 & 77 \\
\hline & 5 & 17 & 50 \\
\hline & 6 & 8 & 79 \\
\hline & 7 & 15 & 80 \\
\hline
\end{tabular}

Source: Estimated using data from Asahi Glass Foundation

These can be viewed as indications that not enough is being done to take all countries to higher compliance and there not enough support given conservation programs. The big question then is why with such high mobilization of governments 
globally, conservation organizations, and other experts, is biodiversity conservation facing huge challenges? Estimating the overall differences between those that agree and those that disagree, $14 \%$ agree and $75 \%$ disagree. This brings a total to $89 \%$. Those are neutral were only $11 \%$. This is an insignificant figure to tilt overall perceptions and opinions. The conclusion is that more people share the idea that more needs to be done.

The high percentage of people that disagree with existing conservations practices which does not in general optimize the whole confirms hypothesis $2 \mathrm{~b}$ which was stated as: National and local environmental policies that evolve on the basis of shared meaning at all levels and across sectors and institutions have a higher rate of acceptance and would therefore lead to high levels of compliance with CBD goals.

\subsection{Theory in biodiversity conservation}

International relations theories try to galvanize global governmental cooperation to develop solutions to conservation problems, but this is only the first steps. Galvanizing global cooperation need to be accompanied with innovation, education and training, and transparency in order to be able to break away from traditional belief systems and mindsets of self-interest behavior. Findings from compliance levels established by this research show the clear need for cooperation as various countries have specific weaknesses and strengths in biodiversity protection. The 20 criteria used in determining compliance levels show the need for institutional cooperation within countries. Biodiversity protection must and should have the support of various institutions across different levels and sectors working together. 
Governments as well as all other organizations involved in biodiversity protection need to know all available conservation options from other stakeholders. This is information is not often available, thus making it difficult to arrive at appropriate decisions. For instance, it is not enough to ask communities to implement conservation programs if there no clearly established compensation mechanisms for reduced/lost biodiversity benefits. People are not empowered and key supportive institutions are either too weak or missing all together. It is at this point that the wheels of biodiversity protection begin to grind to a stop. National and local capacities within countries need to be continuously improved so as to effectively address biodiversity challenges.

\subsection{Systems theory in biodiversity protection}

According to AGF (2012), there is a limit to conservationists being able to speak to people outside of the field in a language that is easily understandable. People in governments, private sector institutions and communities should also be able to speak a conservation language alongside other priorities within their own settings. What is needed is properly trained science communicators, policy developers and effective implementers (AGF, 2012) across different levels and sectors.

For example, The South Africa NBSAP (2006) asserts that scientific experts, policy makers and local policy implementers should be able to work together to determine the carrying capacity of a specific area or resource. Such carrying capacity cannot be defined in absolute terms because of the dynamic nature of resources use. It is only after the carrying capacity of a specific area has been established that managers are 
able to provide appropriate forms of management to ensure that use of that area is kept within sustainable limits. Local communities need to have the capacity also not just to understand the management aspects but to also be able to implement remedial measures should the carrying capacity be exceeded at some stage. This means that local level institutions should be able to understand and establish standards that a farmland can withstand without acceptable physical damage, or how much water can be taken from an aquifer without going beyond recharge level, or how much pollution rivers can withstand before the fish are killed.

In the context of information management, the CBD can be viewed as a decider subsystem (Miller, 1978). Wang (2004) argues that the decider is an information process sub-system which receives, in this case, reports, plans and data from all other subsystems and transmits information outputs for guidance, coordination and management of the whole global structure. The relationship between the $\mathrm{CBD}$, its member countries and local institutions can be viewed as a living system. Information Technology facilitates communication across these systems otherwise known as countries, and facilitates global, national and local coordination. Governments with information, policy and data rich websites will enhance local level biodiversity protection through better communication, sharing ideas and feedback (Witzel, 2012). The systems concept is a presentation of how the different units/structures in different hierarchies within an organization interact and manipulate when it is convenient or adopt the organization to the external environmental demands (Almaney, 1974).

The level of support in financial terms, technical, education and communication given to national governments should be replicated within countries to their local levels. 
The people and institutions at all levels in society should have a sound understanding of how vulnerable and fragile various species and ecosystems are to land use changes. It is important to communicate and explain conservation to all sectors at all levels of society so as to sufficient supply knowledge that can bring positive changes and change perceptions of people on biodiversity conservation. How such communication is done needs a thorough analysis and evaluation.

There is inertia in the public and private institutions, and community beliefs against movement towards adoption of stronger biodiversity policies (Bickford et al. 2012). Partly, the problem is due to low environmental literacy thus no shared meaning and this makes it difficult for stakeholders and consumers to make informed decisions that support conservation (Bickford et al. 2012; Jordan et al. 2009). What is needed is more effective communication and outreach. In addition to my study, other studies have found big gaps between knowledge and action and efforts should be placed upon making everybody engaged in lifestyles that reduce this gap (Bickford et al. 2012; Daily and Matson, 2008). Higher level of environmental literacy correlates with a higher degree of supportive lifestyles and small gaps between knowledge and action (Bickford et al. 2012; Rickinson, 2001).

Brechin et al. (2003) makes a compelling argument that biodiversity protection is a social and political process requiring human organization. Interactions among governments at global level need to recognize the strong links between human wellbeing and biodiversity. Ecologically sound conservation programs also need to be socially and politically feasible, and morally just (Brechin et al. 2003). 


\subsection{Application of game theory strategies}

From a practical point of view, game theory approach to conservation is a continuous exercise that does not limit any country from cooperating with any other country. It is therefore possible that countries will cooperate with several other countries simultaneously. For purposes of this study, two assumptions were made: (1) two players are cooperating at any given time (2) these players are not in competition with each other but want to support each other to move to more efficient outcomes/higher compliance.

When players (donors and implementers) base their conservation priorities on self-interests, both follow a maximin (low-risk) strategy. With a maximin strategy, a player would determine the lowest outcome for each option, and then choose the option that provides the highest benefit at the expense of the other player. Conservation is thus driven into the prisoner's dilemma situation which is characterized with a free-rider problem. As for biodiversity conservation, best strategies would be when countries cooperate and support each other at conservation points that lead to highest compliance for the two cooperating players.

\subsubsection{Cooperation and consensus compared}

The best conclusion to draw from maximin strategic cooperation between various countries was that conservation through cooperation allows countries to carry on with many aspects of conservation that they feel are their best strategies or have the capacity to handle. Those aspects that specific countries are weak in are identified and therefore can get supported under a cooperative arrangement. 
Under international relations theories, conservation through a managed consensus is not structured to identify strengths and weaknesses of specific countries. This is because different parties come to a negotiation table often to win an argument. This leads to less than optimal decisions for some countries. Parties to the negotiation could easily be made to surrender their strong capacities and instead be made to implement strategies that they have no advantage. It is not easy to determine areas that may need more support under a negotiation.

This outcome supports hypothesis 2 which was stated that Biodiversity protection efforts undertaken cooperatively leads to higher compliance with CBD goals.

\subsection{Opportunity costs of biodiversity protection}

Opportunity cost estimates presented in this study was based on the number of hectares a country has either in deficit or in surplus. There exist several types of costs and categories that various policy actions can take into consideration. The findings by this study on opportunity costs may not reflect the full range of variables that could go into measuring conservation costs. These findings by this study are very important in determining compensation levels by biodiversity deficit countries. Financial support to biodiversity protection by countries should be calculated based first on the deficit status of each country, secondly, on the country's level of development. Every country should compensate for biodiversity protection the equivalent of its biodiversity deficit. 


\section{CHAPTER VI}

\section{CONCLUSIONS}

\subsection{Discussion and conclusions}

This chapter brings together all the key findings regarding the strengths and weaknesses of biodiversity protection globally. The challenges that the CBD faces and the ways governments are managing conservation programs have been summarized. Limitations, the gaps and policy implication of the findings from this research are also explained.

\subsection{Introduction}

My research examined a broad and yet focused biodiversity conservation strategies globally. It was broad enough to bring to light the extent to which the CBD has influenced conservation of biodiversity by countries. Yet, the study conducted a detailed investigation into the extent to which the global policies penetrated into local levels within countries to effect changes. I argue that it is not enough to for countries to send representatives to treaty conferences, draw national plans, submit reports and claim that treaty goals are being implemented at all levels from global to local levels based on written words. The drawing of plans and writing of reports is the first step in a very long and difficult journey towards implementation of goals and compliance.

It was against this background that my study was designed to analyze multiple levels of CBD implementation. I have examined how globally designed biodiversity conservation policies are adapted into national programs and then passed down to local 
settings where they are implemented. Implementation and compliance was divided into three levels: (i) global compliance; (ii) national compliance; and (iii) local compliance. The requirement to comply with the CBD goals at these three levels was found to be very different taking into account different actions on the part of those implementing the goals of the convention. What emerged was that those involved in both decision making and negotiations at different levels wanted to see final policy decisions that satisfied their own interests first. Although conservation outcomes have been clearly stated by the CBD, parties have been conducting negotiations without a model that is able to align global conservation interests with national and local interests, and private sector priorities.

Key variables that most influence implementation and compliance at global, national and local levels were examined. Ways to reconcile local, national and global conservation challenges were analyzed. Two variables that emerged as the most influential and also that appeared to present numerous conservation challenges were communication and national capacities. Although the CBD has well-established information sharing tools, these have not been replicated by national governments to allow for sufficient sharing of knowledge between sectors and governments. Global biodiversity conservation policies have not been localized. This was evidenced by the complete lack of data that links global conservation initiatives and national policies to local level implementation.

Hathaway (2005) argues that countries with robust domestic institutions on one hand can have better implementation. At the same time such countries are more reluctant to commit themselves to international treaties. However, findings from this research point 
to who actually makes the decisions. If decisions are made at national level without structures that involve local level institutions, implementation of the CBD goals will remain problematic. Commitments to international treaties should be clearly worked at local levels using support mechanisms ranging from funding, actual capacity building and developing information sharing tools.

\subsection{Historical context}

International treaties are created and recognized through the Vienna Convention on the Law of Treaties of 1969. The Vienna Convention was entered into force on January 27,1980 and has been ratified by more than 100 countries. Since then, more than 500 international treaties dealing with environmental problems have been created (UNEP, 2008). However, the rising number of treaties being created has not translated into greater achievement of environmental conservation (CBD, 2010). It is clear that with the rising number of treaties, environmental challenges are increasing too.

It was with this knowledge in mind that the CBD was created at the Earth Summit in Rio de Janeiro on June 5, 1992 and entered into force on December 29, the same year. Under the CBD, conservation of biological diversity is recognized as a common concern of all countries and as an integral part of economic development. The treaty covers all ecosystems, species and genetic resources and links traditional conservation efforts to the economic goals of using biological resources sustainably under the guidance of national governments (Global Biodiversity Outlook 3, 2010). 
After a period of more than two decades, tremendous amount of awareness has been created but there is void in exactly how countries should proceed with implementation of the CBD goals and the nature of specific actions that countries should take to increase compliance. It should not be because the international law lacks enforcement powers within countries as this is technically fulfilled once countries sign the treaty and agree to abide with it. Guzman (2014) argues that treaty obligations should be taken in many small, low cost and observable steps toward compliance and not one big single obligation.

Findings from this study indicate that there is much more that needs to go into just one small step that is taken to conserve biodiversity. Some countries do not simply have the capacity and funding to facilitate implementation of specific actions. Second, there are also those that have the capacity but have not made biodiversity protection their priority. Thirdly, many countries are in very huge biological capacity deficit but have instead chosen to focus their efforts to support other countries. The big problem is that the level of support given to other countries is so insignificant because this is a mere fraction of what it would take to bring donor countries out of the biological deficit. As of 2008, the European countries in this study are in deficit of biological capacity going into a negative of about 3.4 million hectares. Asian countries and Australia combined are running a negative of 765,000 hectares.

\subsubsection{International treaties' effectiveness}

Going by the findings of this study, one cannot qualify the CBD as having been very successful in all aspects of biodiversity protection. Compliance by all countries was 
found to be at about $35 \%$. Implementation of the CBD goals at local levels cannot be evaluated using information and data from the CBD documents. Such data is unavailable. Countries have not invested in data collection surveys to facilitate estimation of trends and losses of biological resources. It is extremely difficult to make good judgment and develop policies on the basis of unreliable, insufficient or missing information. It is therefore correct to make an assumption that the CBD may not know how and to what extent implementation has been carried out at local levels.

Information gathered from country reports generally highlights various obstacles to achieving the 2010 biodiversity protection targets. These were weak governance in particular, lack of law enforcement and focusing on direct drivers of biodiversity loss rather than underlying causes. Looking beyond the 2010 biodiversity protection targets, governments need to re-position themselves to address these specific challenges.

It is also clear that the convention has had some tremendous first few successful steps. The CBD has mobilized global governments and is now the international treaty with highest membership of 195 countries. Each of these countries has a developed National Biodiversity Strategy Action Plan (NBSAP) and some countries have made up to four revisions to the original plan. All these countries have submitted from between one to four national reports explaining national progress and problems countries are facing. These are indications that discussions are being conducted at national level, information is being shared and knowledge passed to facilitate effective conservation. 


\subsection{Global biodiversity protection initiatives}

So many global initiatives aimed at improving biodiversity protection efforts have been developed. These initiatives range from public-private partnerships, creation of ministries and government agencies targeting conservation of environmental resources, pushing for legislation, seeking funding opportunities and developing human resources.

These initiatives face numerous challenges though. Global economic inequality and the number of people living in poverty at the rate of one dollar per day declined in the 1990s from 1.3 billion to 1.2 billion (World Bank, 2007). However, a large majority of people in developing countries that are also rich in biodiversity are still living in poverty and depend on land based resources (World Bank, 2007). There is a tremendous pressure to expand agricultural land in both developed and developing countries (World Bank, 2007). Expanding agriculture in the developing world will put high pressures on many ecosystems that support biodiversity. It is a well-known fact that greatest threat to forests, wetlands, mountains and biodiversity is the expansion of agricultural land due to increasing demand for food and loss of arable land due to over-intensive cultivation (World Bank, 2007)

\subsubsection{Sustainable use of biodiversity}

Sustainable use is one of the primary goals of the CBD which also relates to consumption and how natural resources are used. Sustainable use is a strong assurance for the protection of biodiversity which guarantees use of resources now without depletion so that there is some left for future generations. From the literature and data 
examined in this study, it is not clear how and what governments are doing to find ways and design sustainable use programs at both national and local levels.

The challenges facing the CBD under the goal of sustainable use is that rather than countries devise policies that bring about fundamental changes into the growth oriented cultural paradigm, the policies being developed are only producing reforms at policy level with insignificant impact at implementation levels. Over time, there has been an increase in high-sounding rhetoric and numerous environmental legislations in many countries but economic growth through over-exploitation of biodiversity has continued to be the focal political agenda (Rees, 2003). Going by the level of compliance globally as estimated in this study, it might be necessary to advocate for much stronger conservation measures than sustainable use approach. This is one of the surest ways to bring most countries that are both in biological deficit status to surplus and low compliant countries to at least $50 \%$ compliance level.

\subsubsection{Implications of global biodiversity deficit}

Overexploitation of biodiversity occurs because there is need to satisfy both local needs as well as supply for the deficits in other regions and countries. The status of biological resources globally is estimated to be in deficit by about 0.9 hectares per person (GFN, 2013). Most developed countries have very high biological resources deficits. In addition, local level compliance as per my study is at $14 \%$. Global and national consumption of biodiversity does influence local level interests and thus compliance. Large-scale national and international trade undertaken by pharmaceutical companies, the timber industry, high fossil fuel use and land demanded by agriculture are all meant to 
take resources from biodiversity rich to deficit regions. Compensation for the supply of biodiversity from rich to deficit countries is not based on the need to ensure sustainable use but rather on the economic concept of supply as much as possible and obtain maximum payment from the sale by supplying countries.

Examining this situation from an economic standard theory, the sharing of biological resources can be divided into two attributes: (i) the extent to which one country's consumption reduces the supply available to other countries (ii) the extent to which access to the use of biological resources can be controlled so that it is not overexploited (excludability) (Polski, 2005). Controlled use is the most difficult since there are no mechanisms except trade that show how regions or countries share biological resources to eliminate the biodiversity deficits. Trade between regions or countries is not based on fair compensation of actual resources used. There is really no way of telling if countries that consume more do care about how much is left for other countries. This is demonstrated by the low compliance at local levels.

To adequately explain the challenges that come with overexploitation of biological resources, the study used the figure 12 below. This is a two-by-two matrix with high and low scales of typical consumptive resources (Polski, 2005). This figure presents public resources that have low subtractability and low excludability, club (toll) resources that have low subtractability and high excludability, private resources with high subtractability and high excludability and common pool resources with high subtractability and low excludability. Biological resources easily fit into the four sections of the matrix below depending on the type of ownership and the specific resource. 
Figure 12 below explains the complexity of overexploitation of biodiversity either through controlled use or developing effective compensation mechanisms. Existing compensation mechanisms based on trade ignore many aspects of overexploitation. These include the justification for consumption on the basis that it is paid for at a price agreed between the buyer and the seller. As most literature has mentioned, there is no welldeveloped value of biodiversity thus making it difficult to determine a just pay to control use.

Figure 12: The difficulties in managing biodiversity deficits

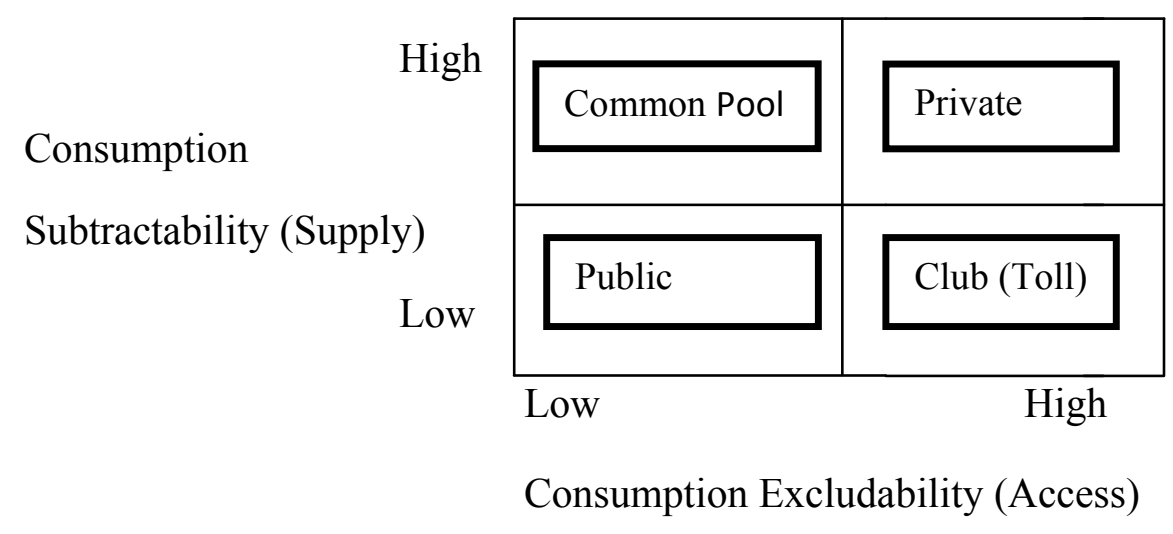

Source: Modified from Polski, 2005

Resources at high subtractability region are those whose quantity is reduced in direct proportion to the quantity consumed. The supply of resources with a perfect subtractability can only be sustained if management institutions can provide incentives to sustain adequate supply to meet the demand. It is the demand that drives how the resource is managed and not sustainable use.

Resources located at high excludability region are those whose access can be controlled at a low cost. Consumers of such goods cannot just take or consume without 
paying for their supply. Suppliers of these resources are incentivized to invest and produce enough to meet the demand. Once again, the desire is to overexploit in order to meet the demand.

Biological resources are private when owned by an individual or corporations, they are common pool resources when communally owned, they are public when owned by the government and club when controlled by just a few owners and a small group of individuals/corporations. When they are considered private, control and use cannot be interfered with because that could be considered a violation of private rights in many countries. The benefits of private properties cannot be shared freely. Under club (toll) ownership, when it is costly or difficult to control access, consumers are able to "freeride" effectively removing supplier's incentives to invest in the future production. When biological resources fall under the public resources classification, they have low subtractability and low excludability and therefore will be undersupplied in the private sector. The ownership and management of natural resources is in most cases inconsistent with actual political and economic conditions of a place. The management of biological resources cannot simply be a stated goal but there is need for an expanded dialogue between all stakeholders to establish monitoring systems, measurement criteria and effective compensation schemes.

According to Polski (2005), natural resources governing institutions are more nested in numerous systems such as unified forms of self-governance by individual or collective entities. These may include citizens, corporations, NGOs and government agencies. Collective entities also can take other forms such as centralized, decentralized or polycentric institutions or market mechanisms such as tradable quotas. This makes it 
difficult to determine compensation levels. Governments have not made any attempt to develop structures that would facilitate equitable sharing of the benefits of biodiversity.

\subsection{Measuring compliance and implementation}

The broad goal of my research was to analyze implementation of the goals of the $\mathrm{CBD}$ and estimate compliance by parties. The key challenge to my study was the lack of agreed standard measures for program implementation and compliance. The study designed two types of measures for international and national compliance; one based on score card approach and the other was based on identified criteria which were determined from NBSAPs and national reports providing information about local implementation. Measuring local compliance was rather problematic because of missing data and reports. The option sought was to identify primary data collected by the ASAHI Glass Foundation from local level conservation program implementation. To see compliance in more details, it was divided into three levels: paper, policy and implementation compliance.

Measuring compliance was meant to show the level of influence of the CBD on countries, status of biodiversity and implementation of global policies at local levels. Most existing measures use direct measurement of species. These measures are the Red List developed by IUCN and the Living Planet Index developed by WWF (Barbault, 2010). Using species as a measure of the health of biodiversity tells just the scientific story leaving out social, economic and political aspects of biodiversity protection. The criteria used to measure compliance at national level by my study looked at implementation, what countries are doing and how they are developing specific goals, objectives and initiatives across various conservation elements. The 20 criteria of 
compliance provided a broad and long-term picture of biodiversity protection from the perspective of science, policy, politics, economics and communities. There is a big gap between the role of communities and the scientific community, political leadership and economic considerations. Ways to reconcile interests across sectors were also analyzed.

\subsubsection{Paper compliance}

Compliance requirements at the CBD level can be defined as merely paper and talk compliance, it is a participatory process meant to mobilize talks and conservations that set agendas. Countries define and identify commitments to specified goals and negotiate action strategies and partnerships with other stakeholders. Countries are required to abide with the treaty by merely signing to the treaty, submitting plans, reports and also attend conferences. Although paper compliance was found to be at about $64 \%$, this does not actually reflect what actually takes place within countries as well as compliance at country levels.

\subsubsection{National compliance}

Compliance at national level, defined by my study as policy compliance, is much more than paper compliance. This is where policies are made, institutions are created, legislation is enacted, management staffs are hired and coordination structures are created. Strong national leadership bolsters local level conservation efforts. Every government must be a part of the local solutions to conservation problems through coordination, training, reporting, funding and technological support.

National compliance should both define and create the intersection between policy development and implementation. At this intersection, guidelines for implementation and appraisal standards to help strengthen local capacities and 
implementation should be developed. Potential trade-offs and conflicts of interests between various stakeholders are identified and goals that take all stakeholders to higher understanding discussed. At the moment, there is no clear relationship between national policies development and local level implementation. The national mechanisms for taking conservation policies to local levels are not strong while local level institutions have no adequate capacity to implement conservation programs. This is demonstrated by the compliance gap at national level which is about $50 \%$ and local level compliance of $14 \%$.

\subsubsection{Local compliance}

There was no data and information in the NBSAPs and national reports on specific program implementation in all the countries analyzed to facilitate analysis of compliance at local levels. There were no specific local reports about local level implementation. Either very little is going on and therefore there is nothing to report from local levels or reporting structures are not developed in most countries. I would like to reiterate that there exists conservation programs in many local levels but most community institutions have no sufficient capacities to develop reporting structures, collect data, analyze and report.

National governments have not provided standards to guide program design, implementation, monitoring and evaluation. There is need for clear negotiations with explicit interventions, expectations of all stakeholders and positions with regard to balancing local needs with biodiversity protection. National governments should ask all 
international and local conservation organizations to report to a central depository where these reports are made accessible to all stakeholders.

\section{5 Policy implications}

The ongoing debates on biodiversity conservation bring out the intertwined relationships between the political, social and economic interpretations of both the perceptions on the status and scientific understanding of the management of natural resources (Rosenau, 1993; Brechin et al. 2002). Results from this research indicate that compliance still remains very low, coordination at national level is weak and capacities of many institutions are low. The challenges of biodiversity protection therefore should involve without exclusion of scientific conservation experts, national political institutions and communities. Herein again lies the problem because most communities and local level institutions not only fall short in various capacities, there is also disconnect in the re-alignment of priorities. There is a need to develop policies to bring about a common position across sectors. There is a need to have a shared meaning and also reconciled priorities across levels and sectors in society.

Self-interest behavior by countries has greatest influence on country decisions when it comes to support both within and across countries. Although the benefits of protecting biodiversity are clearly understood, free-riding by countries and high consumption sectors is still seen as something beneficial. There is need to develop policies and clearly compensation mechanisms to cap free-riders and also ask high consumers for a just compensation to suppliers of biological resources. 


\subsection{Limitations of the study}

Measuring compliance with the CBD goals should take into account many more factors beyond government plans, reports and works of conservation organizations. The compliance analysis presented here though credible, could as well be a partial compliance. The Millenium Ecosystems Assessment, for example, measures ecosystem services using the quality of ecosystem services. Ecosystem services come from biological resources. The quality and quantity of ecosystem services are good indicators of biodiversity status. Major losses of ecosystem services in various countries should be included in measuring compliance. The IUCN measures biodiversity using the number of species. WWF measures biodiversity using the Living Planet Index. What needs to be included in measuring compliance is a topic for future research. There is a welldeveloped methodology for measuring compliance.

The economic value of biodiversity does not exist. This makes measuring losses as well as developing compensation mechanisms more difficult. The current use of the number of hectares available to every individual (GFN, 2008) does not give a true status of biodiversity in every country. This method takes into account the size of the country regardless of the quality of land to support biological resources.

There are no clearly established methods of measuring compliance. Many disciplines involved in biodiversity protection are likely to establish their measurement criteria leading to more confusion on the exact level of compliance. Establishing standards of measuring compliance is left for future researchers. 


\subsection{Conclusions}

The pre-2010 biodiversity protection strategies have had tremendous impact on the relationship between countries and the CBD but not so much at local levels within countries. Global structures that bring all countries, conservation organizations and public-private partnerships together have been established under the CBD. Detailed conservation plans and action strategies have been developed, and commitments by countries to specific goals and objectives made. Although there seems to be heightened conservation activities globally, there is insignificant impact at local level implementation. This is partly because of inadequate capacities as well as giving higher priority to other needs.

Going by the estimated compliance level and the approach that countries have taken to implement biodiversity protection goals, it is unlikely there is going be any improvement going into the future. There are numerous weaknesses and capacity challenges that countries have not addressed in their plans. In order to increase the local level compliance, the study recommends a set of robust policies that build local capacity, incentivize local resource owners, and implement biodiversity protection programs that are akin to local needs and aspirations.

The current global conservation efforts should not lose sight of the past conservation challenges as new targets are set and plans begin to be revised. As long as the capacity challenges of each country are not identified specifically and addressed, not so much will be achieved. Secondly, communication between conservation experts, 
government agencies, policy makers, communities and NGOs remains weak and uncoordinated.

The Convention on Biodiversity (CBD) has played a very active and constructive global environmental role to bring governments together to debate, draw national plans and build national conservation institutions. Going forward, more attention should be paid to domestic economic and political factors as these are the ones that have ultimately shaped local policies towards biodiversity protection challenges. There is not much in terms of reporting on local level implementation and compliance. Depending on how implementation is done at local levels, overall conservation outcomes can only get worse than what it is at present. There is a need to do more on reporting, planning and information sharing. Progress has also been constrained by inadequate funding for conservation programs and weak enforcement of environmental laws. This is also because of inadequately trained human resources.

Turning to the results of this research, compliance is lowest at local levels, is slightly better at national level and much better at the international level. This is an indication that both the international community and national governments need to give more support towards local level conservation initiatives. Insufficient national and local capacities, funding deficiencies, communication problems and coordination challenges are not adequately planned for in most NBSAPs. 


\section{REFERENCES}

Adams W. M. and Hutton J. (2007). People, Parks and Poverty: Political Ecology and Biodiversity Conservation. Conservation Society 5 147-83.

Adenle A. A. (2012). Failure to achieve 2010 biodiversity's target in developing countries: How can conservation help? Biodiversity conservation. 21: 2435 - 2442.

Alagona P. S., Sandlos J. and Wiersma Y. F. (2012). Past Imperfect: Using historical ecology and baseline data for conservation and restoration projects in North America. Environmental philosophy 9(1), $49-70$.

Albert B. and Wintrobe R. (1982). The Logic of Bureaucratic Conduct: An Economic Analysis of Competition, Exchange, and Efficiency in Private and Public Organizations. Cambridge: Cambridge University Press.

Almaney A. (1974). Communication and the systems theory of organization. Journal of Business Communication, 12 (1).

Atisa G., Bhat M. G. and McClain M. E. (2014). Economic Assessment of Best Management Practices in the Mara River Basin: Toward Implementing Payment for Watershed Services. Water Resources Management

Bamberger P. (1991). Reinventing innovation theory: Critical issues in the conception, measurement, and analysis of technological innovation. Research in sociology of organizations. Vol $9265-294$.

Barbault R. (2010). A new beginning for biodiversity. Coptes Rendus Biologies, Academy is Sciences.

Basurto X. (2008). Strengthening Locally-Based Biodiversity Conservation Governance in Costa Rica: A Cross-Scale Analysis and the Role of NGOs.

Berke P.R. and French S. P. (1994). The Influence of State Planning Mandates on Local Plan Quality. Journal of planning Education and Research. Association of Collegiate Schools of Planning.

Berke P.R. and Conroy M.M. (2000). Are we planning for sustainable development? An evaluation of 30 comprehensive plans. Journal of the American Planning Association.

Bickford D., Mary R. C., Qie P. L., Campos-Arceiz A.C. and Kudavidanage E. P. (2012). Science communication for biodiversity conservation. Biological Conservation.

Boisverta V. T. and Vivien F. D. (2005). The convention on biological diversity: A conventionalist approach. Ecological Economics 53 (2005) 461-472. 
Boston J., Martin J., Pallot J. and Walsh P. (1996). Public management. The New Zealand Model. Oxford University Press.

Brechin S. R., Wilshusen P. R., Fortwangler C. L., and West P. C. (2002). Beyond the Squared Whell: Toward a more comprehensive understanding of biodiversity conservation as social and political process. Society and natural resources 15:41-64.

Brody S.D. (2003). Are we learning to make better plans? A Longitudinal Analysisof Plan Quality Associated with Natural Hazards. Department of Landscape Architecture and Planning, TAMU 3137, Texas A \& M University.

Brody S.D. (2003). Are we learning to make better plans? A Longitudinal Analysisof Plan Quality Associated with Natural Hazards. Department of Landscape Architecture and Planning, TAMU 3137, Texas A \& M University.

Bull, J.W., Suttle K.B., Gordon A., Singh, N.J., and Milner-Gulland, E.J. (2013). Biodiversity offsets in theory and practice. Review: Fauna and Flora International.

CBD (2006). The Secretariat of the Convention on Biological Diversity, Global Biodiversity Outlook 2. Montreal 81.

CBD (2010). The Secretariat of the Convention on Biological Diversity, Global Biodiversity Outlook 3. Montreal 81.

CBD (2010). The Secretariat of the Convention on Biological Diversity, Action for Biodiversity: Towards a society in harmony with nature.

Chape S., Spalding M. and Jenkins M.D. (2008). The World's Protected Areas. Prepared by the UNEP World Conservation Monitoring Centre. University of California Press.

Chayes A. and Chayes A. H. (1993). On Compliance. International Organization. MIT Press, Vol 47: 175 - 205.

Clark T. W., Willard A. R. and Cromley C. M. (2000). Foundations of natural resources policy and management. Yale University Press.

Coglianese C. and Nash J. (2002). Policy options for improving environmental management in the private sector. Environment 44: $10-23$.

Colyvan M., Justus J. and Regan H. M. (2011). The conservation game. Biological conservation.

Devall B. (2006). Conservation of Biodiversity: Opportunities and Challenges. Human Ecology Review, Vol. 13, No. 1, 2006 
Drumbl M. A. (2002). Northern Economic Obligation, Southern Moral Entitlement, and International Environmental Governance. HeinOnline (http://heinonline.org)

Eisenhower B. (2014). Modeling energy systems - Modeling for compliance. Center for Energy Efficient Design, University of California, Santa Barabara.

Esty, D. C. and Ivanova, M. (2004). Globalization and Environmental Protection: a Global Governance Perspective. Working paper No. 0402. Yale School of Forestry \& Environmental Studies.

Faure M. and Lefere J. (2012). Compliance with global environmental policy. Social science research network. Maastricht University.

Frank D. M. and Sarkar S. (2010). Group decisions in biodiversity conservation: Implications from game theory. PLoS ONE S(S): e10688.dol:1371/journal.pone.0010688

Future generations (2008). An environmental right for future generations: Model state constitutional provisions and model statutes; Science and environmental health network. The international human rights clinic at Harvard Law School.

Gibbs G. (2007). Analyzing qualitative data. The SAGE qualitative research kit. SAGE Publications.

Gibbons P. and Lindenmayer D. B. (2007). Offsets for land clearing: No net loss or the tail wagging the dog? Ecological Management and Restoration 8: 26-31.

Guzman A. T. (2014). A compliance based theory of international law. University of California at Berkley.

Guzman A. T. (2002). A Compliance-Based Theory of International Law, 90 Cal. L. Rev. 1823 (2002). Available at: http://scholarship.law.berkeley.edu/californialawreview/vol90.

Harrop S. R. and Pritchard D. J. (2011). A hard instrument goes soft: The implications of the Convention on Biological Diversity's current trajectory. Global Environmental Change 21 (2011) 474-480.

Hathaway O. A. (2005). Between power and principle: An integrated theory of international law. Yale law school legal scholarship repository.

Hove V. D. S. (2004). Between consensus and compromise: acknowledging the negotiation dimension in participatory approaches. Land Use Policy.

Jackson M. O. (2011). A Brief Introduction to the Basics of Game Theory. Stanford University - Department of Economics; Santa Fe Institute; Canadian Institute for Advanced Research (CIFAR). Available at: http://dx.doi.org/10.2139/ssrn.1968579

Jones E. (2001). The purse strings and the policy process: Bureaucratic shaping of industry policy capacity after 1945. National Council of the Institute of Public Administration, Australia. 
Kaphengst T., Bassi S., Davis M., Gardner S., Herbert S., Mazza L., Pieterse M., and Rayment M. (March 2011). Taking into account opportunity costs when assessing costs of biodiversity and ecosystem action. Institute for European Environmental Policy.

Kiesecker J. M., Copeland H., Pocewicz A., Nibbelink N., McKenney B., Dahlke J., Holloran M., and Stroud D. (2009). A Framework for Implementing Biodiversity Offsets: Selecting Sites and Determining Scale. American Institute of Biological Sciences.

Kline K. and Raustiala K. (2000). International environmental agreements and remote sensing technologies. Center for international earth science information network. Columbia University.

Koh H. H. (1997). Why Do Nations Obey International Law? Yale Law School Legal Scholarship Repository. Faculty Scholarship Series Yale Law School Faculty Scholarship Yale Law School.

Kremen C. I., Niles J. O. Dalton M. G., Daily G. C., Ehrlich P. R., Fay J. P., Grewal D. and Guillery R. P. (2000). Economic Incentives for Rain Forest Conservation Across Scales.

Koetz T., Farrell K. N. and Bridgewater P. (2011). Building better science-policy interfaces for international environmental governance: assessing potential within the Intergovernmental Platform for Biodiversity and Ecosystem Services. International Environmental Treaties.

Lisa M., Campbell L. M., and Vainio-Mattila A. (2003). Participatory Development and Community-Based Conservation: Opportunities Missed for Lessons Learned. Human Ecology, Vol. 31, No. 3.

McShane T.O., Hirsh P.D., Trung T.C., Songorwa A.N., Kingzig A., Monteferri B., Mutekanga D., Thang H.V., Dammert J.L., Pulgar-Vidal M., Welch-Devin M., Brosius J.P., Coppolillo P. and O'Connor S. (2011) Hard choices: Making trade-offs between biodiversity conservation and human wellbeing. Biological conservation 144.

Mockler, R. J. (1968). The systems approach to business organization and decision making. California Management Review 11(2)

Munda G., Nijkamp P. and Rietveld P. (1994). Qualitative multicriteria evaluation for environmental management. Ecological Economics 10 (1994) 97-112

Myers M., Russell A. M., Cristina G. M., Gustavo A. B. and Kent J. (2000). Biodiversity hotspots for conservation priorities. Natures 403 .

Myeong, S. and Choi, Y. 2010. Effects of Information Technology on Policy DecisionMaking Processes: Some Evidences Beyond Rhetoric. Administration and Society $42-4$. 
Naidoo R., Balmford A., Ferraro P. J., Polasky S., Ricketts T. H. and Rouget M. (2006). Integrating economic costs into conservation planning. Trends in ecology and evolution Vol 21 (12).

Oliver E. W (1979). "Transaction Cost Economics: The Governance of Contractual Relations." Journal of Law and Economics 22 (2): 233-61.

Ostrom E. (2011). Background on the Institutional Analysis and Development Framework. The Policy Studies Journal 39 (1)

Ostrom E. (2010). The institutional analysis and development framework and commons. Peterson, O. L. P., and S. E. Williams S. E. (2004). Extinction risk from climate change. Nature 427: $145-148$.

Polski M. (2005). The institutional economics of biodiversity, biological materials. And bioprospecting. Ecological Economics.

Patton W. and McMahon M. (2006). Career development and systems theory. Connecting theory and practice. Sense publishers.

Porter G. and Brown J. W. (1991). Global Environmental Politics. Dilemas in world politics. Westview press.

Pressman J. L. and Vildavsky A. B. (1984) How great expectation in Washington are dashed in Oaklnad; Or why it is amazing that federal programs work at all. The Oakland Project. Regents of the University of California.

Reed M. S. (2008). Stakeholder participation for environmental management: A literature review. Biological Conservation, Sustainability Research Institute, School of Earth and Environment, University of Leeds, Woodhouse lane, Leeds, West Yorkshire LS2 9JT UK.

Rees W. (2003). Economic Development and Environmental Protection: An ecological economics perspective. School of community and regional planning, University of British Columbia, Vancouver, British Columbia, Canada.

Reischl G. (2012). Designing institutions for governing planetary boundaries — Lessons from global forest governance. Ecological Economics 81 (33-40).

Ringquist E. J. and Kostadinova T. (2005). Assessing the effectiveness of international environbmental agreements. The case study of the 1985 Helsinki Protocol. American Journal of Political Science Vol 49: 86 - 102.

Rose R. (1991). What is Lesson-drawing? Journal of Public Policy 11 - 1. 
Rosenau, J. (1993). "Environmental challenges in a global context", in S. Kamieniecki (ed.), Environmental Politics in the International Arena: Movements, Parties, Organizations and Policy. Albany: State University of New York Press.

Saldana J. (2013). The Coding Manual for Qualitative Analysis. Sage Publications.

Smith R. J, Veríssimo D., Leader-Williams N., Cowling R. M., Knight A. T (2009) Let the locals lead. Nature vol 462 (19)

Sinden J. A. (2004). Estimating the opportunity costs of biodiversity protection in the Brigalow Belt, New South Wales. Journal of Environmental Management 70 (2004) 351-362.

Stave K. A. (2002). Using system dynamics to improve public participation in environmental decisions. System dynamics review (18) 2.

Sussman G. (2011). The USA and Global Environmental Policy: Domestic constraints and effective leadership. International Political Science Review

Swanson T. (1997). Global Action for Biodiversity. An international framework for implementing the convention on biological diversity. IUCN Earthscan publications.

Tallberg J. (2002). Paths to Compliance: Enforcement, Management, and the European Union. International Organization, 56, pp 609-643.

Tang Z., Brody S.D., Quuin C., Chang L., and Wei T., 2010. Moving from agenda to action: evaluating local climate change action plans. Journal of Environmental Planning and Management, Vol. 53, No. 1. January 2010, 41-62.

TEEB (2009). The Economics of Ecosystems and Biodiversity for National and International Policy Makers - Summary; responding to the value of nature.

The World Bank (2007). World Development Report. Available from http://siteresources.worldbank.org/INTWDR2007/Resources/14897821158107976655/overview.pdf.

Turner W. R. and Brandon K., Brooks T. M. Gascon C., Gibbs H. K., Lawrence K. S., Mittermeier R. A. and Selig E. R. (2012). Global biodiversity conservation and the alleviation of poverty. American Institute for Biological Sciences 62 (1) pp 85-92.

Turocy T. L. \& Von Stengel B. (2002). Game Theory. Encyclopedia of Information Systems. Academic Press. 
UNDP (2000). United Nations Development Program. Responding to Citizens' Needs: Local Governance and Social Services for All. The Department for Economic and Social Affairs.

UNDP (2010). United Nations Development Program. Human Development Report: The real wealth of nations, pathways to human development. $20^{\text {th }}$ Anniversary edition.

UNEP (2010). Ecosystem management. Valued ecosystems incorporated into national planning processes.

Villasante S. and Sumaila R. (2010). Linking environmental economics, game theory and fisheries: an estimation of the economic benefits to sharing the Illex argentinus fishery in the Patagonian large marine ecosystem. The Beijer Institute of Ecological Economics, The Royal Swedish Academy of Sciences.

Weiss E. B. and Jacobson H. K. (1998). Engaging Countries: Strengthening compliance with International Environmental Accords. Massachusetts Institute of technology.

Wilshusen P.R., Brechin S. R., Fortwang C. L. and West P. C. (2002). Reinventing a Squared Wheel: Critique of a Resurgent "Protection Paradigm" in International Biodiversity Conservation. Society and Natural Resources 15: $17-40$.

WWF (2010). World Wildlife Fund. Integrated conservation and development projects: A positive role in tropical Africa. 
VITA

\section{GEORGE ATISA}

Born, Nyamira, Kenya

1992

Bachelor of Arts in Economics from Kenyatta University, Nairobi, Kenya

1993 - 1998 Field Administrator with International Rescue Committee (IRC), Kakuma, Kenya

1998 - 2003 Field Operations Coordinator with Lutheran World Federation (LWF), Nairobi, Kenya

2003 Master of Arts in Economics, The University of Nairobi, Nairobi, Kenya

2004-2007 Administration and Operations Manager with World Wildlife Fund (WWF), Eastern and Southern Africa Regional Programme Office. Nairobi, Kenya

2007-2009 Master of Science in Environmental Studies, Florida International University. Miami, Florida

2010 - 2014 Doctoral Candidate, Florida International University. Miami, Florida.

PUBLICATIONS AND PRESENTATIONS

Atisa, G., Bhat, M., McClain, E. M. (2014). Economic Assessment of Best Management Practices in the Mara River Basin: Toward Implementation of Payment for Watershed Services. Journal of Water Resources Management.

Atisa, G (2014). Information Technology: Placing Global Biological Resources

Protection Initiatives in the Local Settings. Paper presented at the American Society for Public Administration (ASPA). Washington DC.

Bhat, M. G., M. McClain, D. Ombara, W. Kasanga and G. Atisa (2013). "Payment for Watershed Services in the Mara River Basin: Part I - Institutions and Stakeholder Engagement." In Nile River basin: Ecohydrological Challenges, Climate Change and Hydropolitics. Assefa M Melesse, Wossenu Abtew and Shimelis G. Setegn (Editors).

Atisa, G and Wiedman D. (2013). Role of Historical Documents and Objects in Environmental Protection Planning at Everglades National Park. Paper presented at the Southeastern Conference for Public Administration (SECoPA), Charlotte, NC. 